\title{
VEHICLE FUEL ECONOMY AND VEHICLE MILES TRAVELED: AN EMPIRICAL INVESTIGATION OF JEVONS' PARADOX
}

\author{
VINOLA VINCENT MUNYON \\ Bachelor of Science in Microbiology \\ Bharathidasan University \\ June 2000 \\ Master of Science in Environmental Sciences \\ Anna University \\ June 2002 \\ Master of Arts in Environmental Studies \\ Cleveland State University
}

May 2007

Submitted in partial fulfillment of requirements for the degree

DOCTOR OF PHILOSOPHY IN URBAN STUDIES AND PUBLIC AFFAIRS

at the

CLEVELAND STATE UNIVERSITY

June 2014 
We hereby approve this dissertation

For

Vinola Vincent Munyon

Candidate for the PhD in Urban Studies and Public Affairs degree for the Department of

Maxine Goodman Levin College of Urban Affairs

And

CLEVELAND STATE UNIVERSITY'S

College of Graduate Studies by

Dr. William M. Bowen

Maxine Goodman Levin College of Urban Affairs, 06/19/2014

Dr. John P. Holcomb

Department of Mathematics, 06/19/2014

Dr. Nicholas Zingale

Maxine Goodman Levin College of Urban Affairs, 06/19/2014

June 19, 2014 


\section{DEDICATION}

Dedicated to my parents; to my dear father, Capt. S. K. Vincent, who did not get to see this come to be in its entirety but who believed it would, even when I did not. And to my mother, Mrs. Rukmani Vincent, who saw to it that it came to be with not-sosubtle daily reminders of how I needed to get this done, for myself. 


\section{ACKNOWLEDGMENTS}

It took a village and then some.

Acknowledging every single person who has helped prod me along in this journey from "vague idea" to tangible product would result, in and of itself, in a sizeable tome. So, thank you, you all know who you are, for being there at the right place and the right time for giving me that little nudge when I was in stall mode.

To my committee; I couldn't have asked for a more involved and committed group of advisors. Dr. William Bowen, my chair and my mentor, thank you for making sure I did not become one among the "driven female student who got married, had a baby and fell off the PhD wagon" statistic. While I took my 2.5-year hiatus from working on my dissertation, you made frequent check-ins and kept pushing me to jump right back in. You believed in my potential far more than I did. To my methods guide; Dr. John Holcomb, if you hadn't stepped in and volunteered to help me with wading through my mammoth dataset, I would have never gotten around to the analysis part of this study. I never had to ask you for help, you just offered and followed through. Thank you. To Dr. Nicholas Zingale, when I first came up with this idea and needed someone with an environmental policy and resource conservation bent, you stepped up and helped me hone that part of my study. Thank you. 
To my friend Karen Gurney and her partner-in-good-Samaritanship, Ronald Finnerty; you guys had "been there, done that" and knew what a PhD dissertation involved (blood, sweat, tears and more tears?) and made sure I had all the support I neededacademic, emotional and sometimes physical (driving me to places when I couldn't). "Ron" Finnerty, if you hadn't helped me with the initial prep work on my database and taught me some rudimentary SAS coding, I fear I would still be sitting at my desk staring at rows upon rows upon rows of data not knowing where to begin. You guys really define "a friend in need".

To my other good friends in the doctoral program; Kimberly S Cooper and Loveleen Sharma-Chopra, thank you for cheering me on and taking delight in my progress, however small the progress and however many times it stalled. To my mommy-friends, that special tribe of women known simply as "The BFFs", and in particular to Natalie DeVries, Amy Madain, Sara Bullen and Tanis Robertson; you know how all-consuming motherhood can become, so thank you for being there as an understanding comrade, for the many late-night chats and the virtual hand-holding when I went through a period of intense grief on losing my Dad and had little to no motivation to continue my research.

To my family; my mom, Rukumani Vincent, you blazed a trail at a time when blazing trails as a single, Asian woman involved a lot more than just persistence and singleminded determination. I owe this to you and to Dad. I take comfort in knowing that I can share this with at least one of my two phenomenal parents. To Christina Pinheiro; my 
sister, my confidante and my best friend for 35 years, thank you for being there, always. To my mother-in-law, Wendy Munyon; thank you for swooping in to provide top-notch emergency childcare services, whenever needed, so I could work on my thesis. To my father-in-law, Paul Munyon; thank you for giving me advice and constant encouragement, seasoned academician to a novice, as I embarked on this long and eventful journey.

To my husband; Charles Nelson Munyon, the brilliant neurosurgeon with over 8 publications to his name (to my zero) who maintains that I am the smarter spouse; you are my "everything". Thank you for making this happen; the many nights of staying up after having pulled a grueling shift at the OR just to listen to me talk, waking up early on the rare "off" days and taking our daughter out so I could work without distractions, and always, always reminding me, every single morning, of how I could do anything and do it well. You made this happen. And for the record, I am the smarter spouse, I snagged you, didn't I?

And finally, to my daughter, Marlaina Munyon, I'd be less than truthful if I did not admit that you were my " 2.5 year hiatus" from my work. I'd also be less than truthful if I did not admit that it was worth it, so gloriously worth it, and I hope that someday, you find your mama's journey as inspiring as I find mine. 
VEHICLE FUEL ECONOMY AND VEHICLE MILES TRAVELED: AN EMPIRICAL INVESTIGATION

OF JEVONS' PARADOX

VINOLA VINCENT MUNYON

\begin{abstract}
There has been, in recent decades, a concerted effort to promote energy efficiency as a means to reduce energy consumption, along the supply and demand sides. The general thesis is that, ceteris paribus, an increase in energy efficiency would lead to a decrease in the consumption of the good or service rendered efficient. This is in opposition to Jevons' Paradox which states that "It is wholly a confusion of ideas to suppose that the economical use of fuel is equivalent to a diminished consumption. The very contrary is the truth..." (Jevons, 1865). While many studies have applied Jevons' Paradox to various sectors to estimate rebound effects, few have examined if Jevons' Paradox holds when all available factors that could affect consumption of an efficient good/service are controlled for. This study hoped to fill that gap in literature. The study looked at vehicle fuel economy and vehicle miles travelled (VMT) and examined if, all else being equal, a vehicle that was more fuel efficient accrued greater VMT. Using data from the National Household Travel Survey (NHTS, 2009), a multivariate regression model was built $(\mathrm{N}=82,485)$ controlling for driver, household and vehicle attributes. The findings indicated that, at the microlevel, Jevons' Paradox does hold true; a $1 \%$ increase in fuel efficiency was associated with a $1.2 \%$ increase in VMT.
\end{abstract}




\section{TABLE OF CONTENTS}

List of Tables xii

List of Figures xiii

$\begin{array}{ll}\text { Chapter I Introduction } & 1\end{array}$

1.1 Context and Background 3

1.1.1 The Case for Energy Efficiency 3

1.2 Energy efficiency and the transportation sector 5

1.3 Gaps in Research: Energy Efficiency and Jevons Paradox 12

$\begin{array}{ll}\text { Chapter II Literature Review } & 17\end{array}$

2.1 Review of Concepts, Terms and Definitions 17

2.1.1 Fuel Economy as a Measure of Energy Efficiency 17

2.1.2 Vehicle Miles traveled 21

2.1.3 Rebound; Short-run and Long-run $\quad 22$

2.2 Review of the Theoretical Foundation 26

$\begin{array}{ll}\text { 2.2.1 Jevons Paradox } & 26\end{array}$

2.2.2 Khazzoom-Brookes Postulate 30

$\begin{array}{ll}2.3 \text { Empirical Evidence } & 36\end{array}$

2.5.1 Empirical Studies: Macroeconomic Scale 37

2.5.2 Studies on the Microeconomic Scale 41

2.5.2.1 Rebound Estimates $\quad 41$

2.5.2.2 Beyond Estimating Rebound $\quad 47$

2.6 Other Variables that might affect VMT 50

2.7 Conceptual Model $\quad 55$

2.8 Summary $\quad 55$ 
3.1 The Dataset $\quad 60$

3.1.1 The Source $\quad 60$

3.1.2 Survey Methodology 61

3.2 Data Organization 63

3.3 Derived/Computed Variables 64

$\begin{array}{lll}\text { 3.3.1 BESTMILE } & 64\end{array}$

3.3.2 DRVRCNT

3.3.3 EIADMPG 66

$\begin{array}{ll}\text { 3.3.4 URBRUR } & 67\end{array}$

$\begin{array}{ll}\text { 3.3.5 VEHAGE } & 67\end{array}$

$\begin{array}{ll}\text { 3.3.6 WRKCOUNT } & 67\end{array}$

$\begin{array}{ll}\text { 3.4 Missing Data } & 67\end{array}$

$\begin{array}{ll}3.5 \text { Analysis } & 68\end{array}$

3.5.1 Data Merging and Extraction 68

3.5.2 Variables 70

$\begin{array}{ll}\text { 3.6 Model Specification } & 77\end{array}$

Chapter IV Results and Discussions $\quad 80$

4.1 Introduction $\quad 80$

4.2 Results and Discussions $\quad 81$

4.2.1 Driver Characteristics $\quad 82$

4.2.1.1 Respondent Age (R_AGE) 82

4.2.1.2 Occupational Category (OCCAT) 82

4.2.1.3 Number of Bike Trips (NBKTRP) 83

4.2.1.4 Number of Walking Trips (NWALKTRP) 84

4.2.1.5 Number of Public Transit Trips Taken (PTUSED) 84 
4.2.2.1 Home Owned/Rented (HOMEOWN) 85

4.2.2.2 Household Size (HHSIZE) 86

4.2.2.3 Number of Drivers (DRVRCNT) 86

$\begin{array}{ll}\text { 4.2.2.4 Worker Count (WRKCOUNT) } & 87\end{array}$

4.2.2.5 Household Vehicle Count (HHVEHCNT) 87

4.2.2.6 Annual Household Income (INCDUMMY) 88

4.2.2.7 Presence of Rail in the MSA (RAIL) 90

4.2.2.8 Urban or Rural (URBRUR) 90

4.2.3 Vehicle Characteristics 90

4.2.3.1 Age of the Vehicle (VEHAGE) 90

4.2.3.2 Number of Months Owned (VEHOWNMO) 91

4.2.3.3 Commercial License Plates (VEHCOMM) 91

4.2.3.4 Fuel Economy (EIADMPG) 92

4.2.3.5 Hybrid (HYBRID) 92

4.2.4 Fuel Cost (GSCOST) 93

$\begin{array}{ll}4.3 \text { Diagnostics } & 93\end{array}$

4.3.1Model Fit 93

4.3.2 Residuals and Normality $\quad 94$

$\begin{array}{ll}\text { Chapter V Summary and Conclusions } & 98\end{array}$

5.1 Introduction 98

5.2 Summary of the Study $\quad 98$

5.3 Findings in the Context of Existing Literature 99

5.3.1 Variables of interest; fuel economy, hybrid and fuel cost 99

$\begin{array}{ll}\text { 5.3.2 Other Control Variables } & 102\end{array}$

$\begin{array}{ll}\text { 5.4 Limitations of the Study } & 106\end{array}$ 
5.4.1 Limitations of the Dataset 106

5.4.2 The Question of Consumer/Producer Behavior Modification 107

5.4.3 The Vehicle Choice Question 108

$\begin{array}{ll}\text { 5.4.4 External Validity/Generalizability } & 109\end{array}$

$\begin{array}{ll}\text { 5.4.5 Validity of Statistical Conclusions } & 110\end{array}$

$\begin{array}{ll}5.5 \text { Policy Implications } & 111\end{array}$

$\begin{array}{ll}\text { 5.5.1 Pricing Policies } & 111\end{array}$

$\begin{array}{ll}\text { 5.5.2 Shifting Modes of Transit } & 113\end{array}$

$\begin{array}{ll}\text { 5.6 Future Directions } & 113\end{array}$

5.7 Conclusions: The Paradox and Fuel Efficiency Policy 115

$\begin{array}{ll}\text { References } & 118\end{array}$ 


\section{List of Tables}

Table 1: Population and Household Vehicle Profile; Average

Annual Change 1950-2011

Table 2: Rebound; Mathematical Representation and Interpretation

Table 3: Summary of empirical evidence for rebound effects

45

Table 4: Variables to be Used in This Study and Expected Associations

58

Table 5: Continuous Variables, Summary Statistics

72

Table 6: Variables, Expected Directions and Actual Directions

105 


\section{List of Figures}

Figure 1a: Total Energy Consumption by End-use Sector, $\begin{array}{ll}\text { Quadrillion Btu (1949-2013) } & 6\end{array}$

Figure 1b: Energy Consumption by Source and Sector, 2012

Figure 2: End-Use Sector Emissions of $\mathrm{CO}_{2}$ from Fossil-Fuel Combustion, 20127

Figure 3: Adjusted Fuel Economy for Model Year, 1975-2013 10

Figure 4: Adjusted $\mathrm{CO}_{2}$ Levels for Model Year 1975-2013 10

Figure 5: Weekly US Gasoline Supplied at the Pump Vs. VMT

$$
1993-2013
$$

Figure 6: Driving Population By Age and Gender 51

Figure 7: Driver Age and VMT 52

Figure 8: Economic Indicators of VMT (1975-2012) 54

Figure 9: Conceptual model for the study 56

Figure 10: Residual Plot Versus Fits 95

Figure 11: Residuals Versus Order 96

Figure 12: Residual Distribution, Histogram 96

Figure 13: Normal Probability Plot of Residuals 97 



\section{CHAPTER I}

\section{INTRODUCTION}

The possibilities of a repeat of the 1973 oil crisis, growing concerns about pollution from fossil fuel consumption, reports of fossil fuel depletion, climate change, and the demand for energy security have been the primary drivers for the current interest in discovering new, renewable and efficient modes of energy production, distribution and consumption. A resurgence in the environmental movement and the economics of "green jobs" and green growth have further advanced this cause. Considered the twin pillars of sustainable energy policy, targeting the demand and supply sides respectively, energy efficiency and renewable energy are increasingly the primary focus of a large number of energy policies at regional, national and international scales in all sectors of the economy (ACEEE, 2007; Colorado School of Law, 2011; IEA, 2013).

In its energy-efficiency policy recommendation to nations, of the many end-use sectors, the International Energy Agency (IEA, 2013) identifies the transportation sector 
as one that has the greatest potential to benefit from energy efficiency improvements (in the form of more fuel efficient vehicles). The transportation sector has; 1. the greatest reliance on gasoline as fuel of choice (and the implications of this for energy security), 2. is the second largest emitter of $\mathrm{CO}_{2}$ and 3. plays a vital role in mobility of consumers and goods and therefore in economic productivity and growth. Fuel efficiency improvements in this sector are, therefore, expected to drive down fuel consumption and result in economic and environmental benefits at multiple jurisdictional levels. Policies that promote fuel efficiency improvements i.e., fuel economy are, therefore, considered a win-win proposition.

This underlying assumption is in opposition to Jevons' hypothesis-“Jevons' Paradox" which postulates that an increase in efficiency, ceteris paribus, does not lead to a decrease in consumption of that good/service rendered efficient but that it rather, paradoxically, leads to an increase in consumption (Jevons, 1865). Studies on vehicle fuel economy and on policies promoting vehicle fuel economy have traditionally focused on; 1. projections of fuel-savings (Goldberg 1996, 1998; NRC 2002; Greene 2010; Helfand and Wolverton 2010; NHTSA 2010) 2. estimations of GDP growth and job growth (ACEE, 1992; Davis et al., 1990, 1999; Geller et al., 1992; Teotia, 1999; UCS, 2001, 2002) 3. projections of greenhouse gas emissions reduction (Creyts et al., 2007, 4. Short-term effects on manufacturers' outlook (MVMA, 1990; Kleit, 2002). However, few studies have examined if increase in fuel economy has been associated with decreased driving and fuel consumption, all else being constant. Jevon' paradox posits that the opposite would be true. This study examines vehicle miles travelled (VMT) and vehicle 
fuel economy, in the household travel (personal transportation) sector and examines if Jevons' paradox holds, ceteris paribus.

\subsection{Context and Background}

\subsubsection{The Case for Energy Efficiency}

Energy efficiency and renewable energy are, unlike options such as nuclear energy, clean coal or carbon capture and storage, relatively non-controversial policy focuses and generally perceived to be "green" strategies (Dernbach, 2007; IEA, 2012). As early as 1970, Amory Lovins made the case for society to move toward a "soft energy path", a "path" that relied heavily on energy efficiency as opposed to energy production. Lovins also introduced the concept of negawatts-energy "created" through increasing energy efficiency instead of increasing energy production (Lovins, 1970). In 1987, The World Commission on Environment and Development (WCED) named energy efficiency as a component of sustainable energy practices (WCED, 1987), a move that was followed by the United Nations Conference on Environment and Development (UNCED) when in 1992 Agenda 21 was scripted to include an emphasis on energy efficient technologies and practices. "The need to control atmospheric emissions of greenhouse and other gases and substances will increasingly need to be based on efficiency in energy production, transmission, distribution and consumption ..." (Agenda 21, 1992; emphasis added). The Johannesburg Plan of Action from the World Summit of Sustainable Development of 2002, specifically calls for “...improving energy efficiency 
through innovative financial and technology transfer and capacity building mechanisms and removal of market distortions" (WSSD, 2002). The McKinsey Global Institute, in a report published in 2006 (MGI, 2006) reiterated that "there are sufficient economically viable opportunities for energy-productivity improvements that could keep global energy-demand growth at less than 1 percent per annum" (the estimated annual energy demand growth is 2.2 percent). More recently, the International Energy Agency (IEA, 2013) declared energy efficiency a "hidden fuel" that could "extend energy supplies, increase energy security, lower carbon emissions and generally support sustainable economic growth" (IEA, 2013).

In the period between 1991 and 2014, the Global Environmental Facility (GEF) which operates as a partnership between the World Bank, United Nations Development Programme (UNDP) and United Nations Environment Programme (UNEP) has financed or approved funding for 138 energy efficiency projects; 10 of these projects are regional or global in scope while the remaining 128 projects are national (GEF, 2014).

In the United States, the primary driver for a shift in energy policy has been energy security; the Energy Independence and Security Act of 2007 aims to reduce emissions by six billion metric tons by 2030 through energy efficiency improvements. The American Recovery and Reinvestment Act of 2009 meanwhile set aside $\$ 16.8$ billion for "direct spending for renewable energy and energy efficiency programs over the next ten years, \$11 billion to modernize the nation's electricity grid with smart grid 
technology and \$2.5 billion for renewable energy and energy efficiency R\&D, demonstration and deployment activities" (ARRA, 2009).

The preponderance of policies, programs and treaties focused on energy efficiency thus illustrate the concerns with the current energy consumption trajectory while also providing evidence for the widely held premise that the solution lies in energy efficiency (and renewable energy development). Energy efficiency has, therefore, been promoted in all sectors across the production and consumption chain with some estimates indicating that this has resulted in energy savings at least in the short-run (EIA, 2013).

\subsection{Energy Efficiency and the Transportation Sector}

In the US, the transportation sector is the second largest consumer of energy, the primary consumer of petroleum (Figures 1a and 1b; EIA, 2013) and has in recent years been estimated to have surpassed the industrial sector to become the largest contributor (as an end-use sector) to US greenhouse gas emissions of carbon dioxide ${ }^{1}$ (Figure 2; EPA, 2014). The sector relies predominantly on motor gasoline accounting for about $71 \%$ of the nation's total oil consumption (EIA, 2013), which represents both an energy security risk, in that the US has to increasingly rely on crude oil imports to manage the rising demand that has outstripped domestic production, and also represents a primary pollution source. So when it comes to targeting reducing consumption of fuel, the transportation sector is ripe for policy action; however, the

\footnotetext{
${ }^{1}$ Note that this is when only "end-use" sectors are considered, when all economic sectors are considered, Electricity Generation becomes the largest contributor to $\mathrm{CO}_{2}$ emissions while Transportation becomes a close second.
} 
policy focus for this sector has been predominantly based on energy efficiency arguments which necessitate an examination of the efficacy of this strategy to reduce fuel consumption.

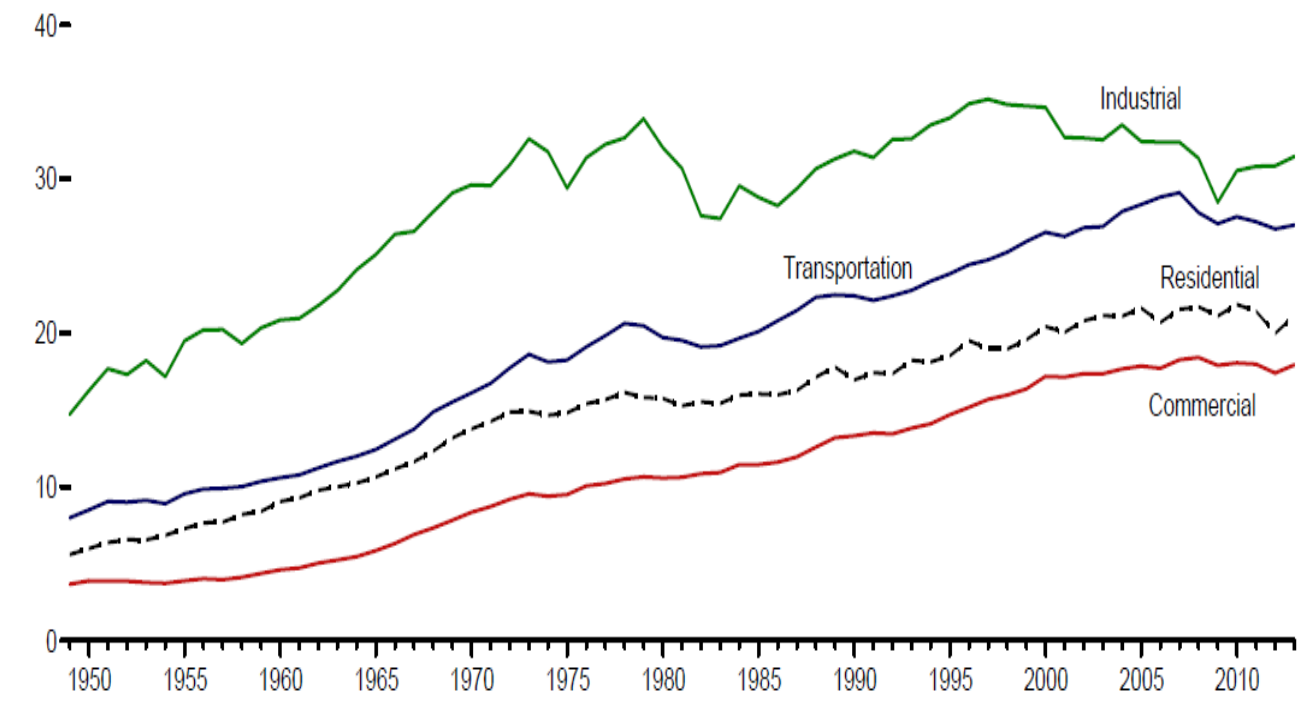

Figure 1a: Total Energy Consumption by End-use Sector, Quadrillion Btu (1949— 2013)

Source: EIA, April 2014

The transportation sector is made up of passenger travel and freight; the former consists of light-duty vehicles such as automobiles, motorcycles, and light trucks and heavy-duty vehicles which include buses, airplanes, boats, and trains and is the focus of most studies and policies that promote increasing fuel economy (EIA, 1999). In 1975, The Energy Policy and Conservation Act (EPCA) which established Corporate Average Fuel Economy (CAFE) standards came into effect. The stated goal for the enactment 


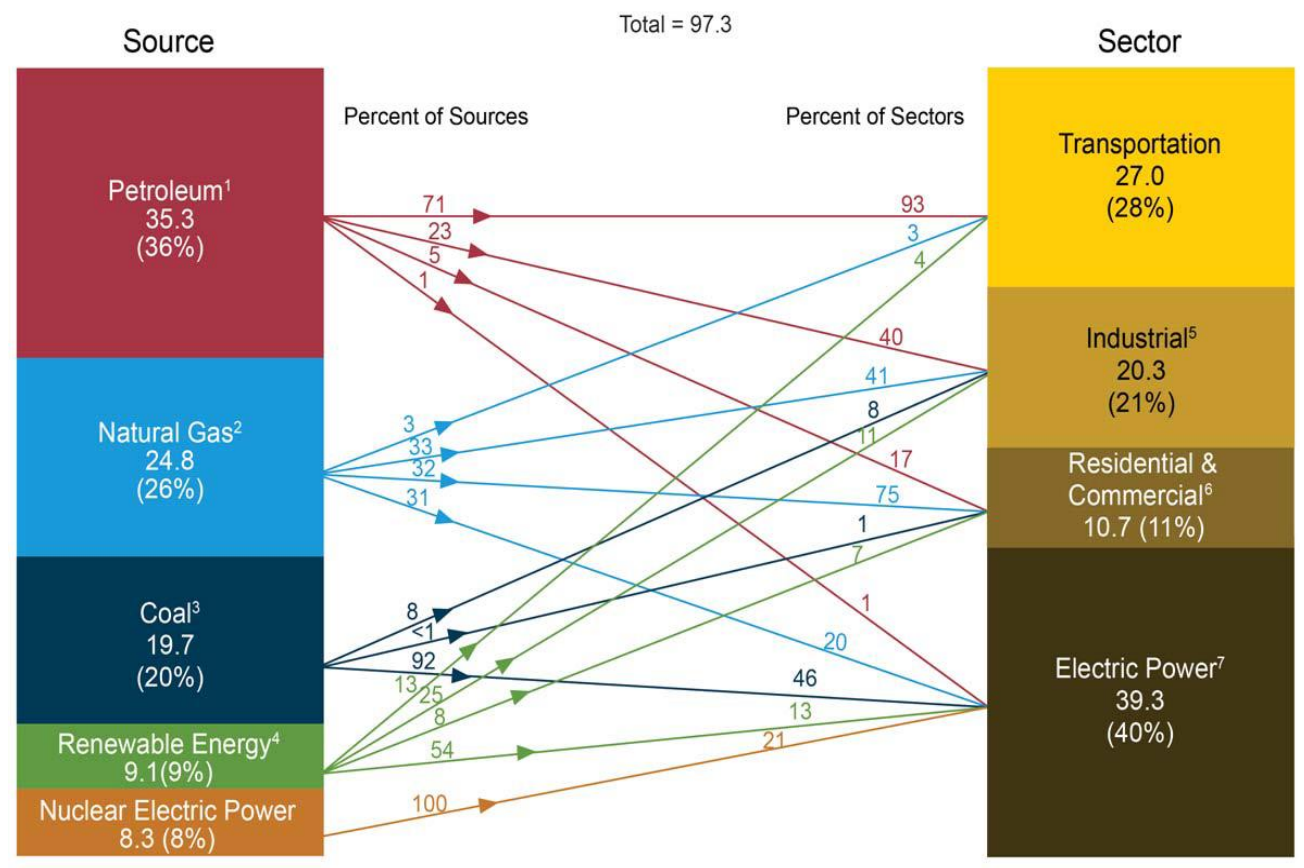

Figure 1b: Energy Consumption by Source and Sector, 2012

Source: EIA, 2013

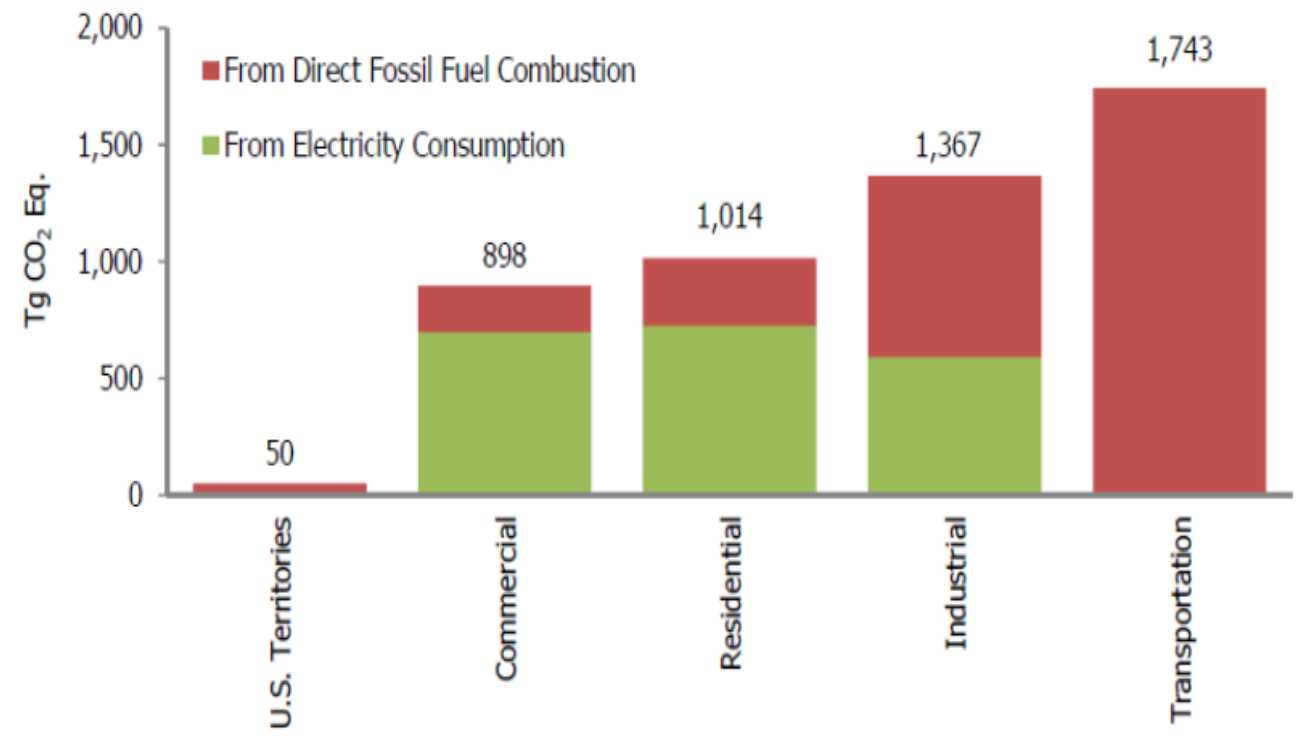

Figure 2: End-Use Sector Emissions of $\mathrm{CO}_{2}$ from Fossil-Fuel Combustion, 2012

Source: EPA, 2014 
was reduction of national fuel consumption in the transportation sector; the underlying assumption was therefore that an increase in vehicle efficiency would result in a decrease in fuel consumption. Under EPCA, manufacturers of new vehicles were required to meet an established CAFE standard for all cars and choose between a single standard or class standards for light trucks. The CAFE standards mandated for passenger cars were increased from 18 miles per gallon (mpg) in 1978 to $27.5 \mathrm{mpg}$ by 1985 . From 1985 through 2007, the CAFE standard for cars stalled at the 1985 standard of $27.5 \mathrm{mpg}$.

In late 2007, the Energy Independence and Security Act of 2007 mandated auto manufacturers to increase fuel economy ${ }^{2}$ of all passenger vehicles (including light trucks) to $35 \mathrm{mpg}$ by 2020 . The penalty for noncompliance for a vehicle was set at a $55 \$ / m p g$ for every $1 \mathrm{mpg}$ that the vehicle tested under target. For manufacturers, the penalty for an entire fleet would then be mpg fee/vehicle multiplied by the total manufactured stock for that model year. The expressed intent was to raise fuel economy standards by $40 \%$ and thereby reduce consumption of fuel by several billions of gallons (GAO, 2009). There was concurrently, an increased interest on the part of the public, in improved fuel economy standards, often perceived as a cost-saving adaptation. A poll conducted July 2007 across 30 congressional districts in seven states reported that $84-90 \%$ of those polled were in favor of legislating mandatory increases (Green Car Congress, 2007). The next significant change in this arena came about in August 2012, when the Obama administration announced newer, stricter fuel economy

\footnotetext{
${ }^{2}$ In the case of automobiles, the term fuel economy is used to specifically indicate fuel efficiency of that particular automobile. It is measured as the distance traveled (output) per unit of fuel used (input); in the US this is measured as miles per gallon (mpg.).
} 
standards; the new standards require passenger vehicles sold in the United States by 2025 to have a fuel economy, on average, of 54.5 miles per gallon. ${ }^{3}$ Studies by the EPA indicate that achieving these fuel economy standards would result in reducing US oil consumption by 2.2. million barrels of oil per day by 2035 (EPA, 2012). Following the announcement of these new standards, there was a rapid increase in manufacture of vehicles of greater fuel economy and reduced $\mathrm{CO}_{2}$ emissions; a record high in 2012, in fact (Figures 3, 4; EPA, 2013).

The EPA also reports that out of 11 manufacturers studied, 10 increased their fleet's fuel economy between 2012 and 2013 (EPA, 2013). Vehicles are therefore getting more and more efficient, however at the same time, the vehicle miles travelled steadily increased between 1970 to 2007; in 1970 the vehicle miles travelled (in millions) was recorded as 1,109,724 miles while in 2007 they had risen to 2,973,509 miles (USDOE, 2009). Since 2007-February 2014 there has been, interestingly a decline in total vehicle miles travelled (Figure 5; USDOT and EIA, 2014).

\footnotetext{
${ }^{3}$ Note that the official fuel economy has been often found to an overestimate of "real-world" fuel economy. In this instance, the Union of Concerned Scientists estimate that this sticker figure of $54.5 \mathrm{mpg}$ would translate to an average on-road fuel economy of $34.5 \mathrm{mpg}$ (Union of Concerned Scientists, 2011).
} 


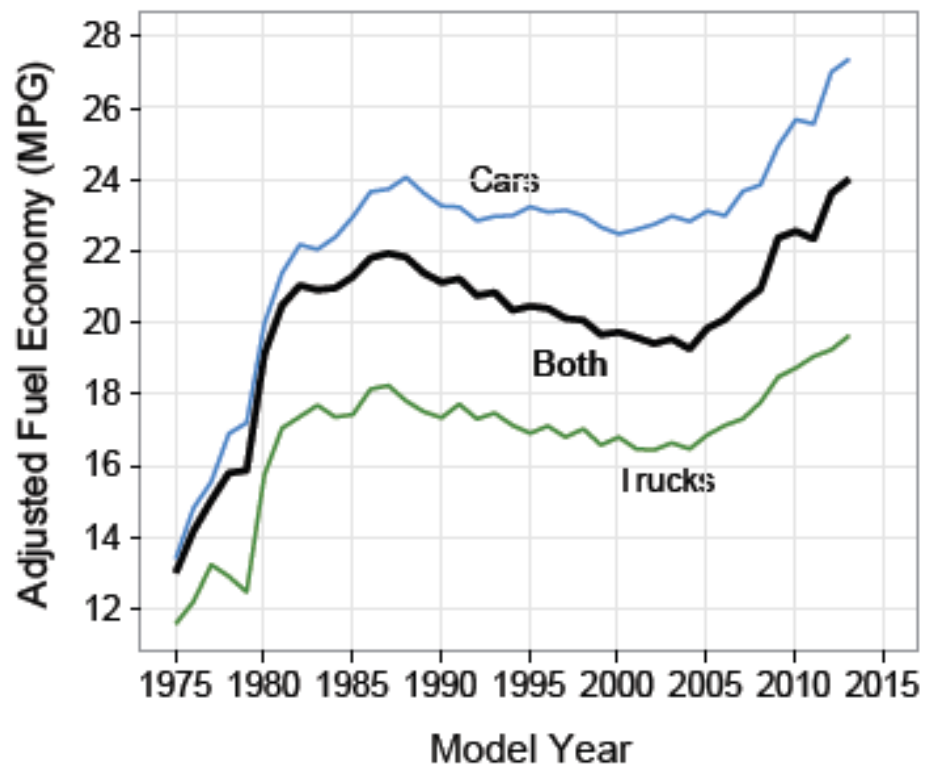

Figure 3: Adjusted Fuel Economy for Model Year, 1975-2013 Source: EPA, 2013

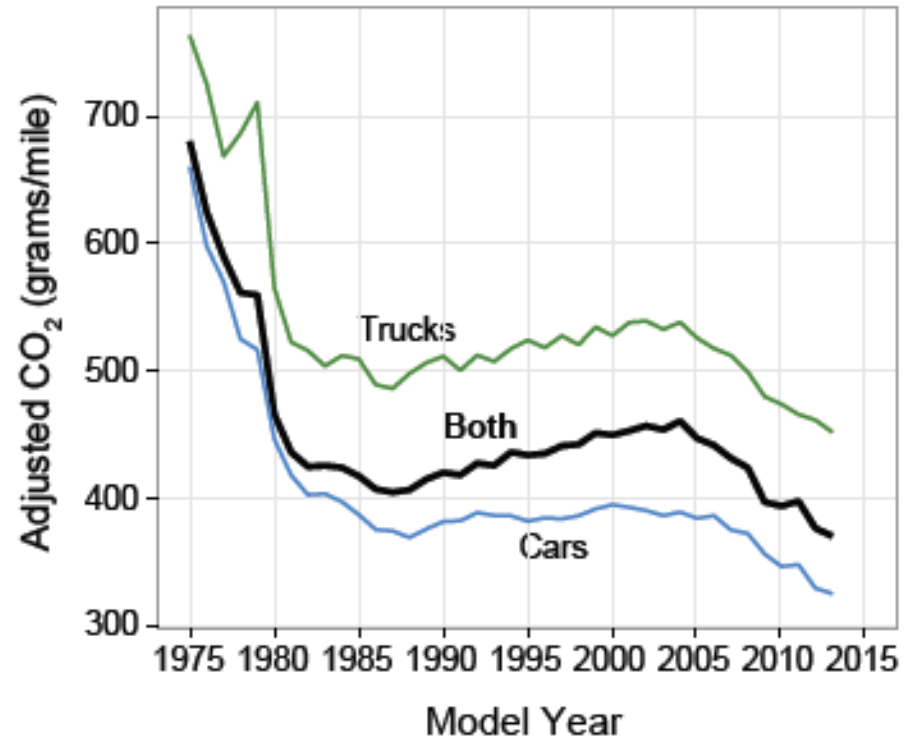

Figure 4: Adjusted $\mathrm{CO}_{2}$ Levels for Model Year 1975-2013 Source: EPA, 2013 


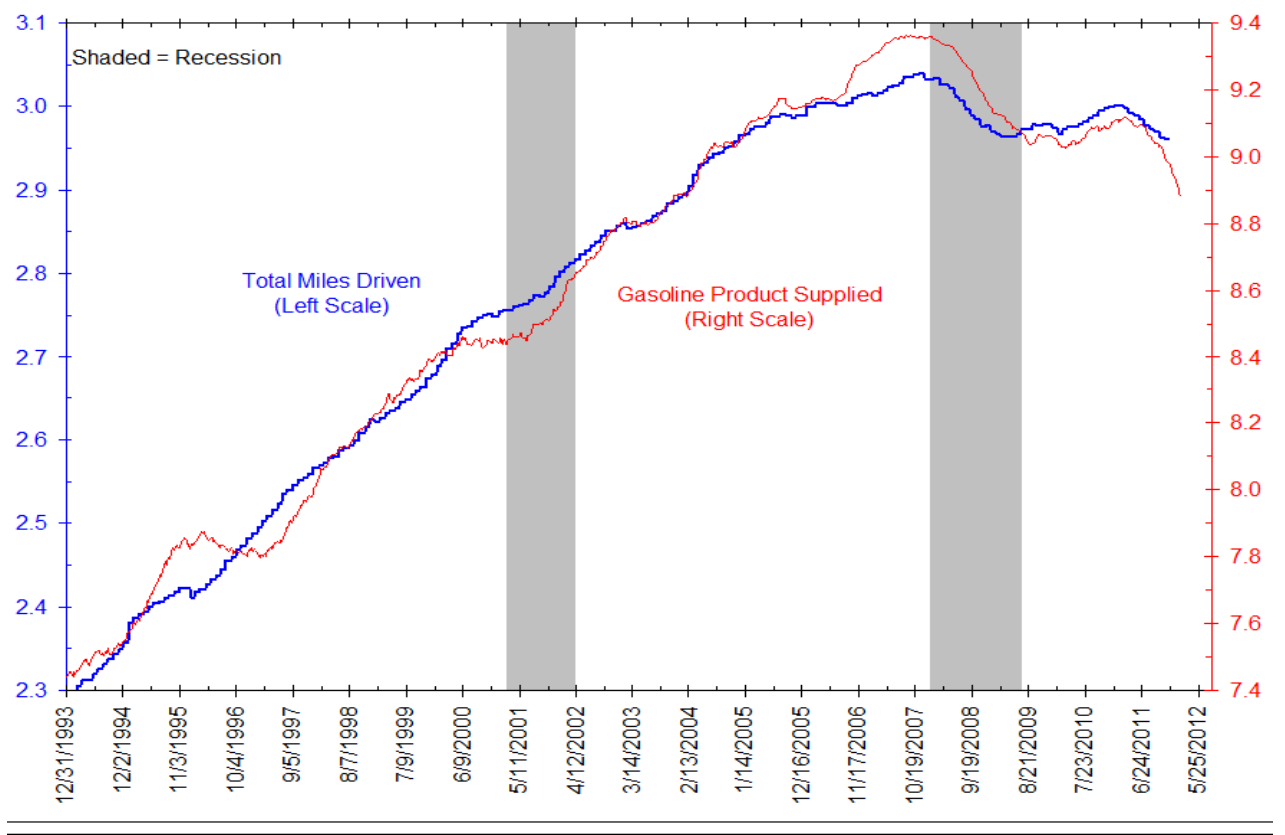

Figure 5: Weekly US Gasoline Supplied at the Pump vs. Vehicle Miles Driven, 1993--2013

Source: Based on USDOT and EIA, 2014

These figures represent total VMT and not per capita VMT. Factoring in population figures for these corresponding years, there was a slight increase in per capita VMT in 2012 from 2011 but that increase was not sustained into 2013 (USDOT, 2014). Trends in US gasoline consumption indicate that following peak consumption in the summer of 2007 (9.6 million barrels per day) consumption declined and continued to do so up until September 2012 (8.6 million barrels per day; most recent available data, EIA, 2014). Trends in cost of gasoline mirror trends in gasoline consumption in the opposite direction; annual gas prices were as low as \$1.03/gallon in 1998 and went up as high as $\$ 3.56 /$ gallon in late 2012 . There has therefore been, over the same period; historical increases in fuel efficiency, increases in gasoline price, historical declines in VMT and historical declines in gasoline consumption. 


\subsection{Gaps in Research: Energy Efficiency and Jevons' Paradox}

While there has been a documented increase in policies and programs promoting energy efficiency, a corresponding increase in scrutiny of the effectiveness of such policies and programs or a corresponding increase in research into the effectiveness of energy efficiency, is lacking. The general thesis is that, ceteris paribus, an increase in efficiency of modes of energy production, transmission, and utilization would lead to a decrease in total energy consumed. This, therefore, is the rationale for the promotion of adoption of energy efficiency throughout the supply chain. Whilst the reasoning seems to follow general engineering principles, it holds only when demand is held constant. However, neoclassical economic theory demonstrates that, when price is reduced (in this instance, due to technology improvements that increase efficient use of automobiles, more miles can be driven with the same quantity of fuel) the total demand for that good increases. Biswanger (2001) explains it thus: “...the amount of product or service usually does not stay the same. Because the equipment becomes more energy efficient, the cost per unit of product or service decreases which, in turn, increases the demand for the product or service." In economic theory this has been dubbed as the "rebound effect", "feedback" or "snap back". When the demand (and therefore, consumption) is greater than the savings made through efficiency improvements, the resulting effect is referred to as a "boomerang" or "back fire" (Khazzoom, 1980; Saunders, 2000). 
Three different types of rebound effects have been proposed (Greening and Greene, 1997); 1. direct rebound effects, 2. indirect rebound effects and 3. general equilibrium effects. Direct rebound effects occur when there is an increase in the use of an energy service due to the decrease in its price brought on by greater efficiency. Indirect rebound effects occur when, assuming the prices of other commodities are held constant, the reduction in the cost of an energy service leads to more available spending dollars for the consumer to spend on other goods and services (income effect). Given that these other goods and services also require energy to produce, transport and/or consume total energy use will increase. General equilibrium effects occur when direct and indirect effects propagate throughout the economy.

Then there is the "Green Paradox". Eichner and Pethig (2009) coined the term the "green paradox", to refer to the phenomenon when policies such as CAFE standards that were aimed at greening might have paradoxically increased rather than decreased consumption. In light of this, some economists have questioned using the efficiency approach, suggesting that application of market based instruments such as increased gasoline taxes would be a more effective alternative instead (Portney et al., 2003; Austin and Dinan, 2005; Fischer et al., 2007). Their argument being that the fuel efficiency approach "works against itself" by lowering operating costs promoting greater driving on account of the price elasticity of driving. Furthermore, standards that are aimed at improving fuel efficiency are not retrospective and affect only new vehicles, while an increase in gasoline taxes affects all vehicles. Consumer behavioral modifications in response to perceived "savings" earned through fuel efficiency may result in greater 
consumption--the "rebound effect" and is therefore a factor to be considered during evaluation of choice of policy instrument.

The other factors that are known to affect vehicle miles travelled and fuel consumed, such as; fuel price, income, vehicle ownership, to specify but a few, have hardly remained constant. Data collected by the National Household Travel Survey (NHTS: 1969, 1977, 1983, 1990, 1995, 2001, 2009; DOE, 2012) demonstrates that while the number of persons per household has decreased vehicle ownership per household and even per adult have increased (Table 1).

Table 1: Population and Household Vehicle Profile; Average Annual Change 1950-2011

\begin{tabular}{|c|c|c|c|c|c|c|}
\hline Year & $\begin{array}{l}\text { Resident } \\
\text { Population }\end{array}$ & $\begin{array}{l}\text { Total } \\
\text { Households }\end{array}$ & $\begin{array}{l}\text { Number of } \\
\text { vehicles }\end{array}$ & $\begin{array}{l}\text { Total } \\
\text { VMT }\end{array}$ & $\begin{array}{c}\text { Licensed } \\
\text { Drivers }\end{array}$ & $\begin{array}{l}\text { Employed } \\
\text { Civilians }\end{array}$ \\
\hline $\begin{array}{l}1950- \\
2011\end{array}$ & $1.2 \%$ & $1.7 \%$ & $2.9 \%$ & $3.1 \%$ & \begin{tabular}{l|l}
$2.0 \%$ \\
\end{tabular} & \begin{tabular}{l|l|}
$1.4 \%$ \\
\end{tabular} \\
\hline $\begin{array}{l}2001- \\
2011\end{array}$ & $0.9 \%$ & $0.9 \%$ & $1.4 \%$ & $0.5 \%$ & $1.0 \%$ & $0.2 \%$ \\
\hline
\end{tabular}

Source: U.S. Department of Commerce, Bureau of the Census, U.S Department of Transportation, Federal Highway Statistics, 2011.

The increasing number of vehicles on the road has been associated with increased daily commute times; the data from the NHTS indicate that while average miles traveled on daily commutes have increased the average speed of the commute have declined (NHTS, 1983-2009, DOE; 2012). The average per capita income has 
increased, the federal gasoline tax has meanwhile not increased as would be expected, but has stayed at the same fixed rate of 18.4c per gallon for 2 decades (ITEP, 2013).

Given that fuel price and fuel efficiency can influence driving behavior and consequently fuel consumption, an examination of the relationship between vehicle fuel efficiency, fuel price and vehicle miles travelled is therefore pertinent for policy prescription.

Originally hypothesized by William Stanley Jevons as early as 1865, Jevons' Paradox suggests that contrary to popular notions, efficiency would lead to increased (and not decreased) consumption of that resource whose use was rendered efficient (Jevons, 1865). Brookes (2000) states it thusly, “...the market for more productive fuel is greater than for less productive fuel, or alternatively that for a resource to find itself in a world of more efficient use is for it to enjoy a reduction in its implicit price with the obvious implications for demand." Jevons' Paradox therefore raises the issue that while some energy-efficient technologies may have the potential to reduce the energy intensity of economic activity, others might not and therefore efficiency improvements must be considered within the context of the possibility of rebound.

Whilst Jevons' Paradox has been studied largely from a theoretical perspective, much of the empirical work on energy efficiency and the paradoxical nature of the rebound has been restricted to a calculation of the simulated rebound effect for various sectors and appliances. Little work has been done to econometrically study the many variables (including fuel efficiency and fuel price) that can affect fuel consumption (for 
personal vehicle use) and to understand which among these factors have greater explanatory power for VMT. A study of this nature and a finding that, for instance, fuel price has a greater explanatory power than fuel efficiency would have significant implications for policy direction. This study proposes to do that.

In the case of motor vehicles, efficiency is a measure of the fuel economy, the service derived is the vehicle miles travelled and the resource consumed is fuel. Applying the theory behind Jevons' Paradox to passenger vehicles, it would follow that with increase in fuel economy of vehicles, the cost of driving per unit fuel consumed would decrease (so given that the demand for fuel is elastic and holding all else constant) vehicle miles travelled will increase with increase in fuel economy. This study will look at passenger vehicle fuel economy and vehicle miles travelled and empirically examine if Jevons' paradox holds, ceteris paribus.

The remainder of this dissertation proceeds as follows: Chapter 2 provides a compilation and overview of the body of literature pertinent to the theory informing the research question. Chapter 3 summarizes the attributes of the data, source and collection methods, variables used and mathematical model applied to study the proposed hypothesis. Chapter 4 presents the results of the analyses. Chapter 5 summarizes the findings and provides policy prescriptions. 


\section{CHAPTER II}

\section{LITERATURE REVIEW}

Following is a review of literature on; 1. the theoretical foundations of Jevons' Paradox, 2. the related Khazzoom-Brookes postulate and 3. an overview of empirical studies that have been built on these theories. Studies that have investigated Jevons' paradox on the microeconomic and macroeconomic scales are presented with a particular focus on the transportation sector. However, before delving into a review of the theory, the data, or modes of analyzing data it is imperative that the concepts under examination be defined and described. To that end the concepts of energy efficiency, fuel economy (as a measure of energy efficiency), vehicle miles travelled and "rebound" are first described.

\subsection{Review of Concepts, Terms and Definitions}

\section{$\underline{\text { 2.1.1 Fuel Economy as a Measure of Energy Efficiency }}$}


Energy efficiency has been defined variously in different studies across different disciplines, and consequently the choice of variables for inputs and outputs that measure energy efficiency also vary. The following is a summary of the most-frequently applied definitions/conceptualizations of energy efficiency.

An EIA report (EIA, 2005) states that “there doesn't seem to be a single technical definition of energy efficiency-but rather a concept that increases in energy efficiency take place when either energy inputs are reduced for a given level of service or there are increased or enhanced services for a given amount of energy inputs". As energy efficiency, across the board, on a macro-economic scale is rather cumbersome to be captured by a single measure, EIA therefore, uses the concept of energy intensity as a proxy for energy efficiency. The EIA defines energy intensity as "the ratio of energy consumption to some measure of demand for energy services-...a demand indicator" and that "the highest level of aggregated energy intensity used at the country level is energy used per dollar of real disposable income" (EIA, 2005). Other relevant indicators used on a less aggregate, microeconomic scale are energy consumption per household, energy consumption per household member, and energy consumption per square foot.

Per Alcott (2005) "efficiency denotes the ratio of physical inputs to physical outputs. It means technological changes rather than institutional or organizational ones which lower other kinds of input like time and human effort per unit of output." Brookes (2004) contends that "Energy efficiency is primarily an engineer's term. It is the ratio of 
the output of a system in terms of useful heat or work to the energy stored in the fuel consumed in producing that output."

According to Patterson (1996) energy efficiency "may be defined as the ratio of useful outputs to energy inputs for a system. The system in question may be an individual energy conversion device (e.g. a boiler), a building, an industrial process, a firm, a sector or an entire economy. In all cases, the measure of energy efficiency will depend upon how 'useful' is defined and how inputs and outputs are measured." Sorrell (2009) categorizes energy efficiency measures into three; 1 . Thermodynamic measures: where the outputs are defined in terms of either heat content or the capacity to perform useful work; 2. Physical measures: where the outputs are defined in physical terms, such as vehicle kilometers or tons of steel; or 3. Economic measures: where the outputs (and sometimes also the inputs) are defined in economic terms, such as valueadded or GDP.

Patterson (1996) meanwhile categorizes energy efficiency indicators into four; 1. Thermodynamic; wherein the indicators are based on simple thermodynamic measures or an "ideal" thermodynamic process or 2. Physical-Thermodynamic; wherein the indicator is a hybrid that measures input in thermodynamic measures but uses a physical output measure 3. Economic-Thermodynamic; wherein the input is measured in thermodynamic units but the output is measured in economic units and 4. Economic; wherein both the input and output measures are in monetary terms.

Brookes (2000) categorizes the many definitions of energy efficiency as falling 
under three main categories; 1) first law energy efficiency (enthalpic efficiency), 2) second law energy efficiency (entropic or thermodynamic efficiency) and 3) economic efficiency. To illustrate that depending on the category of efficiency chosen a particular form of energy may go from being considered efficient to not, Brookes describes the case of electricity (2000); electricity has low enthalpic energy, high entropic efficiency and is economically efficient (cost effective). The author contends (Brookes, 2000) that economic efficiency trumps all other considerations.

Typically the term "energy efficiency" is applied to measures that are thermodynamic or physical in origin while the term "energy productivity" is more commonly used for measures/indicators that are economic in origin (Sorrell, 2009). Sorrel (2009) points out that while thermodynamic measures of energy efficiency are influenced by fewer variables, physical and economic measures of energy efficiency are influenced by a larger number of variables. Patterson (1996) makes a more nuanced distinction; he suggests that economic-thermodynamics indicators are energy productivity measures while purely economic indicators are energy intensity measures.

To summarize; energy efficiency is a concept that is largely subjective. There is no single, agreed-upon measure or indicator of energy efficiency. Studies use different proxies that differ in their theoretical foundations to approximate the energy efficiency quotient. Save for the purely thermodynamic indicators that measure the technical changes in efficiency, all other categories are found wanting in being able to distinguish between efficiency changes brought about by specification effects and those brought 
about by the underlying technical/technological improvements.

Fuel efficiency, often used interchangeably with the term "fuel economy" specifically in the instance of automobiles, is measured as the ratio of unit distance travelled (miles) by an automobile per unit of fuel consumed (gallons of fuel) by that automobile. Per the categorizations of energy efficiency, adopting Patterson's (1996) nomenclature, fuel economy would fall under the physical-thermodynamic category; as Patterson defines a physical-thermodynamic indicator as a hybrid indicator that measures input in thermodynamic measures (fuel consumed) but uses a physical output measure (per mile of vehicular travel). It is a measure of the thermochemical potential energy contained within a unit of fuel that is harnessed as kinetic energy and expressed in terms of miles driven. As Sorrel (2009) indicates thermodynamic measures of energy efficiency are influenced by fewer variables than economic measures and are more quantifiable measures of energy efficiency. Fuel economy is dependent on variables such as a vehicle's engine properties, body weight, drag and resistance all of which are determinable. It is a technical measure of energy efficiency and is therefore directly estimated unlike the proxies derived for other measures of efficiency. For these reasons, for the purposes of this study, fuel economy is used as a measure of vehicular efficiency.

\subsubsection{Vehicle Miles traveled}

Vehicle Miles Traveled (VMT) is a quantitative measure of the number of miles driven by a vehicle in a given time period, in general the time period being a year (VKT is used when the measure pertains to kilometers driven). Data on residential VMT were originally collected by the EIA but are currently tracked using the National Household 
Travel Survey (NHTS). The VMT for a given vehicle can be calculated based on the odometer readings; a beginning-of-year reading and an end-of-year reading are recorded and the VMT is calculated as a difference between the two readings "adjusted for a 365-day year" (EIA, 2002). In instances where one of the two readings has not been recorded, the VMT is imputed using a regression estimate (Details are discussed in Chapter 3).

The United States has a higher VMT/per capita than other OECD countries and this has been attributed largely to the "US's love affair with the automobile" and increasing suburbanization and exurbanization necessitating greater travelling distances from place of residence to place of work (EIA, 2009 ). Per data from the NHTS series, between 1977-2004, total person VMT for daily travel had grown by $151 \%$ and overall VMT had grown by over $90 \%$ (NHTS, 2004). However, starting in 2004, per capita VMT (and total VMT starting in 2007) has shown a sharp decline (USDOT, 2014).

\subsubsection{Rebound; Short-run and Long-run}

Like "efficiency", rebound falls under the category of "fuzzy" terminology in that there exists no standardized definition of rebound across the disciplines. A preliminary review by Madlener and Alcott (2007) found about 28 different constructs for rebound effects in the literature. The categorizations vary as well.

Herring (2008) categorizes the rebound effects into five; 1) direct, 2) income related, 3) product substitution, 4) factor substitution and 5) transformational. Greening et al., (2000) classify rebound into four categories-1) direct, 2) secondary, 3) economy- 
wide and 4) transformational while several others (Wackernagel and Rees, 1996; Small and Dender, 2005; Sorrell, 2009) recognize three; 1) direct, 2) indirect and 3) economywide and still others just two (UKERC, 2007); 1) direct and 2) indirect. For the purposes of this study the typology proposed by Greening et al., (2000) will be adopted as it is specific to fuel efficiency (and not just efficiency, in general) and is widely accepted as a standard categorization. The rebound effects, following Greening et al., (2000) are categorized as accruing due to four "market" responses; 1 ) direct rebound effects that arise due to the decline in "cost" of driving 2) secondary fuel use effects that occur due to the spending of the "saved" dollars 3) economy-wide effects due to the multiplying effect of the fuel efficiency improvements in other sectors, and 4) transformational effects (preference change, partly induced by technological change).

In economic literature, the phenomenon that is encapsulated by that which is at the root of Jevons' Paradox is described as "rebound"; it is the estimate of the energy savings created by the efficiency improvement that is offset through direct, indirect or economy-wide adaptations to the savings. Estimates of rebound are expressed as a ratio of the savings lost to the savings that are expected on account of the efficiency improvement (Grubb, 1990); a mathematical representation of the rebound effect estimate "is one minus actual energy savings (AES) relative to potential energy savings (PES)."

$$
R=1-(A E S / P E S)
$$

When rebound is greater than or equal to $100 \%$ then it is referred to as 
"backfire" or "boomerang" (Table 2). A distinction is made between rebounds that occur within a short time period following the efficiency improvement (short-run rebound) and those that accrue over time long-run rebound).

The term "Potential Energy Savings (PES)" as used in Rebound Studies refer to the energy savings that are typically estimated using engineering models, as likely being achieved by the energy efficiency improvement when holding constant certain assumptions regarding no responses to said energy efficiency improvement. The "Actual Energy Savings" (AES) are the actual savings realized when the energy efficiency improvement is in place and subject to responses as simulated by energy-economic models using "econometrically estimated production or cost functions" (Sorrell, 2014). Since the term potential in this content, in essence, means "Expected" and consequently Potential Energy Savings means "Expected Energy Savings" (EES), to avoid the ambiguity associated with using fuzzy terminology this study chooses to use EES or Expected Energy Savings in lieu of PES. 
Table 2: Rebound; Mathematical Representation and Interpretation

\begin{tabular}{|c|c|c|}
\hline Rebound Scenarios & $\begin{array}{l}\text { Mathematical } \\
\text { Representation }\end{array}$ & Interpretation \\
\hline$R=0$ & $A E S=E E S$ & $\begin{array}{l}\text { All expected energy savings } \\
\text { are preserved: actual } \\
\text { energy savings equal } \\
\text { expected energy savings. } \\
\text { There is no rebound. }\end{array}$ \\
\hline $\mathrm{R}<0$ & $\mathrm{AES}>\mathrm{EES}$ & $\begin{array}{l}\text { Actual energy savings are } \\
\text { greater than expected } \\
\text { energy savings. Rebound is } \\
\text { negative. }\end{array}$ \\
\hline $1>R>0$ & AES $<$ EES & $\begin{array}{l}\text { Rebound effects are at } \\
\text { work: actual energy savings } \\
\text { are negative and lower than } \\
\text { expected energy savings }\end{array}$ \\
\hline$R>1$ & $A E S=0$ & $\begin{array}{l}\text { Actual energy savings are } \\
\text { negative and larger than } \\
\text { expected ones. Referred to } \\
\text { as "backfire", "boomerang" } \\
\text { or "take-back". }\end{array}$ \\
\hline
\end{tabular}

Source: Based on Hernandez and Pifarre, 2009. 


\subsection{Review of the Theoretical Foundation}

\section{$\underline{2.2 .1 \text { Jevons' Paradox }}$}

William Stanley Jevons, as early as 1865, first articulated concerns about the inverse relationship between efficiency and consumption of that resource whose utilization has been rendered efficient. Jevons concerns were centered on coal; the central thesis of his book "The Coal Question: An Inquiry Concerning the Progress of the Nation, and the Probable Exhaustion of Our Coalmines" can be summed up in his own words as "It is wholly a confusion of ideas to suppose that the economical use of fuel is equivalent to a diminished consumption. The very contrary is the truth...Every improvement of the engine, when effected, does but accelerate anew the consumption of coal (Jevons, 1865)." To illustrate he provides the example of the Scottish iron industry; "the reduction of the consumption of coal, per ton of iron, to less than one third of its former amount, has been followed by a tenfold increase in total consumption, not to speak of the indirect effect of cheap iron in accelerating other coal consuming branches of industry (Jevons, 1865)." Presaging what sounds identical to the arguments currently being advanced in favor of efficiency as a panacea for resource limits, Jevons wrote, "It is very commonly urged, that the failing supply of coal will be met by new modes of using it efficiently and economically. The amount of useful work got out of coal may be made to increase manifold, while the amount of coal consumed is stationary or diminishing. We have thus, it is supposed, the means of completely neutralising the evils of scarce and costly fuel". Also in what seems to be a counterpoint 
to the claims that resource availability can be extended with new discoveries/processes that would inevitability occur with progress, Jevons argues that it isn't resource availability but rather the rate of consumption that is the decisive factor. He contends that "the quantity of coal existing is a less important point in this question than the rate at which our consumption increases, and the natural laws which govern that consumption." Among the laws that govern their consumption, being that lowering the output/input ratio (i.e., efficiency) causes neither less input for the same output, nor the same input for more output, but more input for proportionally more output, thereby increasing overall direct consumption effects (Jevons', 1865).

What researchers would much later delineate as direct, indirect and general equilibrium effects, Jevons summarizes as price, profitability, new inventions and uses, and consumer behavior. The three working in conjunction increase the consumption of the resource that has been rendered efficient. Jevons' thesis for a complete feedback, wherein the efficiency improvement negates any gains is thus, based on a macroeconomic scale. He stresses that it is not merely the use of the efficient technology in the one field that leads to greater consumption of the resource but that the efficient, and therefore, profitable technology (or machine) finds uses and application in other fields leading to a ripple that travels through the economy. He puts it thusly: "it must be remembered that the progress of any branch of manufacture excites new activity in most other branches, and leads indirectly, if not directly, to increased inroads upon our seams of coal (Jevons, 1865) and "We substitute cheaper for a dearer [in the same process], a new for an old process" and furthermore, "the 
quantity consumed by each individual is a composite quantity, increased either by multiplying the scale of former applications, or finding wholly new applications."

A century later, Khazzoom (1980) echoed this when he concluded on the basis of his work that, "improved efficiency may. . .result in some reduction in energy consumption, but an improvement in the efficiency of one appliance influences not only the demand for own end-use, but also the demand for other end-uses. This follows from the fact that end uses compete for the same overall budget."

On the nature of consumer behavior and how it is one of the "natural laws that govern consumption" Jevons argues that greater economy enables higher consumption and also enables an increase in the number of consumers. In words that echo the Limits to Growth thesis he states, in his chapter titled "Of the Natural Law of Social Growth" that "coal itself is limited in quantity" and that a "vague but inevitable limit will stop our progress" (Jevons, 1865). He further adds that "We cannot, indeed, always be doubling the length of our railways, the magnitude of our ships, and bridges, and factories" (Jevons, 1865). While the Limits to Growth (Meadows et al., 1972) ${ }^{4}$ thesis and Malthus' (Malthus, 1803$)^{5}$ dire predictions from before that, were largely discredited later on, due to the absoluteness of their estimations of resource depletion which as of yet have come to pass, the underlying principle--that of ever increasing consumption and

\footnotetext{
${ }^{4}$ The book modeled the consequences of the exponential growth of five variables-- world population, industrialization, pollution, food production and resource depletion - on the finiteness of earth's resources and the inability of the earth to sustain growth indefinitely.

${ }^{5}$ Malthus posited that population growth was exponential while food supply was arithmetic thereby necessitating checks on population growth.
} 
exponential growth in population being unsustainable is entirely credible. Jevons addresses this when he says "our environment or the powers and capabilities of inorganic nature have elastic yet inexorable limits, subject moreover to diminishing returns" (Jevons, 1865). In another instance of very forward thinking, Jevons alludes to the "I =PAT" ${ }^{6}$ formula (Alcott, 2005; Alcott actually credits Jevons for being the first to allude to the I=PAT relationship) in that society's consumption consists of "the number of people, and the average quantity consumed by each" (Jevons, 1865)--the number of people coding for the variable 'Population or P' and the quantity consumed by each coding for the variable 'Affluence or A'.

Jevons summarizes his take on the 'natural laws that govern consumption' as "If children do as their fathers did. . then multiplication and average consumption both rise; If our parents doubled their income, or doubled the use of iron, or doubled the agricultural produce of the country, then so ought we, unless we are changed either in character or circumstances" (Jevons, 1865). The "purposes and needs driving invention come from our reservoir of unmet demand whenever costs go down. These are, then, the natural laws which govern consumption and a natural law of growth, or multiplication in social affairs" (Jevons, 1865).

Jevons' evidentiary support for his hypothesis is largely theoretical and the only empirical evidence he provides, are the historical correlations between increases in

\footnotetext{
${ }^{6} \mathrm{I}=$ PAT where, I=Impact on the Environment, $\mathrm{P}=$ Population, A=Affluence and T = Technology. Ehrich and Holdren (1972) hypothesized that all three factors were influential in combining to affect the quality and capability of the natural environment .
} 
energy consumption and technological improvements that resulted in increased efficiency. Using data and by tabulating them, Jevons demonstrates that "In round numbers, the population has about quadrupled since the beginning of the nineteenth century, but the consumption of coal has increased sixteenfold, and more" (Jevons, 1865). More convincingly, Jevons demonstrates the correlation between the almost tenfold increase in efficiency going from the Newcomen to the Watt to Woolf and Elder steam engines and the increases in consumption of coal in the corresponding time period. Jevons thus made his argument "that efficiency and total consumption had risen together, moreover, the latter more than the former" (Alcott, 2005). However, Jevons' analysis does not speculate about or consider other factors that could have possibly been involved or could even be responsible for this correlation. Recognizing that his demonstration of correlation does not imply causation, Jevons uses theoretical arguments to bolster the case for the paradox. He argues that the purpose of efficiency is in and of itself, to promote consumption.

\subsubsection{Khazzoom-Brookes Postulate}

Not prior to the late 90s was any serious inquiry into Jevons' Paradox made until the works of Khazzoom (1980, 1987, 1989) and Brookes (1979, 1982a, 1982b, 1990, 1990b, 1990c). Brookes and Khazzoom's independent works lead to the formulation of the Khazzoom-Brookes postulate which is essentially a more restrictive application of Jevons' Paradox in that the postulate is specific to energy efficiency and is based on the macroeconomic rebound effect while Jevons' Paradox applies to all efficiency 
improvements and predicts rebound at different levels. In its simplest form, the Khazzoom-Brookes postulate can be stated thusly; energy efficiency improvements that, on the broadest considerations, are economically justified at the microlevel, lead to higher levels of energy consumption at the macrolevel (Saunders, 1992a, 1992b).

Leonard Brookes (2000) contends that national energy efficiency policies are essentially a promise of a "free lunch" in that energy efficiency measures are a profitable means of satisfying environmental regulations, thereby creating what is perceived as a win-win situation. They are therefore extremely "seductive" but are contrary to their intentional outcomes as "economically justified improvement(s) in energy efficiency led to higher levels of energy consumption at the economy-wide level than in the absence of any efficiency response (Brookes, 2000)." Brookes (2000) also makes a distinction between the short-run and long-run response to improvements in energy efficiency noting that "In the short run it is very possibly true that consumers would not expand their demand for an important resource to any very great extent following a rise in productivity (or fall in implicit price)."

Khazzoom's work, that looked at energy efficient appliances in the residential sector and the correlations between energy efficiency gains and energy consumption, bore out the thesis that the correlation between efficiency gains and decrease in energy consumption were less than one (the actual savings were less than the potential savings due to some rebound) primarily as efficiency caused a change in the 'price content' of energy (Khazzoom, 1980). This finding was contingent on the assumption that the price 
elasticity of demand for that particular product/service was greater than (but not equal to) zero ${ }^{7}$. The publishing of Khazzoom's work lead to a debate between Khazzoom and Lovins' (Lovins et al. 1988); the latter disagreed with the basic foundational principle of the 'rebound' effect that the former's work was based on ${ }^{8}$. Grubb (1990) also opposed Khazzoom's interpretation, arguing that there are significant differences between 'naturally occurring' energy-efficiency improvements from on-going technological change, and energy-efficiency improvements as a result of targeted policies and measures. The differences between the two sides reflect a different view of the efficiency of the market. If the market is perfectly efficient, then the traditional view holds and the efficiency improvements come from exogenous technological change (Sutherland, 1996). If there are market failures, then policies can address them, and efficiencies can be improved but require additional investment (Sutherland, 1996). Khazzoom, an economist, approached the study from a neoclassical economic theory standpoint as did Saunders (1992a, 1992b) who continued working on integrating the thesis put forth independently by Brookes and Khazzoom.

Saunders, (1992a, 1992b) following Khazzoom and Brookes, re-examined Jevons'

\footnotetext{
${ }^{7}$ A price elasticity greater than one indicates that changes in price of that good/service have a relatively large effect on the quantity of that good/service demanded. The demand for fuel therefore, has a "price content" in that demand is contingent on price. When efficiency improvements reduce the operating cost, the perceived savings lead to an increase in demand which results in rebound.

${ }^{8}$ The debate between Amory Lovins and Daniel Khazzoom was conducted through articles and rebuttals in The Energy Journal. Lovins (1988), a strong proponent of energy efficiency, maintained that the 'rebound' was minimal and that microeconomic changes in efficiency were disconnected from macroeconomic effects while Khazzoom $(1987,1989)$, a neoclassical economist argued that macroeconomic responses to implicit changes in energy price were caused by efficiency improvements and that rebound was not insignificant.
} 
hypothesis but did so by applying the neoclassical economic growth theory to examine its validity, to identify instances where it held and where it did not. Saunders is also credited with coining the term the "Khazzoom--Brookes postulate" for the statement that arose out of the work of those two authors and his own---"that subject to relatively undemanding conditions, raising energy efficiency leads to a higher level of energy consumption at the macroeconomic level" (Saunders, 1992a). Saunders' work demonstrated that rebound exceeded fuel savings when assumptions of substitution elasticity ${ }^{9}$ held; Saunders' model assumed unitary elasticity of substitution which several other scholars disagreed with. In what would be a verification of Jevons theoretical formulation--that efficiency increased labor and capital productivity leading to the multiplier effect that propagated through the economy causing energy savings to be lost-- Saunders found that backfire was most likely under scenarios when an increase in fuel efficiency was accompanied by increased labor and capital productivity. Solow is said to have commented on Saunders draft (1992b) that "It's hard to break the habit... factor augmenting does not mean factor saving".

When Howarth (Howarth, 1997) examined the same postulate by modifying the model that Saunders used, he found that the Khazzoom-Brookes postulate did not hold. Howarth argued (1990) that "improved energy efficiency cannot give rise to increased

\footnotetext{
${ }^{9}$ Substitution elasticity refers to the propensity to substitute good/service" a" for good/service "b" when price of " $a$ " or " $b$ " changes. It is measured as the ratio of proportional change in relative demand for two goods/services to a proportionate change in their prices. Saunders work found that only when conditions of substitution elasticity held that did rebound exceed potential energy savings.
} 
energy use unless: (i) energy costs dominate the total cost of energy services ${ }^{10}$ and (ii) expenditures on energy services constitute a large share of economic activity." He concluded that since neither of these assumptions can always be satisfied, energy efficiency improvements will yield long-run reductions in energy use. Supporters of Saunders position maintain that for there to be no rebound the following conditions must be met; 1) energy as a good/service should have no substitute, 2) demand for energy should not be sensitive to price of energy and 3) should not be linked to manufacturing and economic productivity. Since these conditions cannot be met, they reiterate that rebound is inevitable. The Howarth study was replicated by Saunders again, who re-examined the Howarth model and added certain functionalities and found that the postulate held true. This is, but an example, of how the empirical verification of the rebound effect has been mired in issues of model specification.

Saunders (1992) concluded that "In the absence of efficiency gains, energy use will grow in lock step with economic growth (energy intensity will stay fixed) when energy prices are fixed. ... Energy efficiency gains can increase energy consumption by two means: by making energy appear effectively cheaper than other inputs; and by increasing economic growth, which pulls up energy use. ... These results, while by no means proving the Khazzoom-Brookes postulate, call for prudent energy analysts and policy makers to pause a long moment before dismissing it."

\footnotetext{
${ }^{10}$ Howarth (1990) contends that energy costs are not always the biggest chunk of total cost of energy services and that in fact, in today's economy, energy is a small percentage of the cost of production ( 5\%) and so a decrease in energy costs can have only a small macroeconomic impact and consequently a small rebound.
} 
Much of the debate over rebound effects of energy efficiency are, as will be evidenced by the studies citied in this literature review, documented in the journals Energy Policy and The Energy Journal. A special issue of the Energy Policy journal and the Energy and Environment journal were published in 2000 that delved into the topic of rebounds due to improvements in energy efficiency. The conclusion of this special issue seemingly is that there is little doubt that rebound occurs but that there remains little consensus with regards to the magnitude of the rebound effect and on whether energy consumption becomes higher or lower than historical levels of consumption predating the improvements in energy efficiency. While some such as Brookes suggest that energy consumption is higher than would have been had the energy efficiency improvement not been made, others such as Schipper maintain that energy consumption levels are ultimately lower than would have been if the improvement had never occurred. Theoretical and empirical studies of the rebound effect provide little resolution for this debate; the estimated rebound effects have varied based on the sector, the scale (micro- or macroeconomic), degree of rebound (small to a full boomerang) and between countries. Further, developing a control variable that can distinguish between energy consumption levels had the energy efficiency improvement never occurred is problematic as the energy efficiency improvement has already occurred and proxies are prone to all the inherent fallacies of assumptions that guide their formulation.

So to summarize; it is theorized that some degree of rebound is expected to be induced by energy efficiency improvements. The pathway for this effect in instances such as improvements in fuel economy are thought to operate through two related 
phenomena; 1) a technical phenomenon that increases the fuel economy and reduces cost which triggers 2) an economic and behavioral phenomenon that influences energy consumption (Bergh, 2010). In terms of fuel economy in particular, Greening et al. (2000) categorize the rebound effects as accruing due to four "market" responses; 1) direct rebound effects that arise due to the decline in "cost" of driving 2) secondary fuel use effects that occur due to the spending of the "saved" dollars 3) economy-wide effects due to the multiplying effect of the fuel efficiency improvements in other sectors, and 4) transformational effects (preference change, partly induced by technological change).

\subsection{Empirical Evidence}

Studies that have investigated Jevons effect or verified the Khazzoom -Brookes postulate have been largely theoretical and anecdotal based on historical estimates. Historical data indicates that the consumption of (all forms of) energy have steadily increased at the macroeconomic level despite the many technological advances in harnessing, converting and utilizing energy that have increased efficiencies. This fact appears to provide some anecdotal evidence for Jevons' Paradox, however, as these increases have been accompanied by increases in population, greater production and increased modes of application, to conclusively provide support for the operation of the paradox, the effects of the latter have to be disengaged from the effects of the former. Brookes (2000) in fact, contends that "The claims of what might be called the Jevons 
school are susceptible only to suggestive empirical support since estimating the macroeconomic consequences of individual improvements in energy efficiency is practically impossible". Others argue that the difficulty with conclusively establishing Jevons' Paradox through empirical studies arises because while the paradox is essentially an empirical formulation, it is not amenable to being studied empirically as the "control" scenario, i.e., energy consumption given that the energy efficiency improvement did not occur is impossible to study. That notwithstanding, there is a growing albeit small body of literature that empirically examines the microeconomic consequences of energy efficiency improvements. These studies have been in most part confined to particular sectors such as the residential energy consumption sector (residential space heating/cooling, energy efficient appliances) and transportation sector (fuel efficiency and vehicle miles travelled). The studies that have looked at empirical evidences for Jevons' Paradox on a macroeconomic scale represent a far smaller subset of this body of literature and will be discussed very briefly before a review of empirical studies that focus on estimating rebounds for increases in fuel economy (microeconomic scale) is conducted.

\section{$\underline{\text { 2.5.1 Empirical Studies: Macroeconomic Scale }}$}

Empirical studies that look at macroeconomic effects of rebound have been few on account of the difficulties associated with modeling economy-wide direct and indirect rebound effects. Brookes (2000) explained the paucity of such studies to be because it is "impossible to compute with any degree of confidence what the final 
macroeconomic effect would be of a host of individual microeconomic changes in energy use. We also have the problem of the lack of any reliable indicator of progress in energy efficiency at the macroeconomic level." The few studies that looked at economy wide rebound effects are summarized.

A study by Sam Schurr (Shurr, 1990) looked at emergence of new technologies that improved energy efficiency, electricity consumption and economic output for the period 1880-1970. The results demonstrated that increases in energy efficiency were accompanied by increases in energy consumption and economic output. The increase in economic output (which presumably lead to greater consumption of energy) was far greater than the increases in energy efficiency thereby ensuring that energy consumption stayed ahead of energy efficiency gains.

Schipper (2000) and Grubb (1990) examined energy intensity trends for the period 1970 to 1995 for International Energy Agency (IEA) countries and determined that "feedback was small in most sectors of the mature economies" and large only in few cases. They posit that improvements in energy efficiency are but one of many reasons for increases in energy consumption; the other factors being increases in population, members per household, income, and economic output.

Barker et al., (2008) studied the effects of efficiency policies (termed "no-regrets efficiency policies") reported by the International Energy Agency in their publication, World Energy Outlook, 2006. They analyzed the effects of these no-regrets energy efficiency policies crafted for the transport, residential and services buildings and 
industrial sectors of the economy on energy consumption levels for the period 20132030. They applied a "Global 'New Economics' or Post Keynesian model, E3MG" and determined the estimated direct rebound effect to be about $10 \%$. The total rebound effect, however, was estimated to be $31 \%$ by 2020 and $52 \%$ by 2030 . They state that "The total effect includes the direct effect and the effects of (1) the lower cost of energy on energy demand in the three broad sectors as well as of (2) the extra consumers' expenditure from higher (implicit) real income and (3) the extra energy-efficiency investments." They concluded that "the rebound effects build up over time as the economic system adapts to the higher real incomes from the energy savings and the investments (Barker et al., 2008)."

Saunders et al., (2010) analyzed energy consumption and the availability of new (and more efficient) solid-state lighting (SSL) technologies. They determined that "over the last three centuries, and even now, the world spends about $0.72 \%$ of its GDP on light. This was the case in the UK in 1700 , is the case in the undeveloped world not on grid electricity in modern times, and is the case for the developed world in modern times using the most advanced lighting technologies." They go on to outline that the current belief that new, highly-efficient, solid-state lighting such as LED technology will result in reduced energy consumption has been disproved by their analysis. They (Saunders et al., 2010) conclude that "there is a massive potential for growth in the consumption of light if new lighting technologies are developed with higher luminous efficacies and lower cost of light." They further reiterate that "These conclusions suggest a subtle but important shift in how one views the baseline consequence of the increased 
energy efficiency associated with SSL. The consequence is not a simple 'engineering' decrease in energy consumption with consumption of light fixed, but rather an increase in human productivity and quality of life due to an increase in consumption of light."

Using the I=PAT equation as a theoretical foundation, Polimeni and Polimeni (2006) performed a macroeconomic examination of multicountry-level (154 countries of the world were categorized into 6 regions; 1) North America, 2) Central and South America, 3) Western Europe, 4) Asia, 5) Africa and 6) the Middle East) energy consumption to verify if energy efficiency gains were in keeping with Jevons' Paradox. Using Time Series Cross Section data from the EIA for the period 1980-2002 for the 154 countries and coding the factors of the I=PAT equation as; I (environment Impact) = total primary energy consumption, $\mathrm{P}($ Population $)=$ percentage change in population, $\mathrm{A}$ (Affluence) $=$ percentage change in GDP, and $T($ Technology $)=$ percentage change in energy intensity (where T acts as a proxy for improvements in technology that lead to energy efficiency), Polimeni and Polimeni (2006) found that; 1 ) in North America, the percentage change in energy intensity was the primary factor leading to increased energy consumption thereby indicating that there was some evidence that Jevons' Paradox held, 2) in Central and South America, Western Europe and the Middle East the percentage change in GDP and the percentage change in energy intensity increased total primary energy consumption at approximately the same rate which the authors interpreted as providing some evidence that Jevons' Paradox existed at the macrolevel energy, 3) in Asia the impact of percentage changes in energy intensity on energy consumption were more than five times greater than that of percentage changes in 
GDP providing empirical evidence that Jevons' Paradox may exist at the macro-level in the region and 4) in Africa, the percentage change in GDP and Population were negative and percentage change in energy intensity was the only influential variable indicating that there was evidence for Jevons' Paradox. While this study was unique in its approach to verifying the existence of Jevons' Paradox, there are some modeling concerns. Some scholars argue that the independent variables are interdependent (e.g., Population is dependent on Technology which is dependent on Affluence) and to best capture the interdependence between population growth, affluence, technology and energy intensity the relationship could be better expressed as a system of simultaneous equations (Alcott, 2006).

\subsubsection{Studies on the Microeconomic Scale}

\subsubsection{Rebound Estimates}

Empirical studies that have examined the paradox on the microeconomic scale have tended to primarily focus on calculating estimates of the rebound effect in the short- and long-run for a particular energy efficiency improvement (Frey and Labay, 1988; Greening and Greene, 2000; Roy 2000; Schipper and Grubb 2000; Small and Van Dander, 2005; Sorrell, 2009). Even when studies on the same energy efficiency improvement are considered, there is little real agreement on the actual estimates either in the short-run or the long-run. The estimates appear to vary based on the timescale or period for which the data were considered and the methods and models 
followed (the so-called "modifiable unit scale problem"). The studies invariably find that rebound does occur, however the magnitude of the rebound varies, in so much that significance of the level of rebound becomes questionable for policy directions.

The most studied sector is transportation; the factors considered are fuel efficiency and vehicle miles travelled. The rebound effect for motor vehicles is typically defined in terms of the factors; Fuel efficiency (E), fuel consumption (F) and vehicle miles travelled (VMT) and related through the identity F=VMT/E (Small and Van Dender, 2005). The rebound effect arises as VMT depends ceteris paribus, on the cost per mile of driving which decreases with increases in fuel efficiency. While data collected by the EIA and FHWA indicate that the direct rebound effect for personal transportation may become operational in three different ways (Dahl, 1986, 1994; Dahl and Sterner, 1991, Greene et al., 1998); (1) an increase in the number of vehicles, (2) an increase in size of the vehicle, and (3) an increase in vehicle miles traveled. There is little in the literature documenting these three effects, save for the last. Scholars have however, produced a number of estimates of rebound for vehicular travel in the United States, using both aggregate and microlevel data. A few are discussed below (Table 3).

Greene (1992) looked at fuel prices, fuel efficiency and vehicle miles travelled for the years 1957-1989 and estimated the rebound effect to be between 5\% (short-run) and $15 \%$ (long run) with a best estimate of $12.7 \%$. Jones (1993) replicated Greene's (1992) study and determined the estimates of the rebound effect to be far higher (31\% and $11 \%$ for long-run and short-run respectively) when data for 1990 were added to the 
model and the model as specified by Greene was modified to address certain issues associated with time-series data. Schimek (1996) also used the Greene (1992) model but added data for a few more years and modified the model to account for effects of gasoline rationing (by applying dummy variables for the years 1974 and 1979) and CAFE regulation (time trend for the year 1978 when the standards came into effect). Schimek's findings, consistent but not equal to the Jones' (1993) finding, were that the long-run (29\%) and short-run (7\%) rebound effects were larger than the Greene (1992) finding. Haughton and Sarkar (1996) examined data on fuel prices and VMT for the years 1970-1991 for the 50 U.S. States and the District of Columbia and observed a short-run rebound effect of about $16 \%$ and a long-run rebound effect of $22 \%$. The study lead them to conclude that improvements in fuel efficiency were independent of the current price of gasoline, provided the current price did not exceed the historical peak price.

Small and Van Dender (2005) used a panel of US states and looked at data on fuel economy, VMT and income for the years 1966-2001 and determined rebound estimates to be about $4.7 \%$ and $22 \%$ in the short-run and long-run. Their models controlled for fuel-economy standards and autocorrelation and lagged effects. A caveat to the estimates they derived was the income effect; they found the "rebound effect to be much smaller when computed for values of per capita income characterizing recent years than when computed for average values over the 36-year estimation period" i.e., the rebound effect seemed to decease with increases in income $(2.6 \%$ and $12.1 \%$ as opposed to $4.7 \%$ and $22 \%$ in the short-and long-run estimates). Their results in 
particular indicated that "it was barely half as large in the years 1997-2001, and is likely to diminish still further as rising incomes reduce the significance of fuel costs in decisions about travel"(Small and Van Dender, 2005). They therefore conclude that the rebound effect is probably "considerably smaller today than has been measured in the past, and is likely to become smaller still as time goes on" (Small and Van Dender, 2005). This conclusion is a departure from other studies that theorize that rising incomes would lead to greater rebounds.

Barla et al., (2009) conducted a study of Canadian light-duty vehicle fleet using panel data at the provincial level from 1990 to 2004 and estimated the rebound effect, price elasticties and income elasticities. They applied a simultaneous three-equation model of aggregate demand for vehicle kilometers traveled, vehicle stock and fuel efficiency. They found that; a) income has a positive impact on gasoline demand essentially through increased driving distances b) an increase in the fuel price of $10 \%$ was associated with a decrease in VMT by $2 \%$ of the average fuel consumption rate c) the estimates of the short- and long-term rebound effects were $8 \%$ and $20 \%$. Barla et al., (2009) concluded that "the results suggest that the effectiveness of new fuel efficiency standards will be somewhat mitigated by the induced increase in driven distances." They also suggest that since "the demand for gasoline by light-duty vehicles (LDV) is quite inelastic, even in the long term...major prices changes are necessary to induce significant reduction in the use of gasoline. Moreover, income growth could progressively erode gasoline savings associated with higher prices." 
Table 3: Summary of empirical evidence for rebound effects

\begin{tabular}{|c|c|c|c|c|}
\hline $\begin{array}{l}\text { Economic } \\
\text { Actor }\end{array}$ & End Use & $\begin{array}{l}\text { Potential } \\
\text { Size of } \\
\text { Rebound }\end{array}$ & $\begin{array}{l}\text { Number } \\
\text { of Studies }\end{array}$ & Comments \\
\hline \multicolumn{5}{|l|}{ Consumers } \\
\hline & Space heating & $14-60 \%$ & $26^{++}$ & $\begin{array}{l}\text { The unmeasured part of this } \\
\text { effect includes } \\
\text { an increase in the space } \\
\text { conditioned and an increase } \\
\text { in comfort. }\end{array}$ \\
\hline & Space cooling & $0--50 \%$ & $9^{+}$ & $\begin{array}{l}\text { The unmeasured part of this } \\
\text { effect includes } \\
\text { an increase in the space } \\
\text { conditioned and an increase } \\
\text { in comfort. }\end{array}$ \\
\hline & Water heating & $<10--40 \%$ & $5^{*}$ & $\begin{array}{l}\text { Reports of increased length } \\
\text { of shower or the } \\
\text { purchase of increased water } \\
\text { heating unit } \\
\text { size indicate some indirect } \\
\text { effects, which cannot be } \\
\text { measured }\end{array}$ \\
\hline \multirow[t]{3}{*}{$\begin{array}{l}\text { Economic } \\
\text { Actor }\end{array}$} & End Use & $\begin{array}{l}\text { Potential } \\
\text { Size of } \\
\text { Rebound }\end{array}$ & $\begin{array}{l}\text { Number } \\
\text { of Studies }\end{array}$ & Comments \\
\hline & $\begin{array}{l}\text { Residential } \\
\text { lighting }\end{array}$ & $5--12 \%$ & $4^{*}$ & $\begin{array}{l}\text { An indirect effect in terms of } \\
\text { an increase in operating } \\
\text { hours was reported. }\end{array}$ \\
\hline & $\begin{array}{l}\text { Appliances } \\
\text { ('White Goods) }\end{array}$ & $0 \%$ & $2^{*}$ & $\begin{array}{l}\text { Indirect effects in terms of } \\
\text { the purchase } \\
\text { of larger units with more } \\
\text { features were reported. }\end{array}$ \\
\hline
\end{tabular}




\begin{tabular}{|c|c|c|c|c|}
\hline & $\begin{array}{l}\text { Automotive } \\
\text { transport }\end{array}$ & $5-87 \%$ & $32^{++}$ & $\begin{array}{l}\text { The unmeasured part of this } \\
\text { effect includes changes in } \\
\text { automotive attributes, } \\
\text { particularly the shifts toward } \\
\text { attributes such as increases } \\
\text { in weight, horsepower and } \\
\text { acceleration. }\end{array}$ \\
\hline \multicolumn{5}{|l|}{ Firms } \\
\hline & $\begin{array}{l}\text { Process uses } \\
\text { (Short-run) }\end{array}$ & $0--20 \%$ & $1^{*}$ & $\begin{array}{l}\text { Although increases in output } \\
\text { occurred for less than } 20 \% \text { of } \\
\text { the study participants, no } \\
\text { values were reported. }\end{array}$ \\
\hline & $\begin{array}{l}\text { Lighting (Short- } \\
\text { run) }\end{array}$ & $0--2 \%$ & $4^{*}$ & $\begin{array}{l}\text { Changes in output were not } \\
\text { reported. However, labor } \\
\text { productivity probably } \\
\text { improved. }\end{array}$ \\
\hline & $\begin{array}{l}\text { Change in total } \\
\text { output growth }\end{array}$ & $0.48 \%$ & 1 & $\begin{array}{l}\text { Postulated effects include an } \\
\text { increase in standard of living } \\
\text { and consumption of more } \\
\text { energy-intensive "luxury" } \\
\text { goods. }\end{array}$ \\
\hline
\end{tabular}

Source: Based on Greening and Lorna, 2000; Sorrell, 2007; Gavankar and Geyer, 2010.

Note: These estimates are expressed as a percentage increase in consumption estimated to result from a $100 \%$ increase in energy efficiency (i.e., the estimated elasticity of demand times * $100 \%$ ). All estimates assume a $10 \%$ increase in efficiency of fuel consumption.

${ }^{++}$These studies are done with a number of methods that provide good correspondence of estimates.

${ }^{+}$These studies are done with only a moderate number of different methods that show some variability in estimates.

${ }^{*}$ These studies are done with only one or two methods and are inconclusive in results. 
The review of the extensive literature on rebound suggests that; 1 ) theoretical definitions of the rebound effect vary in the literature and among researchers, 2) empirical specifications vary, 3) depending on the model specifications (time frame, level of aggregation etc.) the magnitude of the rebound varies from almost negligible to significant and most importantly that 4) the magnitude of rebound relies heavily on the type of technology and/or the quality of energy and how central they are to the economic productivity. The technology that is more wide-ranging in its application, more universal in its presence is likely to generate larger rebound upon becoming more efficient than the one that's more specific in its application at least at this point in time. A recent study by Turner (2013) estimates that there have been over 80 articles (in just 6 leading energy/environmental journals) on rebound since 2007 when Sorell's 2007 seminal work was published. Turner (2013) summarizes the huge disconnects in the theory and empirical modelling that these studies employ and urges caution in interpreting results.

\subsubsection{Beyond Estimating Rebound}

While much of the literature on efficiency gains and actual energy savings is devoted to estimating a measure of rebound, there are some studies that have looked at other indicators of the paradox. From the study by Newman (1991) that demonstrated that expanding roads to improve traffic efficiency paradoxically lead to 
increased congestion due to an increase in the number of vehicles plying the nowexpanded roads, to the study by Khazzoom (1987) who reported that increases in efficiency of refrigerators was associated with increased purchases of bigger refrigerators, there are studies that document and examine Jevons' Paradox by going beyond the mathematical estimation of the rebound. Findings from a few of the studies pertaining to consumer behavior with regard to personal vehicle travel are summarized.

A study by Kurani and Turrentine (2004) that was presented to the US Department of Energy and the Energy Foundation surveyed 57 households from 10 "lifestyle sectors" to study how consumers think and behave relative to fuel economy and efficiency, both on a daily basis and when they purchase motor vehicles. The study found that; 1) Households with limited funds, paid attention to fuel economy by purchasing at least one smaller and less expensive vehicle (or used vehicle). They were not prone to however, track or consider annual fuel costs. 2) Affluent families were more concerned with amenities (seating capacity, cargo room etc.) that eclipsed fuel economy concerns. They had a threshold value of fuel economy that the vehicle had to meet but were not particularly interested in fuel economy per se (authors refer to this behavior as having "submerged concerns for fuel economy"). 3) Those that were interested in "luxury and performance" who therefore did not consider fuel economy at all (the authors refer to this as having "sunk concerns for fuel economy"). 4) Individuals who hailed from a low-economic background who were ambivalent about fuel economy and tended to alternate between thrift and extravagance; for instance purchasing a less fuel efficient car and then shopping for inexpensive gasoline. 5) Hybrid owners whose 
purchase of the hybrid vehicle was less due to a motivation about fuel cost and almost exclusively (every individual interviewed) due to an interest in resource conservation, reduced air pollution, and utilizing new technology. While this study's sample was by no means large ( $n=57$ households), the commonalities observed are an interesting indicator of consumer behavior with regard to purchase of vehicles.

The EIA report "Household Vehicles Energy Use: Latest Data and Trends" (EIA, 2005) that analyzed data collected over three time periods: 1988-1991, 1991-1994 and 1994-2001 indicates that while increases in fuel economy had reduced energy use, the effects "sharply diminished over time, suggesting significant savings occurred prior to 1991 and much less so in following years". Based on a decomposition analysis that sought to identify which of the factors (vehicle use, vehicle type, vintage effects, housing, ownership, lifecycle and energy intensity) had the most influence on creating and off-setting the savings, the analysis found that energy intensity had the most effect in creating energy savings but that these savings were offset by vehicle use, vehicle type and ownership. In effect, decreases in energy intensity or the increase in vehicle efficiency had saved the nation several billions of gallons of fuel but that had been offset through vehicle purchases made by consumers that had become heavier, more powerful, and faster, while only moderately less fuel intensive. An increase in fuel efficiency of vehicles was found to have been offset by increased travel by consumers; to quote "energy intensity improved 1.6 percent per year, from 66.2 GEG (Gasoline equivalent gallons) per 1000 miles in 1983 to 49.5 GEG in 2001, while per-vehicle travel offset this improvement by increasing 1.4 percent per year, from 9.4 thousand miles per 
vehicle to 12.0 thousand miles, as the number of vehicles in total increased 2.2 percent per year - simply put, more vehicles are traveling farther" (EIA, 2005).

The results of a survey in May 2004 by the National Renewable Energy Laboratory (NREL, 2004) indicated that some automobile buyers would be willing to pay $\$ 1,000--\$ 2,000$ more for a vehicle that provides $\$ 400$ of fuel cost savings per year.

\subsection{Other Variables that might affect VMT}

Household Income: Using a nonparametric regression model and data from the 1995 Nationwide Personal Transportation Survey, Kweon and Kockleman (2004) found that household VMT rises with income and vehicle ownership. In a report that evaluates the impact of transportation policy on economic development, Litman (2010) shows that vehicle ownership and VMT increase with increase in income, particularly in the instance of a household's move from low income to moderate income. When the move is from a high income bracket to even wealthier levels, there is a reverse effect; VMT decreases (Litman posits that it is most likely due to the ability to move to locations voiding the need to drive as much as before). A study by the EIA found that vehiclemiles traveled was better correlated with disposable income than retail prices of gasoline as while real prices of gasoline has only increased slightly (if at all) the real price of other consumer products have risen dramatically taking a bigger share of the consumer budget. The EIA report (EIA, 2005) found that between 1983--2001, with some minor deviations, the growth in vehicle-miles traveled was significantly associated 
with increases in real disposable income. A more recent study by Wang and Chen (2013) found that the association between fuel price, disposable household income and VMT was "unequal and unfair"; lower income households drove less and made only necessary trips with increase in fuel price.

Motorist's Age: A 2006 study by Steve Polzin found that motorists aged 20--64, ceteris paribus, had a greater VMT/year; they drove on average 11,000 VMT/year while motorists younger than 20 years of age clocked an average of only 4,486 VMT/year. The decline in VMT post-65 years of age was significant (Figure 6). It could be hypothesized that those of the population who fall within the "working population"-age would drive more on account of commutes to work, whereas those who are retired or yet to be licensed-drivers and/or unemployed would be bound to drive less. Data from the NHTS surveys $(1991,1995,2009)$ is consistent with this finding (Figure 7).

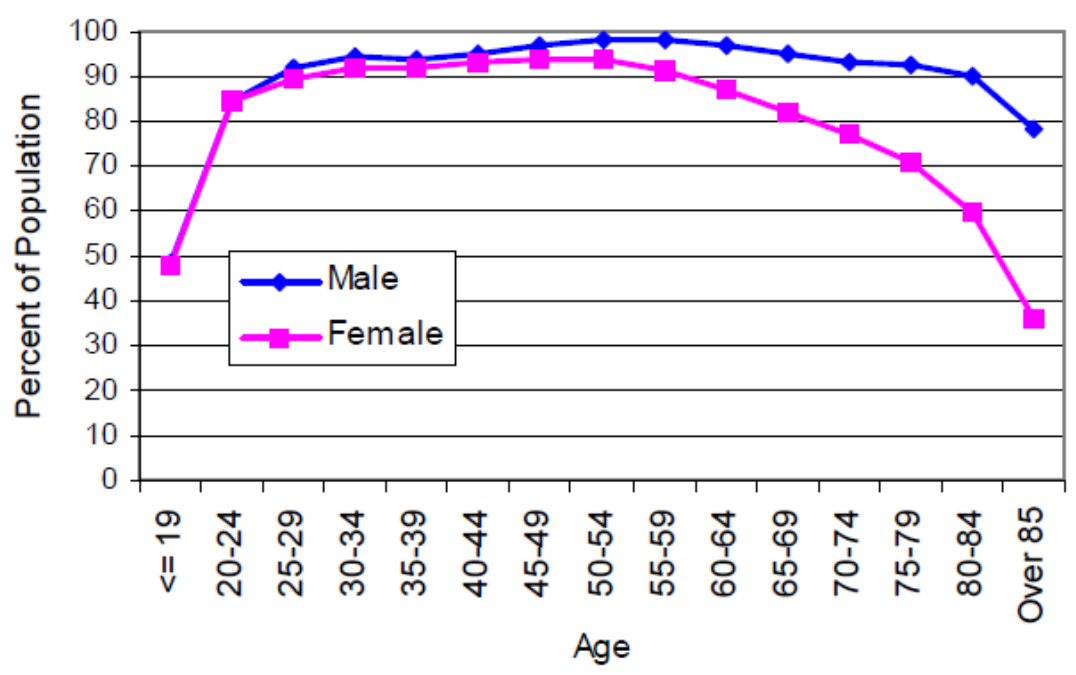

Figure 6: Driving Population By Age and Gender Source: FHWA Highway Statistics Series, 2000 


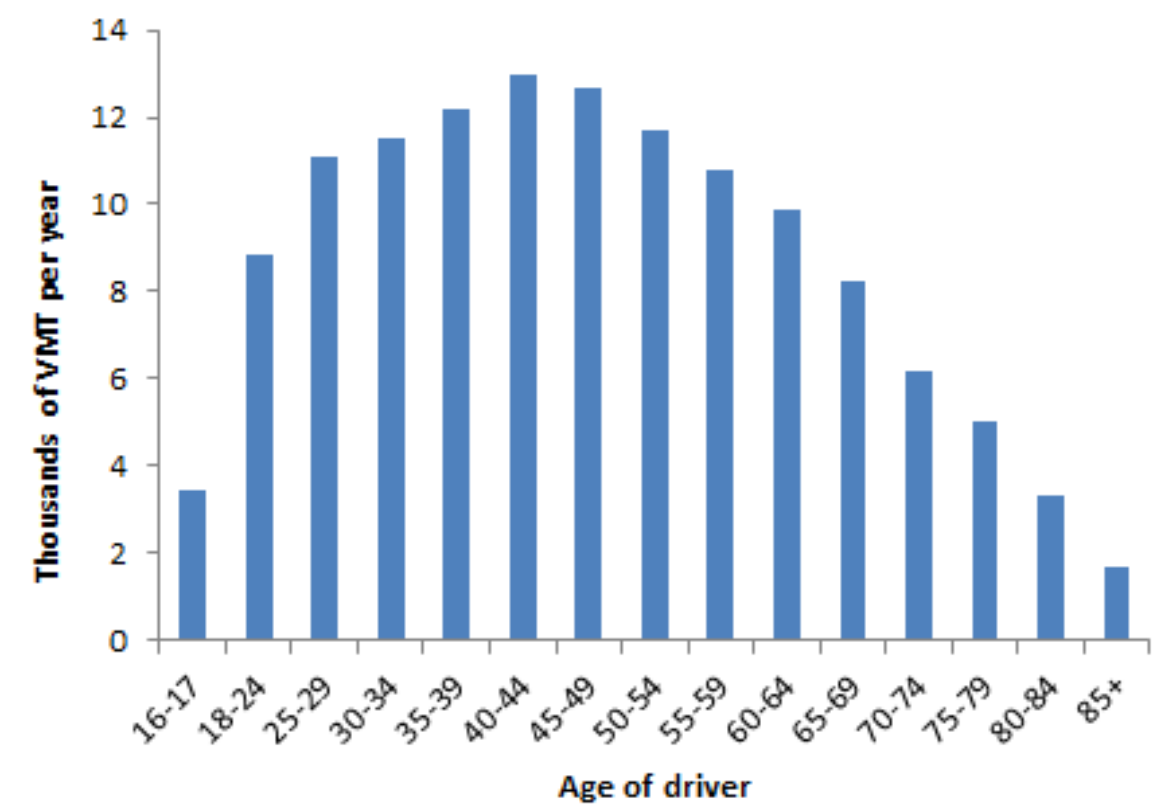

Figure 7: Driver Age and VMT

Source: NHTS, 1991, 1995, 2009

Household Size and Structure: An analysis of the National Household Travel Survey (NHTS, 2001) revealed that motorists who indicated their household status as being "married-couple households with children" drove on average $23 \%$ more than those who indicated that they were "married-couple households with no children" and 40\% more than those who were indicated being "single adult households". Polzcin (2006) found that larger households had lower number of trips than smaller households due to an increase in the number of pooled-trips. However, 2 person households posted almost double the VMT as single-person households (Polzin, 2006). Kweon and Kockleman (2004) found, similarly, a positive relationship between the number of members in a given household and greater VMT. A study conducted by the EIA corroborates this finding (EIA, 2005); households with children accrued greater VMT and those with teenage children accrued the most. In particular the EIA report found that per analysis 
of data collected in 2001; 1) Households with children averaged 29,200 miles compared to 19,600 miles that households with no children averaged, 2) Households with children aged 16 or 17 children had the greatest VMT on average (34,000 miles), 3) In singleadult households without children, the VMT average was about 12,000 miles while households with two or more adults (and no children) averaged 24,800 miles and, 4) single-driver households with no children, VMT ranged 8000 miles-14,400 miles (the lower limit corresponding to drivers 60 years of age and older and the upper limit corresponding to drivers under 35 years of age).

Employment Status: Polzin (2006) estimated, based on the NHTS 2001 data, that individuals who were part of the "labor force" (defined as those employed outside the home, the survey made distinctions between those who worked from home) averaged $15,812 \mathrm{VMT} /$ year while those who were not part of this labor force averaged 8,690 VMT/year. The EIA looked at economic, social, demographic, environmental and technological factors affecting VMT and found that employment status, income and VMT were positively correlated (EIA, 2013; Figure 8).

Age of the vehicle: A study by the EIA of the Residential Transportation Energy Consumption Survey data indicated that vehicle age had a significant correlation with VMT; on average, newer model vehicles had greater VMT than older models. The EIA report posits that "The likely explanation for this trend is that the oldest vehicles remaining in the residential fleet were relatively newer, more fuel efficient, and probably more reliable than were the oldest vehicles" (EIA, 2002). 
Density: While there is some uncertainty about the magnitude of the influence of land use characteristics on travel, there is some agreement about the direction of the influence. Areas of greater density and mixed use are associated with lower VMT while greater sprawl is associated with higher VMT (Polzin, 2006).

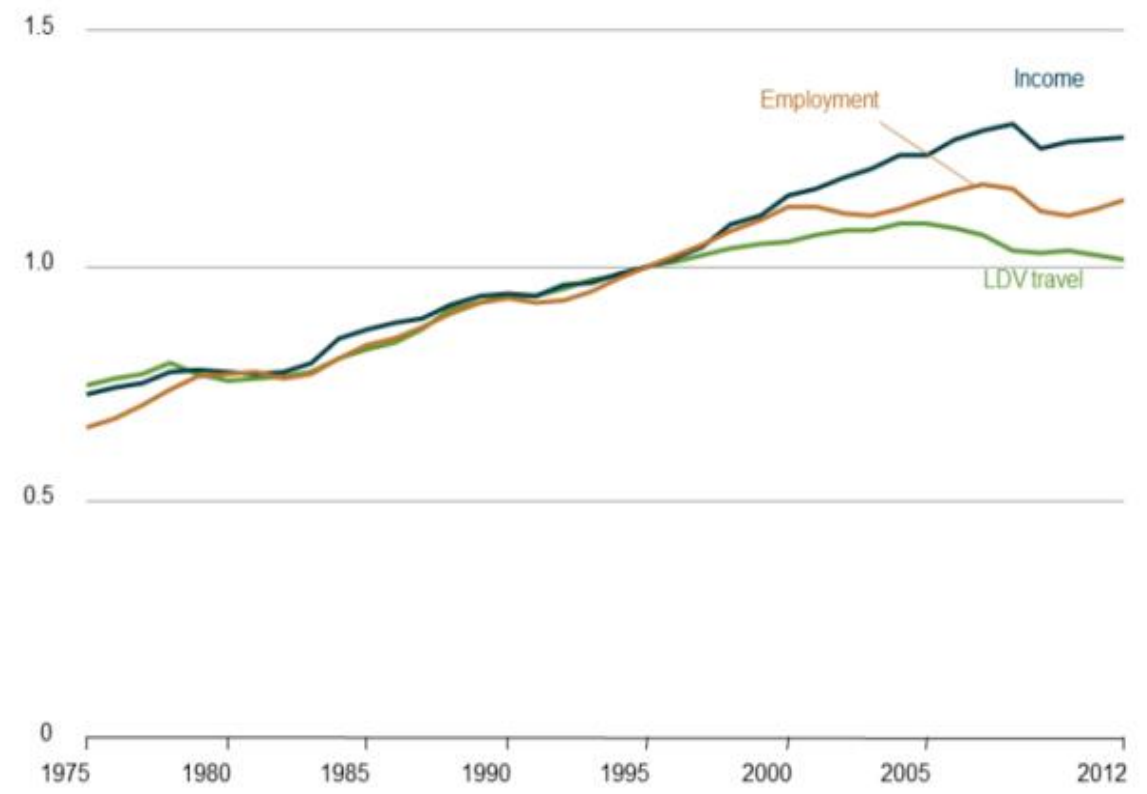

Figure 8: Economic Indicators of VMT (1975-2012) Source: EIA, 2013.

Fuel Price: While it would be intuitive to posit that increases in fuel prices would be associated with a decline in VMT, empirical estimates suggest that demand for travel is inelastic with respect to fuel price. Phil Goodwin et al., (2004) conducted a metaanalysis of 69 studies published since 1990 that studied the elasticities of road traffic and fuel consumption with respect to price and income and concluded that the consensus estimate is that a $10 \%$ permanent increase in fuel costs only lead to a reduction in traffic volume of about $1 \%$. Furthermore, studies estimate that change in 
driving behavior lags increase in fuel price by a minimum of a year (EIA, 2013).

\subsection{Conceptual Model}

As evidenced from the literature, vehicle miles travelled is an aggregate function of several factors; it is influenced by factors as divergent as personal traits and belief systems to aspects of transportation planning and policy. Literature from transportation planning and policy studies yields a long list of factors (some straight forward, others less so) that influence driving behavior among motorists in the United States. Those that are relevant to this study are categorized by context (Person characteristics, Household Characteristics, Vehicle Characteristics, Landuse and Fuel cost) and further differentiated into direct and indirect drivers as an illustration of the conceptual framework that will guide this study's mathematical model (Figure 9).

\subsection{Summary}

There is, as is evidenced by the review, a growing body of literature on theoretical studies on Jevons' Paradox (and the Khazoom-Brookes postulate) and empirical studies on rebound estimates for the household vehicle fleet. What has been documented is that there is consensus on the occurrence of rebound (not of its magnitude though) and consequently some concern about the effect of rebound on fuel consumption and all that it implies for policy instruments. 


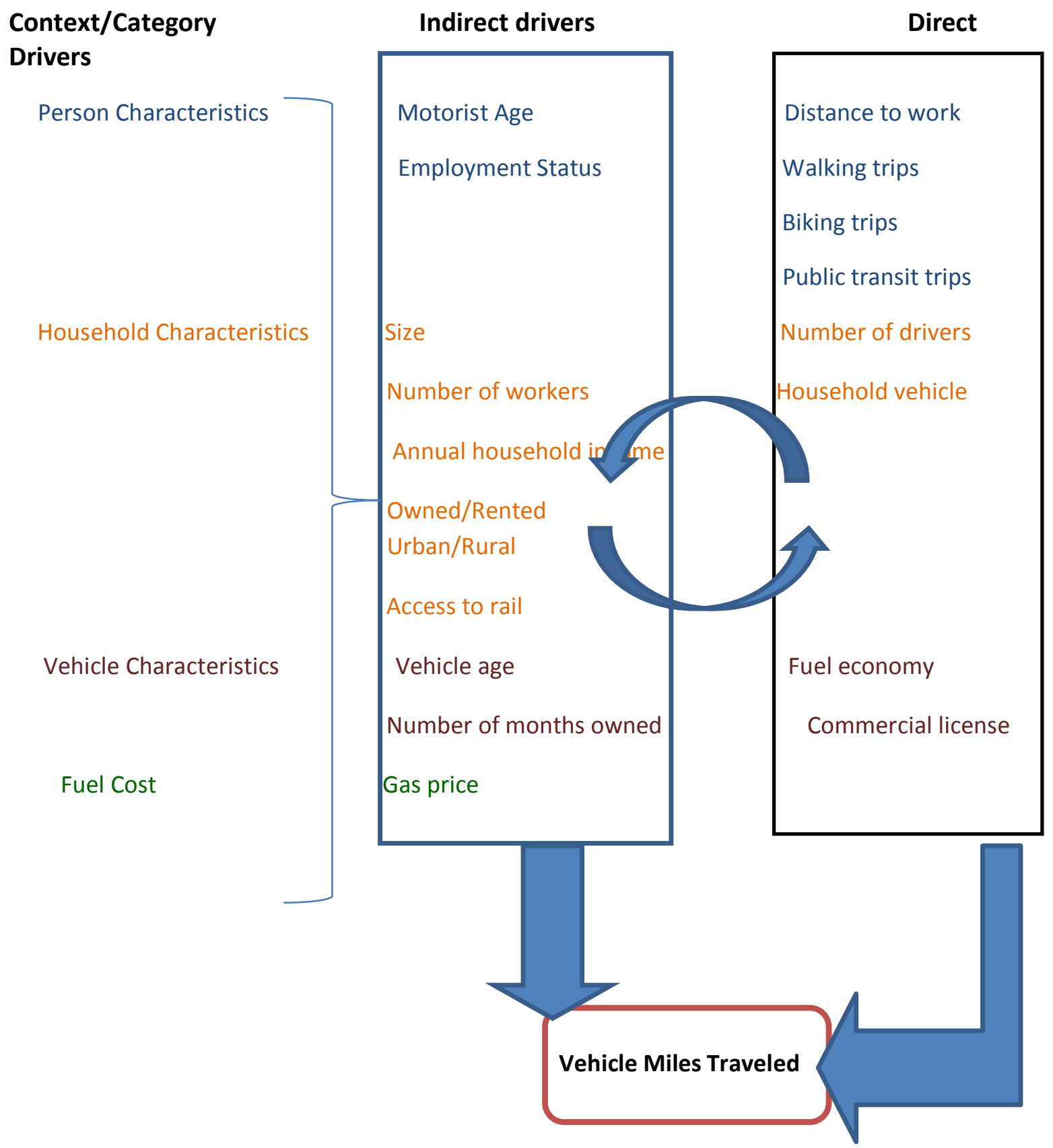

Figure 9: Conceptual model for the study 
What there isn't and what this study aims to do is to address the question of "for motorists who accrue greater VMT, how much of it can be explained by the fuel efficiency of the vehicle they drive, holding all else constant". To do that the hypothesis to be tested can best be stated as:

Vehicle Miles Travelled are greater for vehicles that have a greater fuel economy, holding constant other factors such as Individual characteristics (age of motorist, employment status, employment category, number of walking trips, number of biking trips), household characteristics (housing type, number of members in household, number of drivers in household, household income, number of vehicles in household), vehicle characteristics (vehicle age, number of months vehicle owned, fuel economy, hybrid), location (distance to workplace, urban/rural, access to rail) and fuel price.

Based on the review of literature, the independent variables that are to be applied in this study are categorized and their hypothesized/expected association with the variable of interest (the dependent variable; Vehicle Miles Travelled) is summarized in Table 4. 
Table 4: Variables to be Used in This Study and Expected Associations

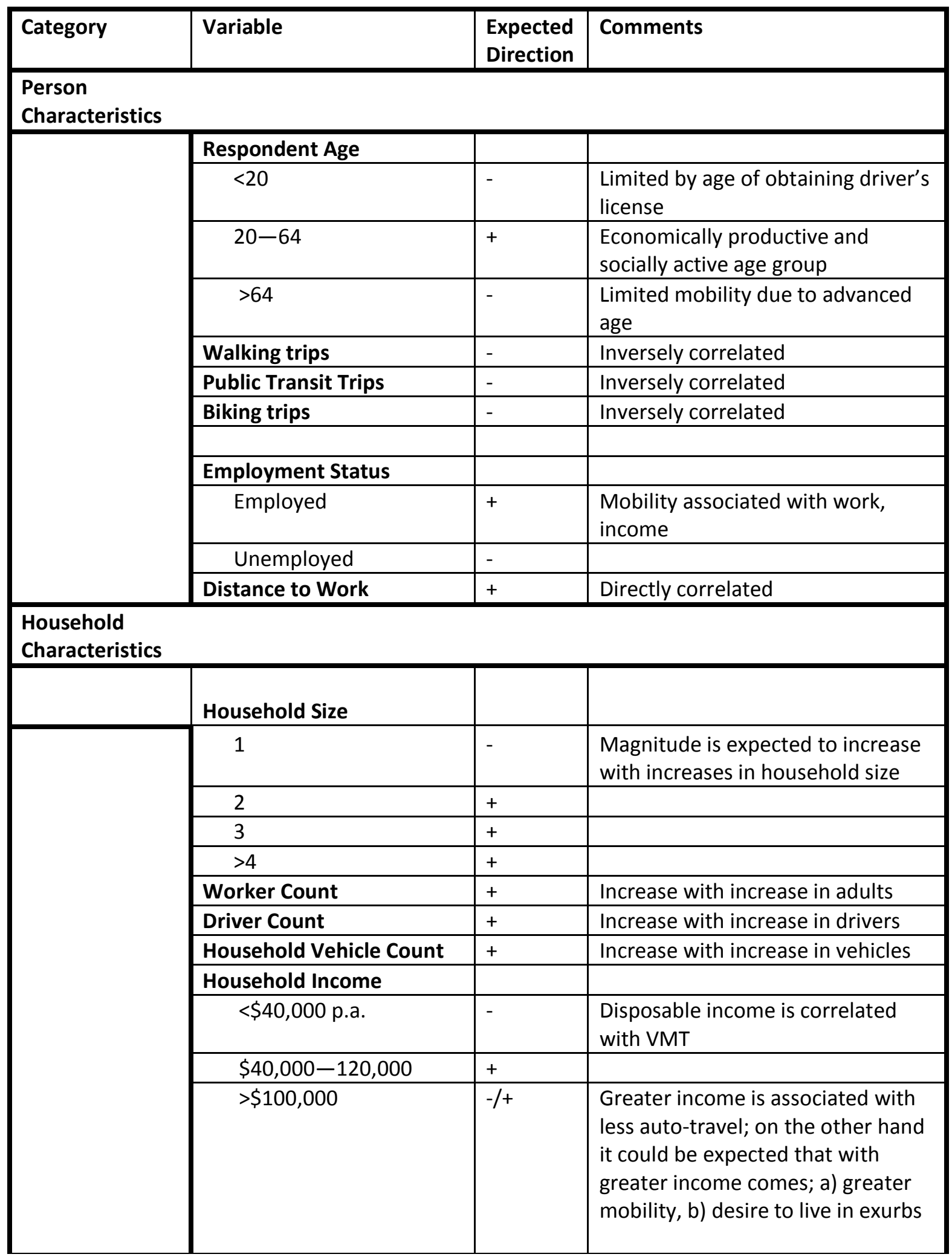




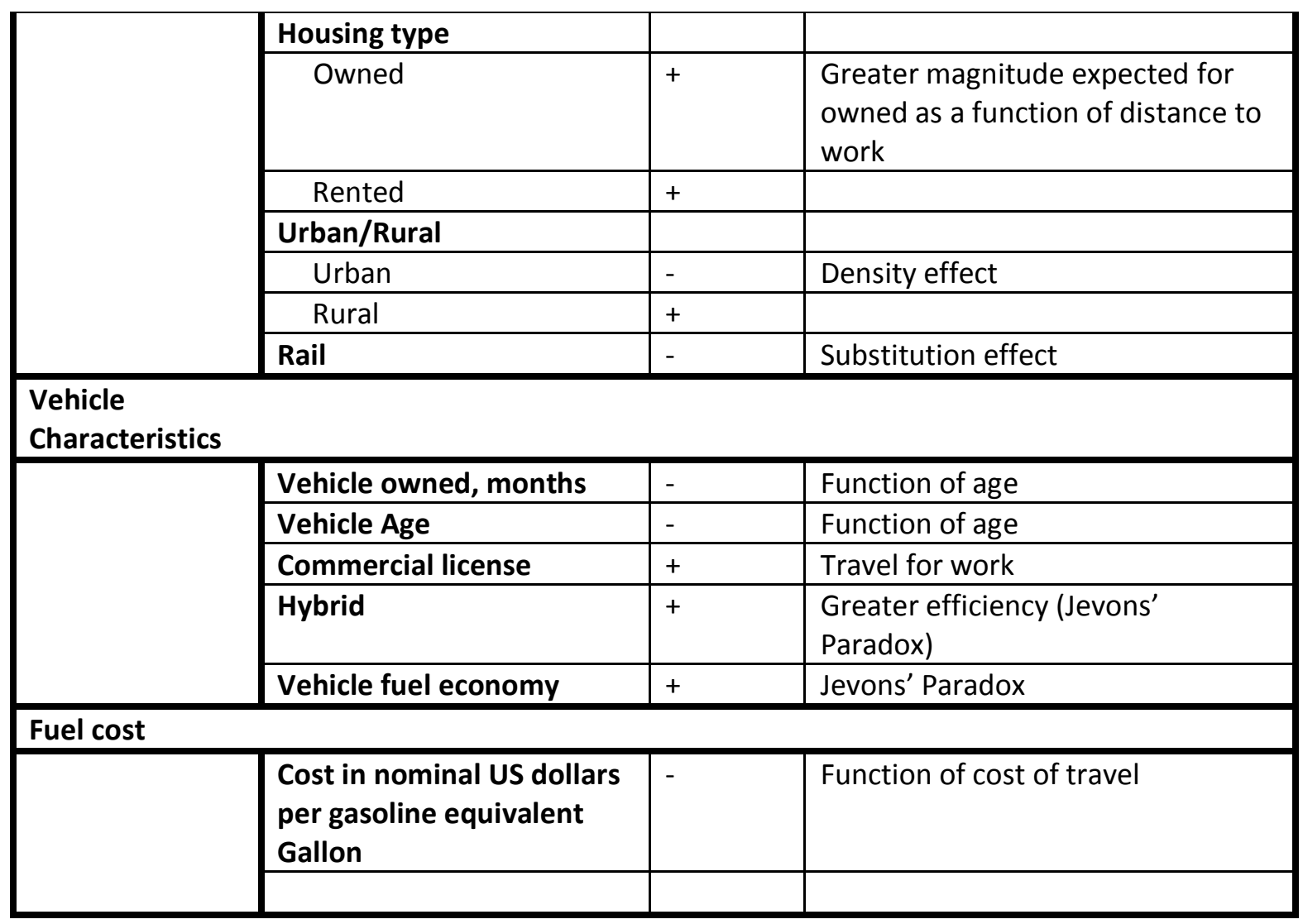




\section{CHAPTER III}

\section{METHODS}

In this Chapter, details of the data, model and assumptions used in this study are elaborated on and discussed. The study follows an empirical approach. The analysis involves a multiple regression model that is designed to best address the question; do individuals, ceteris paribus, who own and drive a more fuel efficient vehicle (as opposed to individuals who own and drive a less fuel-efficient vehicle) accrue greater VMT.

\subsection{The Dataset}

\subsubsection{Source}

The source of data for this study is the National Household Travel Survey 2009 (NHTS), published in the Fall of 2010 and available to the public for download at http://nhts.ornl.gov/download.shtml. The NHTS is a cross-sectional survey of the civilian, non-institutionalized population in the United States aimed at collecting microlevel data pertaining to the "travel and transportation behaviors" of households across 
the United States. The 2009 NHTS was conducted under the auspices of the Federal Highway Administration (FHWA) with support from the Federal Transit Administration, AAA and the Public Policy Institute of AARP. The 2009 NHTS follows previous surveys conducted in 1969, 1977, 1983, 1990, 1995 (then known as National Personal Transportation Survey, NPTS), 2001 (renamed as NHTS) and the American Travel Survey (ATS) conducted in 1977 and 1995. The 2009 NHTS was conducted over a 13-month period from March 2008 through May 2009 and incorporated variables that had not been quantified in previous surveys. It is the most comprehensive source of data on personal travel to date and is referred to as "the nation's inventory of daily travel...and a tool in the urban transportation planning process; it provides national data on personal travel behavior, trends in travel over time, and trip generation rates" (NHTS, 2010).

Also included in Version 2.1 of the 2009 NHTS dataset are; the U.S. Energy Information Administration's (EIA) vehicle fuel economy, fuel cost in nominal US dollars per gasoline equivalent gallon, annual fuel expenditures in nominal US dollars estimates, the Nielsen Claritas Census demographic data, and the Oak Ridge National Laboratory (ORNL) "Best Mile" estimate (NHTS, 2009).

\subsubsection{Survey Methodology}

The sample pool for the NHTS 2009 survey was generated using a list-assisted Random Digit Dialing (RDD) method; telephone numbers were selected at random from a 100 -bank list of all possible landline telephone numbers. A 100 -bank of numbers is a set of 100 telephone numbers with the same first eight digits (area code-next three 
digits - next 2 digits). This sampling scheme ensures that even numbers that could potentially be unlisted in a phone directory have the probability of being included in the sample. Data was collected from the civilian, non-institutionalized population of the United States. Excluded were those living in medical institutions, prisons, and in barracks on military bases. The sample included telephone numbers associated with dormitories, fraternities and sororities; those telephone numbers in such congregations that had no greater than 10 individuals sharing it were retained in the survey (NHTS, 2009).

The telephone survey itself was conducted using Computer-Assisted Telephone Interviewing (CATI) technology. Some households (those that could be associated with an address through their sampled telephone number) were first contacted by an advance letter, followed about a week later by a telephone call. The survey was conducted over a 13-month period so that seasonal variations in travel could be accounted for. Interviews were conducted with households in all 50 States and the District of Columbia. The initial interview was conducted with a household member who was 18 years or older; follow-up interviews were conducted with all members of the households. Travel days were randomly assigned to each household (March 17, 2008 through May 7, 2009 including weekends and holidays) to collect data on day-specific variables. These day-estimates were then annualized. A household was considered a "useable household" and included in the dataset only when at least $50 \%$ of the adult household members had been completely interviewed. Although this was the cut-off determined, of the useable households included in the dataset $87 \%$ had $100 \%$ of all 
household adult members interviewed and recorded (NHTS, 2010).

\subsection{Data Organization}

The NHTS dataset contains data for 150,147 completed households with 309,163 vehicles. Of the total sample, the number of useable vehicle data, i.e., vehicles that had all the required data is 197,454 . Being a micro-level dataset, NHTS contains attributes related to a household, drivers within the household, vehicles in the household and dayspecific travel data for each member and vehicle in the household. The 2009 NHTS dataset includes, but is not limited to data on; “(1) the relationship of household members, education level, income, housing characteristics, and other demographic information, (2) information on each household vehicle, including year, make, model, and estimates of annual miles traveled, (3) data about drivers, including information on travel as part of work, (4) data about one-way trips taken during a designated 24-hour period (the household's travel day) including the time the trip began and ended, length of the trip, composition of the travel party, mode of transportation, purpose of the trip, and the specific vehicle used (if a household vehicle), (5) information to describe characteristics of the geographic area in which the sample household and workplace of sample persons are located, (6) data on telecommuting, (7) public perceptions of the transportation system, (8) Data on Internet usage, and (9) the typical number of transit, walk and bike trips made over a period longer than the 24-hour travel day" (NHTS, 2010).

The data are organized within four separate data files (NHTS, 2010); 
1. "Household File; data collected once for the household (one record per household)

2. Person File; data items collected once for each interviewed household member (one record for each completed person interview)

3. Vehicle File; data items related to the household's vehicles (one record for each household vehicle)

4. Travel Day Trip File; data items collected for each trip an interviewed person made on the household's travel day (one record for each trip each person made)."

\subsection{Derived/Computed Variables}

The NHTS 2009 dataset contains some variables that were not directly determined via survey respondent's answers to questions in the survey but were rather; (a.) estimated based off of one or more other variables determined via the survey questionnaire--for instance, vehicle miles driven (BESTMILE) was computed using responses to questions on annual miles driven and odometer readings etc., or (b.) estimated from external sources based on responses--for instance, mileage for a vehicle was determined from the EIA using the make, model and year of the vehicle reported by the respondent. A description of the methods used to estimate the derived variables that are used in this analysis follows.

3.3.1 BESTMILE - The best estimate of miles driven by each vehicle; this corresponds to 
the Vehicle Miles Travelled (VMT) per annum and was computed by the Oak Ridge National Laboratory (ORNL) for the FHA. While respondents were asked about annual miles driven, these were "estimates" of miles driven and not actual and often found to be largely unreliable and in many cases, unreported. Odometer readings were recorded for an individual trip day for each vehicle in the household and annualizing this helped derive annual miles driven, with some caveats. To get a more reliable and replicable estimate, ORNL developed the BESTMILE.

Using the available data; odometer reading, vehicle year, vehicle type, selfreported annualized miles estimate (when available) etc. ORNL developed and ran models to determine the relationship between miles driven and vehicle type and age. Based on these results they then developed seven scenarios and built three regression models (new vehicle, used vehicle, all vehicles) for each of the six scenarios $\left(7^{\text {th }}\right.$ scenario was "out of scope" vehicles) to predict best estimate of annual miles driven. The seven scenarios were; 1 . Vehicles with a usable odometer reading, self-reported VMT, and information on the primary driver, 2. Vehicles with self-reported VMT, and information on the primary driver, but without a usable odometer reading, 3 . Vehicles with selfreported VMT, but without a usable odometer reading, 4. Vehicles with a usable odometer reading and information on the primary driver, but without self-reported VMT, 5. Vehicles with usable information on the primary driver, but without odometer readings and self-reported VMT, 6. Vehicles with no driving information except that collected on the travel day, 7. Vehicles not assigned a BESTMILE estimate using the other approaches. There were 13, 961 vehicles that had self-reported mileage estimate 
(ANNMILES) and for these BESTMILE was set to be equal to ANNMILES (ORNL, 2011; for more details on the regression models used consult reference)

As a validity check, these scenarios and regression models were applied to data on annual miles driven from the 2001 NHTS survey to cross-check for reliability for estimates.

3.3.2 DRVRCNT - The total number of drivers in a responding household. This variable was derived by summing the number of respondents within a household who responded "yes" to the question "Are you a driver?" which was recorded as a binary variable DRVR where 01 corresponded to yes and 02 corresponded to no.

3.3.3 EIADMPG-The EIA derived Miles Per Gallon Estimate, i.e., fuel economy of a household vehicle in the NHTS survey sample. Vehicle MPG values were estimated using EPA laboratory test MPG that were then adjusted to account for differences between actual on-road MPG and the EPA test MPG, a difference known as MPG "shortfall." Studies by Lax (1987), Mintz (1993), and Reichert (2000), on the reliability of applying shortfall-adjusted MPG in household surveys found that they yield unbiased MPG estimates. Using data collected by the NHTS on the following characteristics of the household vehicle; (1) type, (2) make, (3) model, (4) year, (5) new or used, (5) number of cylinders, (6) cubic inches of engine displacement (7) type of transmission (manual or automatic), and (8) fuel metering (gasoline, diesel, electric, natural gas, duel-, or flexible-fuel vehicle) the EIADMPG estimates were assigned for each vehicle in the dataset. 
3.3.4 URBRUR - Whether the household fell within the boundaries of an urban or rural area. This variable was derived using values obtained for the variable URBAN--a categorical variable where URBAN $=01$ if in an urban or urbanized area, $=02$ if urban and in an urban cluster, =03 if urban and surrounded by urban areas and, =04 if not in an urban area. So values of 01,02 , or 03 on URBAN were assigned $=01$ on URBRUR (coding for urban) and vales of 04 on URBAN were assigned =02 on URBRUR (coding for rural).

3.3.5 VEHAGE - The age of the vehicle. This variable was derived based on model year (VEHYEAR). Vehicles with the current model year were considered to be a year old.

3.3.6 WRKCOUNT - The total number of workers within a household. This variable was derived by summing all instances within a household where a respondent answered yes (01) to the variable WORKER.

\subsection{Missing data}

In the NHTS dataset, an observation was coded with the value -1 for an appropriate or legitimate skip, -7 if the respondent refused to answer the question, -8 if the respondent answered don't know and -9 if the response could not ascertained. To determine how to treat observations that carried such values, for each variable being used in the analysis it was determined whether it was likely; (1.) "Missing Completely At Random" (MCAR)--the probability that an observation $\left(X_{i}\right)$ is missing is unrelated to the value of $X_{i}$ or to the value of any other $X$ or $Y,(2$.$) "Missing At Random" (MAR)--the$ probability that an observation $\left(X_{i}\right)$ is missing is unrelated to $X_{i}$ or $Y$ but could be related some other $\mathrm{X}$, or (3.) Not Missing At Random (NMAR) - the probability that $X_{i}$ is missing 
is because of said X. Based on the case per case analysis of the few variables that carried these values, if it was determined to be likely MCAR or MAR and to affect only a smaller proportion of the data, complete case analysis was performed.

\subsection{Analysis}

\subsubsection{Data Merging and Extraction}

The NHTS is a comprehensive data compilation of microdata pertaining to travel behaviors of households in the contiguous United States; for the purposes of this study only some of those variables were pertinent for the analysis and therefore selectively extracted. All the variables of interest for the study were located in two out of four compiled NHTS data files; the Person File i.e., data items collected once for each interviewed household member (one record for each completed person interview) and Vehicle File i.e., data items related to the household's vehicles (one record for each household vehicle). Within the person file, each household has a unique 8-digit household ID and each "person" surveyed within a household has a two-digit person ID attached to that specific household ID. For instance, if household 1's HOUSEHOLDID were 10000000, person 1 surveyed within HOUSEHOLD 1 would be (10000000) (01); the PERSONID has to be used in conjunction with the HOUSEHOLD to specifically extract all attributes associated with person 1 in household 1 . Likewise, in the Vehicle file, the variables are all attributes associated with a Vehicle-ID. The individual files within the NHTS are not mutually exclusive but rather have some overlap in variables as they were 
designed to be used as stand-alone files. For instance, the two files of interest each have the following variables; HHFAMINC (Household Family Income), HHSIZE (Household size), DRVRCNT (Driver Count) to name a few. To prevent duplication of observations when the files are merged and to maintain the integrity of the two units of observations, the NHTS recommended protocol for merging files was followed.

To combine data from the PERSON files and the VEHICLE files, the NHTS recommends that the linking be performed using the HOUSEHOLDID and PERSONID variables (NHTS, 2009, p. 7-4); this was performed in SAS. While the extracted and merged data contained records for all vehicles within all households, to best study whether a household vehicle's miles travelled was associated with its fuel efficiency, a random sample of just one vehicle per household was drawn from within this dataset. Associated with each vehicle is a variable "WHOMAIN" that indicates who among the household members (i.e., the PERSONID of the household member) was the main driver for a given vehicle ${ }^{11}$. This enabled associating a given vehicle with the attributes of the person who most frequently drives it. After all these data management steps were applied, the sample size was 82,485 .

Henceforth, "data" refers to this dataset that was selectively extracted and compiled from the mother-dataset at the NHTS and all further analyses for the purposes of this study were performed using this dataset.

\footnotetext{
${ }^{11}$ Note however, that WHOMAIN was self-declared during the course of the survey interview process, i.e., respondent was asked "who is the main driver of vehicleID-x?" and respondent's response to that, for instance, "PERSONID\#2 is" was noted as WHOMAIN (further discussions in Chapter 5).
} 


\section{$\underline{3.5 .2 \text { Variables }}$}

Following is a description of the variables used in this study and their summary statistics (Table 6).

Continuous Variables

\section{Household Characteristics;}

HHSIZE: Household Size, a numerical variable ranging in value from $1-13$ that gives the total count of individuals residing in a household.

NUMADLT: Number of Adults, a numerical variable ranging from $1-9$ that gives the total number of adults (aged 18 years and older) that reside in the household.

HHVEHCNT: Household Vehicle Count, a numerical variable with values from $1-27$ that gives the total number of vehicles in a given household.

WRKCOUNT: Worker Count; a numerical variable that ranges from $0-6$ and gives the total number of employed individuals in a surveyed household.

DRVRCOUNT: Driver Count; total number of drivers in the household, ranging in values from 0-9.

\section{Person Characteristics;}

R_AGE: age of the primary respondent (a driver), a numerical variable that provides the 
age of the respondent and ranges in values from 18-92.

NBIKETRP; number of bike trips the primary respondent took in the past week, a numerical value ranging from $0-40$ trips.

NWALKTRP; number of walking trips that the primary respondent took in the past week, a numerical values ranging from 0-99 trips.

\section{Vehicle Characteristics;}

VEHAGE; Age of the vehicle in years. A vehicle purchased the year of the survey is recorded as being a year old. Values for this variable range from 1 year to 7 years.

VEHOWNMO; Number of months the vehicle has been owned, this ranged from 0.03 months to 240 months.

GSCOST; Fuel cost in nominal US dollars per gasoline equivalent gallon. The values for this numerical variable ranged from $1.77 \$$ to $3.78 \$$.

EIADMPG; The EIA derived Miles Per Gallon Estimate, an estimate of the fuel efficiency of the vehicle. Values for this variable within the sample ranged from $5.2 \mathrm{mpg}$ to 64.4 mpg.

BESTMILE; the best estimate of the annual miles driven by a household vehicle (dependent variable). The values for this variable ranged from 0.4 miles to 200,000 . (Note that the values for this variable were capped at 200,000 miles.) 
Table 5: Continuous Variables, Summary Statistics

\begin{tabular}{lcrrrrrr}
\hline $\begin{array}{l}\text { Variable } \\
\text { Maximum }\end{array}$ & Mean & Std Dev & Minimum & Q1 & Median & Q3 & \\
\hline DRVRCNT & 1.9843 & 0.7026 & 0.0000 & 2.0000 & 2.0000 & 2.00 & 9.00 \\
HHSIZE & 2.5178 & 1.2221 & 1.0000 & 2.0000 & 2.0000 & 3.00 & 13.00 \\
HHVEHCNT & 2.3357 & 1.1047 & 1.0000 & 2.0000 & 2.0000 & 3.00 & 27.00 \\
NUMADLT & 1.9980 & 0.6607 & 1.0000 & 2.0000 & 2.0000 & 2.00 & 9.00 \\
VEHOWNMO & 34.059 & 22.550 & 0.0333 & 12.000 & 36.000 & 48.00 & 240.00 \\
WRKCOUNT & 1.1326 & 0.9057 & 0.0000 & 0.0000 & 1.0000 & 2.00 & 6.00 \\
VEHAGE & 4.0723 & 1.9398 & 1.0000 & 2.0000 & 4.0000 & 6.00 & 7.00 \\
BESTMILE & 12698 & 10544 & 0.4 & 6748 & 11008 & 16291 & 200000 \\
GSCOST & 3.0689 & 0.1424 & 1.7700 & 2.9400 & 3.0300 & 3.20 & 3.78 \\
EIADMPG & 21.654 & 6.511 & 5.200 & 17.300 & 20.800 & 24.40 & 64.40 \\
NBIKETRP & 0.1658 & 0.8971 & 0.0000 & 0.0000 & 0.00000 & 0.00 & 40.00 \\
NWALKTRP & 4.4137 & 6.8407 & 0.0000 & 0.0000 & 3.0000 & 6.00 & 99.00 \\
R_AGE & 55.622 & 14.655 & 18.000 & 45.000 & 56.000 & 66.00 & 92.00 \\
\hline
\end{tabular}

\section{Categorical Variables}

\section{Household Characteristics}

HOMEOWN; A categorical variable that determined whether the housing unit that the respondent lived in was owned or rented. Within the NHTS dataset this variable was coded as 01 if the response was owned and 02 if rented. For ease of analysis this was converted into a dummy variable with $0=$ rented and $1=$ owned.

\begin{tabular}{|llcc|}
\hline Variable & Code & Count & Percent \\
\hline HOMEOWN & Rented (0) & 5910 & 7.16 \\
& Owned (1) & $\mathbf{7 6 5 7 5}$ & $\mathbf{9 2 . 8 4}$ \\
\hline
\end{tabular}


HYBRID; A categorical variable that recorded whether the vehicle was a hybrid or used alternate fuel, coded as 01 =yes, vehicle is a hybrid or uses alternate fuel and $02=$ vehicle is not a hybrid and or does not use alternate fuel. This was recoded as a dummy variable with $0=$ hybrid and $1=$ not hybrid.

\begin{tabular}{|lccc|}
\hline Variable & Code & Count & Percent \\
\hline HYBRID & No (0) & 78149 & 94.74 \\
& Yes (1) & 4336 & 5.26 \\
\hline
\end{tabular}

RAIL; Depending on whether the housing unit (of the respondent) was located in a MSA with heavy rail (01) or in a MSA without heavy rail access or if the housing unit was not in a MSA (02). Recoded as a dummy variable with 0 if heavy rail access was not present and 1 if otherwise.

\begin{tabular}{|lccc|}
\hline Variable & Code & Count & Percent \\
\hline RAIL & No (0) & 68515 & 83.06 \\
& Yes (1) & 13970 & 16.94 \\
\hline
\end{tabular}

URBRUR; This categorical variable recorded whether the housing unit was located in an urban (1) or rural area (2). Recoded as a dummy variable with 0 if rural and 1 if urban.

\begin{tabular}{|llcc|}
\hline Variable & Code & Count & Percent \\
\hline Rural (0) & 25492 & 30.91 \\
\hline
\end{tabular}




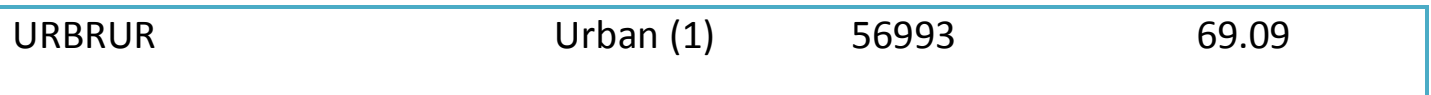

HHFAMINC; The following 17 categories were recorded for the derived total household family income:
1. $=<\$ 5,000$,
2. $=\$ 5,000-\$ 9,999$,
3. $=\$ 10,000-\$ 14,999$,
4. $=\$ 15,000-\$ 19,999$,
5. $=\$ 20,000-\$ 24,999$,
6. $=\$ 25,000-\$ 29,999$,
7. $=\$ 30,000-\$ 34,999$,
8. $=\$ 35,000-\$ 39,999$,
9. $=\$ 40,000-\$ 44,999$,
10. $=\$ 45,000-\$ 49,999$,
11. $=\$ 50,000-\$ 54,999$,
12. $=\$ 55,000-\$ 59,999$,
13. $=\$ 60,000-\$ 64,999$,
14. = $\$ 65,000-\$ 69,999$,
15. $=\$ 70,000-\$ 74,999$,
16. $=\$ 75,000-\$ 79,999$,
17. $=\$ 80,000-\$ 99,999$

These categories were recoded as dummy variables INCDUMMY as follows;

\begin{tabular}{|llrr|}
\hline VARIABLE & CODE & COUNT & PERCENT \\
& & & \\
INCDUMMY01 (<5000\$) & 0 No & 82056 & 99.48 \\
& 1 Yes & 429 & 0.52 \\
\hline INCDUMMY02 (5,000-9,999\$) & & & \\
& 0 No & 81534 & 98.85 \\
& 1 Yes & 951 & 1.15 \\
\hline INCDUMMY03 (10,000-14,999) & & & \\
& 0 No & 80666 & 97.79 \\
& 1 Yes & 1819 & 2.21 \\
\hline INCDUMMY04 (15,000-19,999) & & & 96.73 \\
& 0 No & 9785 & 3.27 \\
\hline
\end{tabular}




\begin{tabular}{|c|c|c|c|}
\hline INCDUMMY05 $(20,000-24,999)$ & $\begin{array}{l}0 \text { No } \\
1 \text { Yes }\end{array}$ & $\begin{array}{r}79819 \\
2666\end{array}$ & $\begin{array}{r}96.77 \\
3.23\end{array}$ \\
\hline INCDUMMY06 $(25,000-29,999)$ & $\begin{array}{l}0 \text { No } \\
1 \text { Yes }\end{array}$ & $\begin{array}{r}78028 \\
4457\end{array}$ & $\begin{array}{r}94.60 \\
5.40\end{array}$ \\
\hline INCDUMMY07 $(30,000-34,999)$ & $\begin{array}{l}0 \text { No } \\
1 \text { Yes }\end{array}$ & $\begin{array}{r}79588 \\
2897\end{array}$ & $\begin{array}{r}96.49 \\
3.51\end{array}$ \\
\hline INCDUMMY08 $(35,000-39,999)$ & $\begin{array}{l}0 \text { No } \\
1 \text { Yes }\end{array}$ & $\begin{array}{r}77353 \\
5132\end{array}$ & $\begin{array}{r}93.78 \\
6.22 \\
\end{array}$ \\
\hline INCDUMMY09 $(40,000-44,999)$ & $\begin{array}{l}0 \text { No } \\
1 \text { Yes }\end{array}$ & $\begin{array}{r}79814 \\
2671\end{array}$ & $\begin{array}{r}96.76 \\
3.24\end{array}$ \\
\hline INCDUMMY10 $(45,000-49,999)$ & $\begin{array}{l}0 \text { No } \\
1 \text { Yes }\end{array}$ & $\begin{array}{r}77000 \\
5485\end{array}$ & $\begin{array}{r}93.35 \\
6.65\end{array}$ \\
\hline INCDUMMY11 $(50,000-54,999)$ & $\begin{array}{l}0 \text { No } \\
1 \text { Yes }\end{array}$ & $\begin{array}{r}79936 \\
2549\end{array}$ & $\begin{array}{r}96.91 \\
3.09\end{array}$ \\
\hline INCDUMMY12 $(55,000-59,999)$ & $\begin{array}{l}0 \text { No } \\
1 \text { Yes }\end{array}$ & $\begin{array}{r}77287 \\
5198\end{array}$ & $\begin{array}{r}93.70 \\
6.30 \\
\end{array}$ \\
\hline INCDUMMY13 $(60,000-64,999)$ & $\begin{array}{l}0 \text { No } \\
1 \text { Yes }\end{array}$ & $\begin{array}{r}80375 \\
2110\end{array}$ & $\begin{array}{r}97.44 \\
2.56\end{array}$ \\
\hline INCDUMMY14 $(65,000-69,999)$ & $\begin{array}{l}0 \text { No } \\
1 \text { Yes }\end{array}$ & $\begin{array}{r}77773 \\
4712 \\
\end{array}$ & $\begin{array}{r}94.29 \\
5.71\end{array}$ \\
\hline INCDUMMY15 $(70,000-74,999)$ & $\begin{array}{ll}0 & \text { No } \\
1 & \text { Yes }\end{array}$ & $\begin{array}{r}80316 \\
2169\end{array}$ & $\begin{array}{r}97.37 \\
2.63 \\
\end{array}$ \\
\hline INCDUMMY16 $(75,000-79,999)$ & $\begin{array}{ll}0 & \text { No } \\
1 & \text { Yes }\end{array}$ & $\begin{array}{r}77849 \\
4636\end{array}$ & $\begin{array}{r}94.38 \\
5.62\end{array}$ \\
\hline INCDUMMY17 (80,000-99,999) & $\begin{array}{ll}0 & \text { No } \\
1 & \text { Yes }\end{array}$ & $\begin{array}{r}72965 \\
9520\end{array}$ & $\begin{array}{l}88.46 \\
11.54\end{array}$ \\
\hline
\end{tabular}




\section{Person Characteristics;}

OCCAT; Occupational category was reported under 4 categories and coded as follows in NHTS, 2009-

$1=$ Sales/service

$2=$ Clerical/admin support

$3=$ Manufacturing, construction or farming

$4=$ Professional, managerial or technical

$97=$ Other

These categories were re-coded for the purposes of analyses as dummy variables with the reference category being "unemployed".

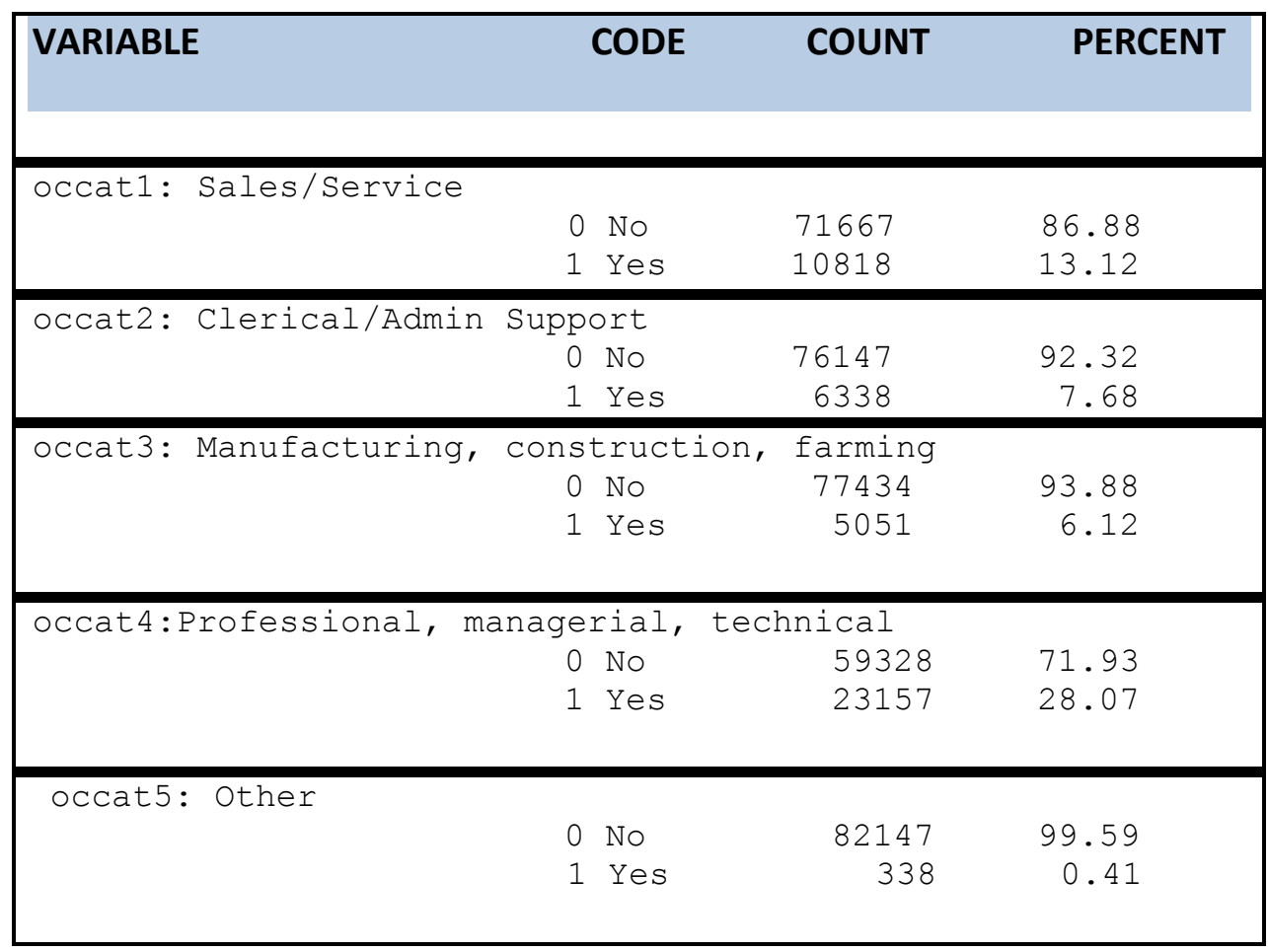

PTUSED; A continuous variable with values ranging from $0-180$, this variable was recoded as a dummy variable. 


\begin{tabular}{|c|c|c|c|}
\hline VARIABLE & CODE & COUNT & PERCENT \\
\hline ptusedcat1: Took public & $\begin{array}{l}\text { transit } \\
0 \\
0 \text { Yes } \\
1 \\
\text { No }\end{array}$ & $\begin{array}{l}38319 \\
44166\end{array}$ & $\begin{array}{l}46.46 \\
53.54\end{array}$ \\
\hline ptusedcat2 : One or more & \begin{tabular}{ll}
\multicolumn{2}{c}{ trips } \\
0 & No \\
1 & Yes
\end{tabular} & $\begin{array}{r}75939 \\
6546\end{array}$ & $\begin{array}{r}92.06 \\
7.94\end{array}$ \\
\hline
\end{tabular}

\subsection{Model Specification}

To best study if holding all else (driver characteristics, household characteristics and vehicle characteristics) constant, the association between annual vehicle miles travelled by a household vehicle (BESTMILE) and the fuel efficiency of the vehicle (EIADMPG) was in accordance with Jevons' paradox a multiple regression model was specified. Based on the findings from a review of the literature (as outlined in Chapter 2), the resulting conceptual framework and available data, the model was of the form

BESTMILE $=\alpha+\beta_{1}$ R_AGE $+\beta_{2}$ OCCAT $+\beta_{3}$ NWLKTRP $+\beta_{4}$ NBKTRP $+\beta_{5}$ PTUSED + $\beta_{6}$ HHSIZE $+\beta_{7-24}{ }^{12}$ INCDUMMY $+\beta_{25}$ HHVEHCNT $+\beta_{26}$ DRVRCNT $+\beta_{27}$ NUMADLT $+\beta_{28}$ WRKCNT $+\beta_{29}$ HOMEOWN $+\beta_{30}$ URBRUR $+\beta_{31}$ RAIL $+\beta_{32}$ VEHOWNMO $+\beta_{33}$ VEHAGE ++ $\beta_{34}$ EIADMPG $+\beta_{35}$ GSCOST $+\beta_{36}$ HYBRID $+\varepsilon$

The regression analysis was run and reliability of the results was tested by performing diagnostic tests. Tests on serial autocorrelation and heteroskadasticity revealed no issues however, the test of residuals revealed; 1) a non-random, distinct " $\mathrm{S}$ "

\footnotetext{
${ }^{12}$ INCDUMMY is a categorical variable coded as a dummy variable with 17 dummy categories.
} 
shaped pattern to the residuals and 2) that the residuals were not normally distributed. This indicated that the predictor variables were not explaining all the variation in the explanatory variable and that some of that which was not explained was reflected in the residuals. Literature indicated that this could occur when;

1. There is a missing higher-order term of a variable in the model

2. There are several or significantly large outliers or influential data points

3. Heteroskedastity

4. In fixed effects model with $N>10,000$ observations, "textbook" normal plots are frequently not encountered.

The dataset used in the analysis has an $\mathrm{N}=82,485$ and it does have a significant number of large and influential observations on several key variables; systematic elimination of these outliers would greatly reduce the information contained within and was therefore to be considered if other possible solutions were not found to be successful . The dataset by itself is not normally distributed and scores high on tests for skewness and kurtosis. Therefore, the next steps followed were to transform variables in the model and to test for robustness.

Each continuous explanatory variable was systematically transformed using quadratic transformations and the model run with each transformed variable. Residual analysis was then performed. The quadratic transformations yielded an even greater non-randomness to the residual pattern. The same steps were then followed for log transformations. The model that yielded the best fit was of the form; 


$$
\begin{aligned}
& \text { In (BESTMILE) }=\alpha+\beta_{1} \text { R_AGE }+\beta_{2} \text { OCCAT }+\beta_{3} \text { NWLKTRP }+\beta_{4} \text { NBKTRP }+\beta_{5} \\
& \text { PTUSED }+\beta_{6} \text { HHSIZE } \quad+\beta_{7-24} \text { INCDUMMY }+\beta_{25} \text { HHVEHCNT }+\beta_{26} \text { DRVRCNT }+\beta_{27} \\
& \text { NUMADLT }+\beta_{28} \text { WRKCNT }+\beta_{29} \text { HOMEOWN }+\beta_{30} \text { URBRUR }+\beta_{31} \text { RAIL }+\beta_{32} \text { VEHOWNMO + } \\
& \beta_{33} \text { VEHAGE }++\beta_{34} \text { In (EIADMPG) }+\beta_{35} \text { GSCOST }+\beta_{36} \text { HYBRID }+\varepsilon
\end{aligned}
$$

This model was therefore chosen as "the" model for analysis for the purposes of this study. 
CHAPTER IV

\section{RESULTS AND DISCUSSION}

\subsection{Introduction}

In this chapter the findings resulting from the analysis of the data are reported and a brief but nuanced interpretation of each is presented. The dataset $(N=82,485)$ compiled from the NHTS 2009's comprehensive database on travel behaviors of households and individuals in the contiguous United States was analyzed by applying a multiple regression model. The model was built to examine if, holding constant all available explanatory factors (driver attributes, household attributes, vehicle attributes, fuel price etc.) that could influence how many annual vehicle miles a non-commercial household vehicle accrued, in keeping with Jevons' Paradox, increase in fuel economy of a random household vehicle was associated with increased vehicle miles traveled. The primary hypothesis was therefore, "ceteris paribus, vehicles with greater fuel economy would accrue greater annual vehicle miles". Also of interest is the association between vehicle miles travelled and fuel price as Jevons' Paradox essentially translates to a decrease in cost of consuming the good that has been rendered efficient (car via improved fuel economy) and consequent increase in consumption. An examination 
of whether direct decreases in fuel price influence driving more than efficiency gains, all things being equal, will be carried out via the analysis.

The model specified was of the form;

In (BESTMILE) $=\alpha+\beta_{1}$ R_AGE $+\beta_{2}$ OCCAT $+\beta_{3}$ NWLKTRP $+\beta_{4}$ NBKTRP $+\beta_{5}$ PTUSED $+\beta_{6}$ HHSIZE $+\beta_{7-24}$ INCDUMMY $+\beta_{25}$ HHVEHCNT $+\beta_{26}$ DRVRCNT $+\beta_{27}$ NUMADLT $+\beta_{28}$ WRKCNT $+\beta_{29}$ HOMEOWN $+\beta_{30}$ URBRUR $+\beta_{31}$ RAIL $+\beta_{32}$ VEHOWNMO + $\beta_{33}$ VEHAGE $++\beta_{34} \ln \left(\right.$ EIADMPG) $+\beta_{35}$ GSCOST $+\beta_{36}$ HYBRID $+\varepsilon$

where,

R_AGE = Respondent age; OCCAT = Occupational category; NWALKTRP = Number of walking trips; NBKTRP = Number of biking trips; PTUSED = Number of public transit trips; HHSIZE = Household size; INCDUMMY = Annual household income; HHVEHCNT = Household vehicle count; DRVRCNT $=$ Driver count; WRKCNT $=$ Worker Count; URBRUR = Urban or Rural location; RAIL = Access to Rail in MSA; VEHOWNMO = Number of months vehicle owned; VEHAGE = Age of the vehicle; VEHCOMM = Commercial license plates; EIADMPG = EIA derived miles per gallon (vehicle fuel economy); GSCOST = Fuel cost; Hybrid = Vehicle is hybrid or uses alternative fuel.

\subsection{Results and Discussion}

The results following the analyses of the multiple regression model are presented in the following tables and the interpretations of the findings discussed. Also 
presented are values for Variance Inflation Factor (VIF) as a test for multicollinearity. The unit of analysis is "a random vehicle in a household from the NHTS".

\subsubsection{Driver Characteristics:}

4.2.1.1.Respondent Age (R_AGE); The results indicate that, all else being held constant, a driver drives $0.6 \%$ miles less per annum for every additional year of age. Put more simply, older drivers drive less than their younger counterparts. Younger drivers are, presumably, associated with having to make vehicle trips for work, for taking young kids to school and other activities and more discretionary "leisure" trips.

\begin{tabular}{|l|l|l|l|l|l|}
\hline Term & Coef & SE Coef & T-Value & P-Value & VIF \\
\hline R_AGE; Respondent Age & -0.006652 & 0.000236 & -28.19 & 0.000 & 1.83 \\
\hline
\end{tabular}

4.2.1.2 Occupational Category (OCCAT); Of the 5 categories of occupations recorded, results indicate that being employed in the manufacturing, construction or farming industries (Category 3 ) is associated with the highest vehicle miles traveled per annum estimate. An employee in the manufacturing, construction or farming industry is associated with $34.64 \%$ more vehicle miles per annum (over one who is unemployed, the reference category). While those in the sales/service industry (Category 1) are associated with $25.94 \%$ miles per annum more, those in the professional/managerial levels (Category 4) are associated with $19.51 \%$ miles per annum more, those in the "other" category" (Category 5) are associated with $19.14 \%$ miles more and those in the 
clerical or administrative category are associated with $18.21 \%$ (Category 2) over those who are unemployed. Results thus indicate that the employed drive more, all else being held constant, than the unemployed.

\begin{tabular}{|l|l|l|l|l|l|}
\hline Term & Coef & SE Coef & T- & P- & VIF \\
\hline OCCAT1; Sales/service & 0.2594 & 0.0112 & 23.22 & 0.000 & 2.18 \\
\hline OCCAT2; Admin/clerical & 0.1821 & 0.0134 & 13.62 & 0.000 & 1.94 \\
\hline $\begin{array}{l}\text { OCCAT3; Manufacturing, farming } \\
\text { construction }\end{array}$ & 0.3464 & 0.0135 & 25.63 & 0.000 & 1.61 \\
\hline $\begin{array}{l}\text { OCCAT4; Professional, manager } \\
\text { OCCAT5; “Other" }\end{array}$ & 0.1951 & 0.0106 & 18.37 & 0.000 & 3.49 \\
\hline
\end{tabular}

4.2.1.3 Number of Bike Trips (NBIKETRP); Results indicate that for every additional bike trip taken per week, all else being equal, there is an associated $0.1 \%$ decrease in vehicle miles driven. This result however, is not statistically significant. In the study sample, therefore, bicycle trips, do not apparently substitute for automobile trips to any significant extent. 


\begin{tabular}{|l|l|l|l|l|l|}
\hline Term & Coef & SE Coef & T-Value & P-Value & VIF \\
\hline NBIKETRP; number of bike & -0.00135 & 0.00286 & -0.47 & 0.636 & 1.01 \\
trips & & & & & \\
\end{tabular}

4.2.1.4 Number of Walking Trips (NWALKTRP); For every additional walking trip made per week there was an associated $0.2 \%$ increase in miles driven. While one would intuitively posit that increase in walking trips might lead to an associated decrease in vehicle trips, the findings suggest otherwise. Plausible reasons for this could be that; 1 . Walking trips are not a substitute for automobile trips in that the "walking" is done just for exercise/leisure, 2. Respondents who tend to make more walking trips could be those that reside in automobile-dependent suburbs, for instance. While statistically significant, this result does not appear to be of practical significance because of the very low numerical value associated with the coefficient.

\begin{tabular}{|l|l|l|l|l|l|}
\hline Term & Coef & SE Coef & T-Value & P-Value & VIF \\
\hline $\begin{array}{l}\text { NWALKTRP; number of walking } \\
\text { trips }\end{array}$ & 0.002256 & 0.000376 & 5.99 & 0.000 & 1.02 \\
\hline
\end{tabular}

4.2.1.5 Number of Public Transit Trips Taken (PTUSED); Results suggest that respondents who made one or more trips using public transit (PTUSEDCAT2) had an associated 9.1\% decrease in vehicle miles travelled per annum over those who did not make any trips using public transit. This result is statistically significant. However, almost a half of the 
sample did not answer the question on account of it being a "legitimate skip". Given that public transit could be a substitute for private vehicle travel and could therefore affect total vehicle miles accrued by a private vehicle, this bears further looking into in future research.

\begin{tabular}{|l|l|l|l|l|l|}
\hline Term & Coef & SE Coef & T-Value & P- & VIF \\
\hline $\begin{array}{l}\text { PTUSEDCAT2; One or more public } \\
\text { transit trips } \\
\text { Reference category; } 0 \text { trips }\end{array}$ & -0.0919 & 0.0105 & -8.76 & 0.000 & 1.23 \\
\hline
\end{tabular}

\subsubsection{Household Characteristics}

4.2.2.1 Home owned/rented (HOMEOWN); Results indicate that respondents who owned the housing unit that they were residing in drove $2.9 \%$ miles more, all else being equal, than those who rented the housing unit that they lived in. This seems to be in line with the findings of previous studies that suggest that plausible reasons for this are; 1 . Homeowners typically chose to buy homes in the suburbs which are traditionally located further from most workplaces necessitating a greater commute to work for homeowners and 2. Homeowners are usually those with households that include children; a category associated with greater vehicle miles travelled due to trips to school and trips associated with other social activities for children and, 3. Rental properties are typically clustered in downtown neighborhoods as they cater to those who are in institutions of higher education, low-income jobs, the young and single and therefore 
associated with those who accrue less VMT.

\begin{tabular}{|l|l|l|l|l|l|}
\hline Term & Coef & SE Coef & T-Value & P-Value & VIF \\
\hline HOMEOWN; Home owned & 0.0299 & 0.0103 & 2.89 & 0.004 & 1.09 \\
\hline
\end{tabular}

4.2.2.2 Household Size (HHSIZE); For every additional member added to a household, the vehicle miles travelled was associated with a $6.1 \%$ increase in miles travelled by a random vehicle in the household, all else being held constant. Increases in household size (when the increase is due to adult driving members) is typically associated with increases in household vehicle count, which could result in little to no-change in the VMT accrued by one random vehicle within the household as the person miles get distributed across vehicles. However, when the increase in household size is due to nondriving members such as children; 1 . The number of members exceeds the number of cars 2 . The number of drivers does not increase and 3. The number of trips taken per car increase. Therefore, VMT accrued by a random vehicle within the household, increases.

\begin{tabular}{|l|l|l|l|l|l|}
\hline Term & Coef & SE Coef & T-Value & P-Value & VIF \\
\hline HHSIZE; household size & 0.06157 & 0.00314 & 19.59 & 0.000 & 2.26 \\
\hline
\end{tabular}

4.2.2.3 Number of Drivers (DRVRCNT); Per the analysis, the addition of one driver to the number of drivers in a household was associated with an increase in $0.6 \%$ miles 
travelled by a random vehicle in the household. This occurs, possibly, when the addition of a driver results in an individual driver within the household being free to take more discretionary trips.

\begin{tabular}{|l|l|l|l|l|l|}
\hline Term & Coef & SE Coef & T-Value & P-Value & VIF \\
\hline DRVRCNT; number of drivers & 0.02483 & 0.00600 & 4.14 & 0.000 & 2.73 \\
\hline
\end{tabular}

4.2.2.4 Worker Count (WRKCOUNT); For every additional employed member of the household, the miles travelled by a random vehicle in the household decreased by $0.23 \%$. This finding seems to be inconsistent with what would be intuitively posited; that with an increase in number of employed household members the VMT accrued per vehicle would increase. This could potentially be because presumably, an additional employed member would result in an additional household vehicle leading to less miles being accrued per vehicle. This result is however, not statistically significant (P-value).

\begin{tabular}{|l|l|l|l|l|l|}
\hline Term & Coef & SE Coef & T-Value & P-Value & VIF \\
\hline $\begin{array}{l}\text { WRKCOUNT; number of } \\
\text { workers }\end{array}$ & -0.00235 & 0.00503 & -0.47 & 0.640 & 3.18 \\
\hline
\end{tabular}

4.2.2.5 Household Vehicle Count (HHVEHCNT); An additional vehicle in the household was associated with a $0.67 \%$ decrease in miles travelled by a random vehicle in the 
household, all else being equal. This is presumably because, the total number of vehicle miles travelled by the household gets distributed among the household vehicles, consequently the larger the number of household numbers the lesser the miles accrued by one random vehicle within the household.

\begin{tabular}{|l|l|l|l|l|l|}
\hline Term & Coef & SE Coef & T-Value & P-Value & VIF \\
\hline HHVEHCNT; number of vehicles & -0.00676 & 0.00298 & -2.27 & 0.023 & 1.66 \\
\hline
\end{tabular}

4.2.2.6 Annual Household Income (INCDUMMY); The overall association between annual household income and miles travelled by a random vehicle in the household showed a pattern of decrease in miles travelled with decrease in income. The reference category for this dummy variable was annual household income over $\$ 100,000$. Households with an annual household income of $\$ 80,000-89,999$ travelled only $4.2 \%$ miles less than households with an annual income of over $\$ 100,000$ while households with an annual income of $\$ 10,000-14,999$ travelled $33.8 \%$ miles less than those with an annual income of over $\$ 100,000$.

\begin{tabular}{|l|l|l|l|l|l|}
\hline Term & Coef & SE Coef & T-Value & P-Value & VIF \\
\hline INCDUMMY1; $<\$ 5,000$ & -0.1893 & 0.0360 & -5.26 & 0.000 & 1.03 \\
\hline INCDUMMY2; \$5000-9,999 & -0.2964 & 0.0247 & -11.98 & 0.000 & 1.07 \\
\hline
\end{tabular}




\begin{tabular}{|c|c|c|c|c|c|}
\hline INCDUMMY3; \$10,000-14,999 & -0.3381 & 0.0186 & -18.21 & 0.000 & 1.14 \\
\hline INCDUMMY4; \$15,000-19,999 & -0.3167 & 0.0157 & -20.21 & 0.000 & 1.20 \\
\hline INCDUMMY5; \$20,000-24,999 & -0.2705 & 0.0157 & -17.25 & 0.000 & 1.18 \\
\hline INCDUMMY6; \$25,000-29,999 & -0.2366 & 0.0127 & -18.58 & 0.000 & 1.27 \\
\hline INCDUMMY7; \$30,000-34,999 & -0.1653 & 0.0150 & -11.04 & 0.000 & 1.17 \\
\hline INCDUMMY8; \$35,000-39,999 & -0.1914 & 0.0119 & -16.12 & 0.000 & 1.27 \\
\hline INCDUMMY9; \$40,000-44,999 & -0.1304 & 0.0153 & -8.50 & 0.000 & 1.13 \\
\hline INCDUMMY10; \$45,000-49,999 & -0.1362 & 0.0115 & -11.89 & 0.000 & 1.25 \\
\hline INCDUMMY11; \$50,000-54,999 & -0.1165 & 0.0155 & -7.50 & 0.000 & 1.11 \\
\hline INCDUMMY12; \$55,000-59,999 & -0.1125 & 0.0115 & -9.75 & 0.000 & 1.21 \\
\hline INCDUMMY13; \$60,000-64,999 & -0.1106 & 0.0168 & -6.58 & 0.000 & 1.08 \\
\hline INCDUMMY14; \$65,000-69,999 & -0.0756 & 0.0119 & -6.35 & 0.000 & 1.17 \\
\hline INCDUMMY15; \$70,000-74,999 & -0.0840 & 0.0166 & -5.07 & 0.000 & 1.08 \\
\hline INCDUMMY16; \$75,000-79,999 & -0.0815 & 0.0119 & -6.84 & 0.000 & 1.16 \\
\hline INCDUMMY17; \$80,000-89,999 & -0.04288 & 0.00902 & -4.75 & 0.000 & 1.28 \\
\hline
\end{tabular}


4.2.2.7 Presence of Rail in the MSA (RAIL); A random vehicle in a household that was located in a MSA that had access to heavy rail (rapid transit included) was associated, all else being equal, with $8.95 \%$ less miles travelled per annum than one in a MSA with no access to rail. This finding seems to confirm that travel by rail can substitute for automobile travel.

\begin{tabular}{|l|l|l|l|l|l|}
\hline Term & Coef & SE Coef & T-Value & P-Value & VIF \\
\hline $\begin{array}{l}\text { RAIL; presence of heavy passenger } \\
\text { rail (including rapid transit) }\end{array}$ & -0.08955 & 0.00760 & -11.79 & 0.000 & 1.24 \\
Reference category: no rail & & & & & \\
\hline
\end{tabular}

4.2.2.8 Urban or Rural (URBRUR); A random vehicle in a household that was located in an urban area was associated with $12.9 \%$ less vehicle miles travelled than a random vehicle in a rural area, all else being equal. This is consistent with the greater density of land use in urban areas, and the correspondingly smaller distances that must be traveled for any given household to meet their subsistence and other basic needs.

\begin{tabular}{|c|c|c|c|c|c|}
\hline Term & Coef & SE Coef & T-Value & P-Value & VIF \\
\hline $\begin{array}{l}\text { URBRUR; Urban } \\
\text { category-rural) }\end{array}$ & -0.12902 & 0.00594 & -21.70 & 0.000 & 1.16 \\
\hline
\end{tabular}

\subsubsection{Vehicle Characteristics}

4.2.3.1 Age of the Vehicle (VEHAGE); An additional year in age of the vehicle was 
associated with a $1.5 \%$ increase in miles travelled by a random household vehicle, holding all else equal. Older vehicles are, all else being equal, driven more than newer vehicles.

\begin{tabular}{|l|l|l|l|l|l|}
\hline Term & Coef & SE Coef & T-Value & P-Value & VIF \\
\hline VEHAGE; age of the vehicle & 0.01582 & 0.00200 & 7.93 & 0.000 & 2.30 \\
\hline
\end{tabular}

4.2.3.2 Number of months owned (VEHOWNMO); For every additional month a vehicle was owned, the associated vehicle miles travelled decreased by $0.1 \%$. The longer a vehicle was owned (not to be confused with the age of the vehicle) by a person, the less it was driven. Note, however that the numerical estimate is just $0.1 \%$ less.

\begin{tabular}{|l|l|l|l|l|l|}
\hline Term & Coef & SE Coef & T-Value & P-Value & VIF \\
\hline $\begin{array}{l}\text { VEHOWNMO; number of } \\
\text { months vehicle owned }\end{array}$ & -0.001346 & 0.000170 & -7.91 & 0.000 & 2.26 \\
\hline
\end{tabular}

4.2.3.3 Commercial License Plates (VEHCOMM); A random household vehicle that had commercial license plates was, all else being equal, associated with $4.1 \%$ increase in miles travelled over a comparable random household vehicle that did not possess commercial license plates. Vehicles with commercial license plates are likely, vehicles that are driven for commercial trip purposes and the means by which the driver earns a living. Therefore it would follow that they accrue greater VMT than a vehicle that does 
have commercial license plates. The idea behind inclusion of this variable in the study is to ensure that the effects from these vehicles do not confound the effects with the discretionary substitution of a more efficient vehicle for more miles traveled, which is at the heart of Jevons' paradox.

\begin{tabular}{|l|l|l|l|l|l|}
\hline Term & Coef & SE Coef & T-Value & P-Value & VIF \\
\hline $\begin{array}{l}\text { VEHCOMM; vehicle with } \\
\text { commercial license plates }\end{array}$ & 0.04055 & 0.00745 & 5.45 & 0.000 & 1.00 \\
\hline
\end{tabular}

4.2.3.4 Fuel Economy (EIADMPG); The analysis indicates that, all else being equal, a $1 \%$ increase in fuel economy $(\mathrm{mpg}$ ) of a random household vehicle is associated with a $1.2 \%$ increase in vehicle miles travelled. This confirms Jevons' paradox.

\begin{tabular}{|l|l|l|l|l|l|}
\hline Term & Coef & SE Coef & T-Value & P-Value & VIF \\
\hline $\begin{array}{l}\text { InEIADMPG; EIA derived miles } \\
\text { per gallon estimate (fuel } \\
\text { economy) }\end{array}$ & 1.20514 & 0.00992 & 121.55 & 0.000 & 1.13 \\
\hline
\end{tabular}

4.2.3.5 Hybrid (HYBRID); Vehicles that had hybrid capabilities were, all else being equal, associated with a $23.57 \%$ decrease in annual miles travelled over vehicles that do not have hybrid capabilities. This presents an interesting dichotomy, as hybrids are vehicles which have a higher estimated fuel economy, yet results indicate that they are associated with fewer vehicle miles travelled. 


\begin{tabular}{|l|l|l|l|l|l|}
\hline Term & Coef & SE Coef & T-Value & P-Value & VIF \\
\hline $\begin{array}{l}\text { HYBRID; hybrid or alternative } \\
\text { fuel vehicle }\end{array}$ & -0.2357 & 0.0118 & -20.02 & 0.000 & 1.06 \\
\hline
\end{tabular}

\subsubsection{Fuel Cost (GCCOST)}

An increase in unit fuel cost was associated with a $17 \%$ decrease in vehicles miles traveled by a random household vehicle, all else being equal. The average consumer thus, behaves rationally in accordance with the laws of supply and demand.

\begin{tabular}{|l|l|l|l|l|l|}
\hline Term & Coef & SE Coef & T-Value & P-Value & VIF \\
\hline GCCOST; fuel cost & -0.1711 & 0.0195 & -8.76 & 0.000 & 1.19 \\
\hline
\end{tabular}

\subsection{Diagnostics}

\section{$\underline{4.3 .1 \text { Model Fit }}$}

To determine if the model specified and analyzed was a good fit for the data employed, model summary statistics were verified. The Standard Error of the Regression $(S=0.733)$ indicates that the observed values fall significantly close to the fitted line. The percentage of variation in the response variable that is explained by this multiple

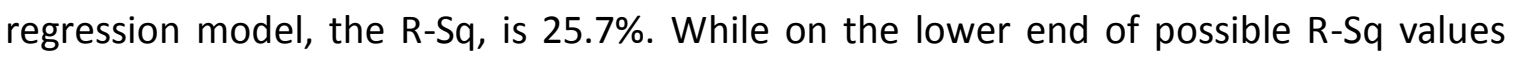
(0-100\%), the following important caveats are fulfilled indicating that the lower R-Sq is not an indicator of an incorrectly specified model (Taylor and Russell, 1939; Rosenthal 
and Rubin 1979; Hunter and Schmidt, 2004 );

1. The predictors are statistically significant

2. The problem being researched and analyzed involves some components of human behavior, choices and decision-making wherein R-Sq is expected to take lower values (as R-Sq measures predictability and human behavior cannot be "predicted").

\begin{tabular}{|l|l|l|l|}
\hline S & R-Sq & R-Sq (Adj) & R-Sq (Pred) \\
\hline 0.733483 & $25.67 \%$ & $25.63 \%$ & $25.59 \%$ \\
\hline
\end{tabular}

\subsubsection{Residuals and Normality}

The residual plots were checked to assess whether the observed error, i.e., the residuals, were consistent with stochastic error. The plot displays residuals that are neither systematically high nor low and that appear to be clustered on zero throughout the range of fitted values (Figures 10 and 11). This indicates that the model does not suffer from any significant misspecification and that, on average, is correct for all fitted values. For the results to be valid, the other assumption that has to be fulfilled is that the random errors produce residuals that are normally distributed. A histogram and a normal probability plot were constructed for the residuals. The histogram (Figure 12) indicates that the distribution is fairly normal with a slight skew to the left. As was explained in more detail in Chapter 3, the size of the dataset used in the analysis for the 
purposes of this study is sufficiently large that this is not a concern. Likewise, with the normal probability plot (Figure 13) a skew is evident (a left "tail").

A closer examination of the data characteristics to study the potential reasons that could account for this skew indicated that; 1 . the values for BESTMILE were set to a "ceiling"; maximum possible annual VMT was recorded as 200,000 and 2. BESTMILE had a large number of extremely small values. The skew in the residuals could therefore be an artifact of the manner in which the data values were recorded.

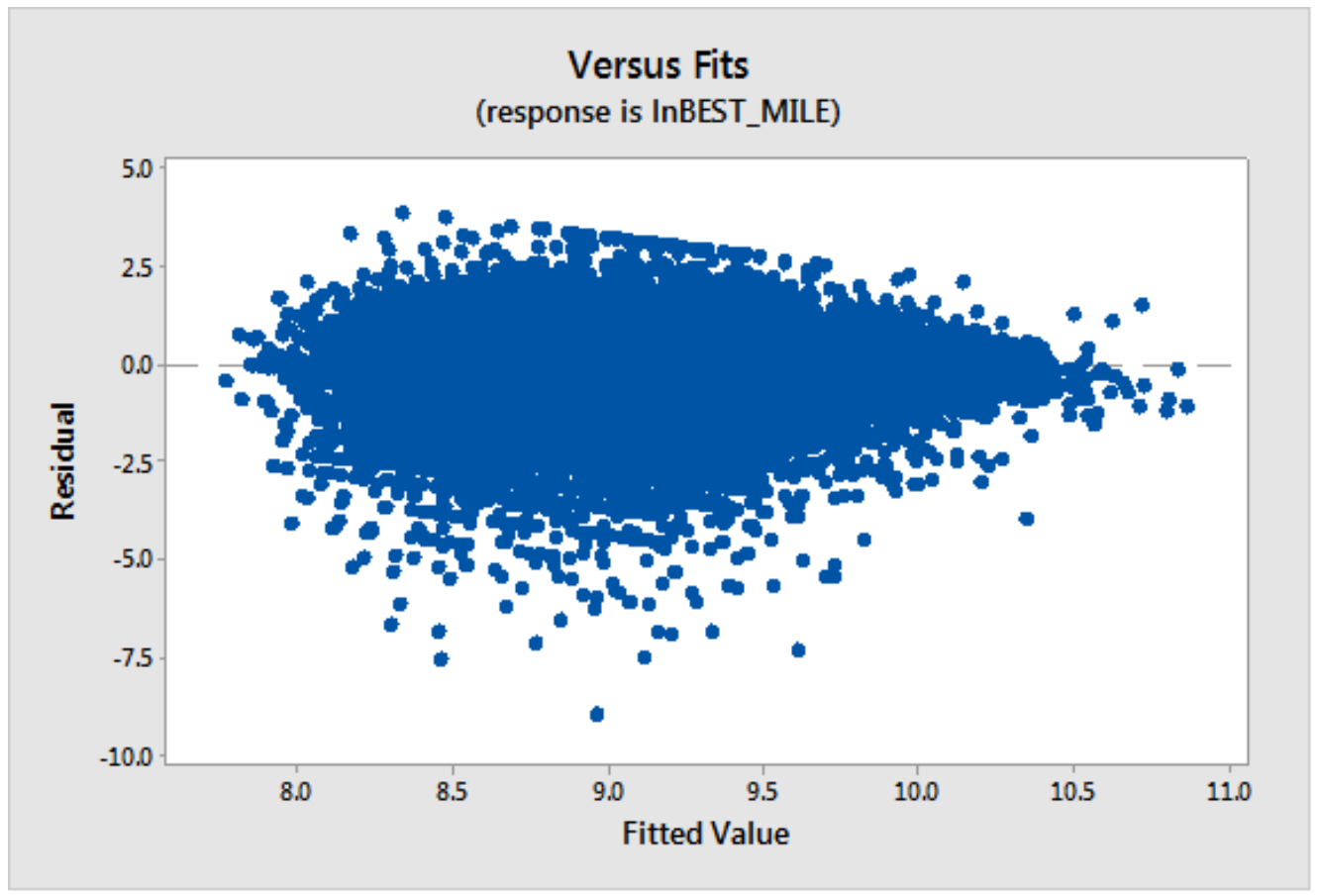

Figure 10: Residual Plot Versus Fits 


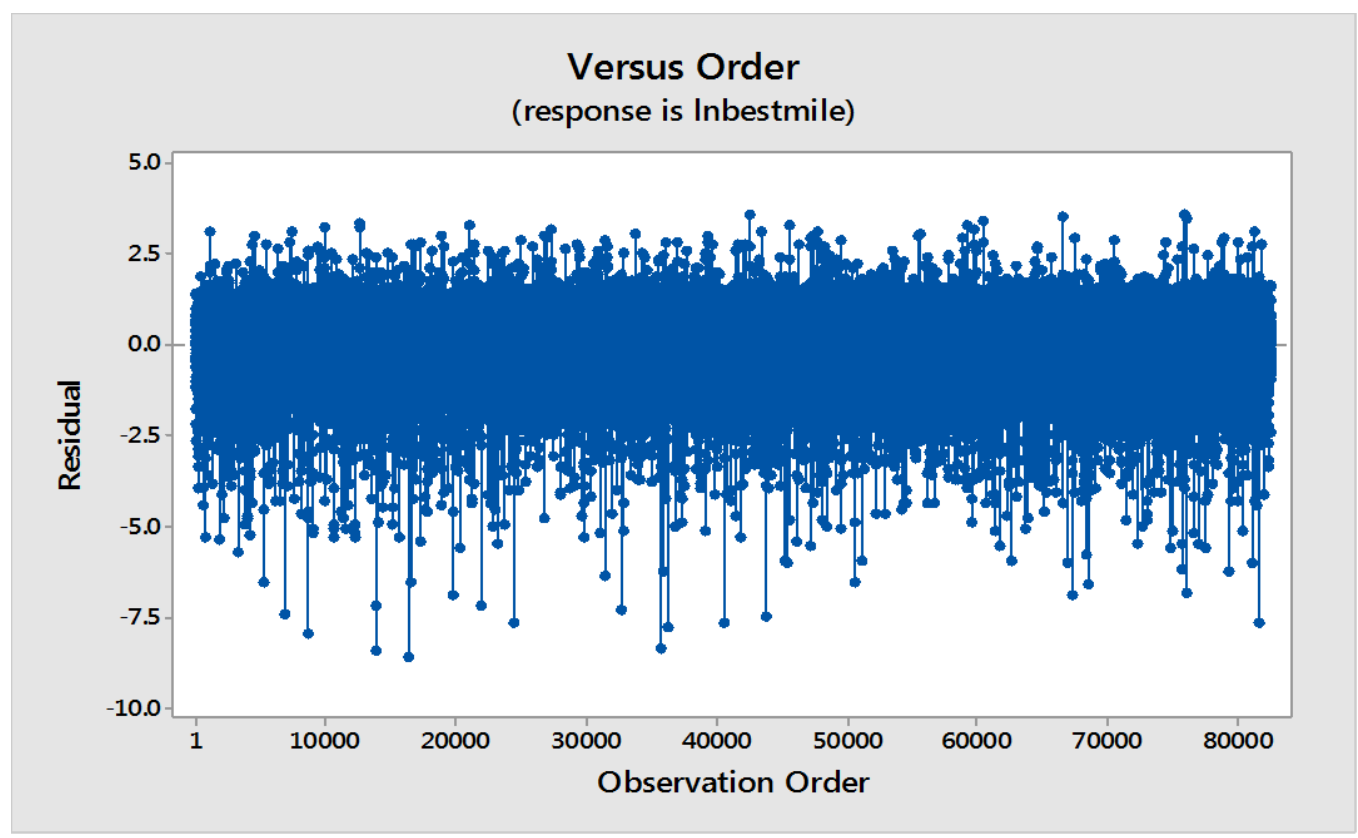

Figure 11: Residuals Versus Order

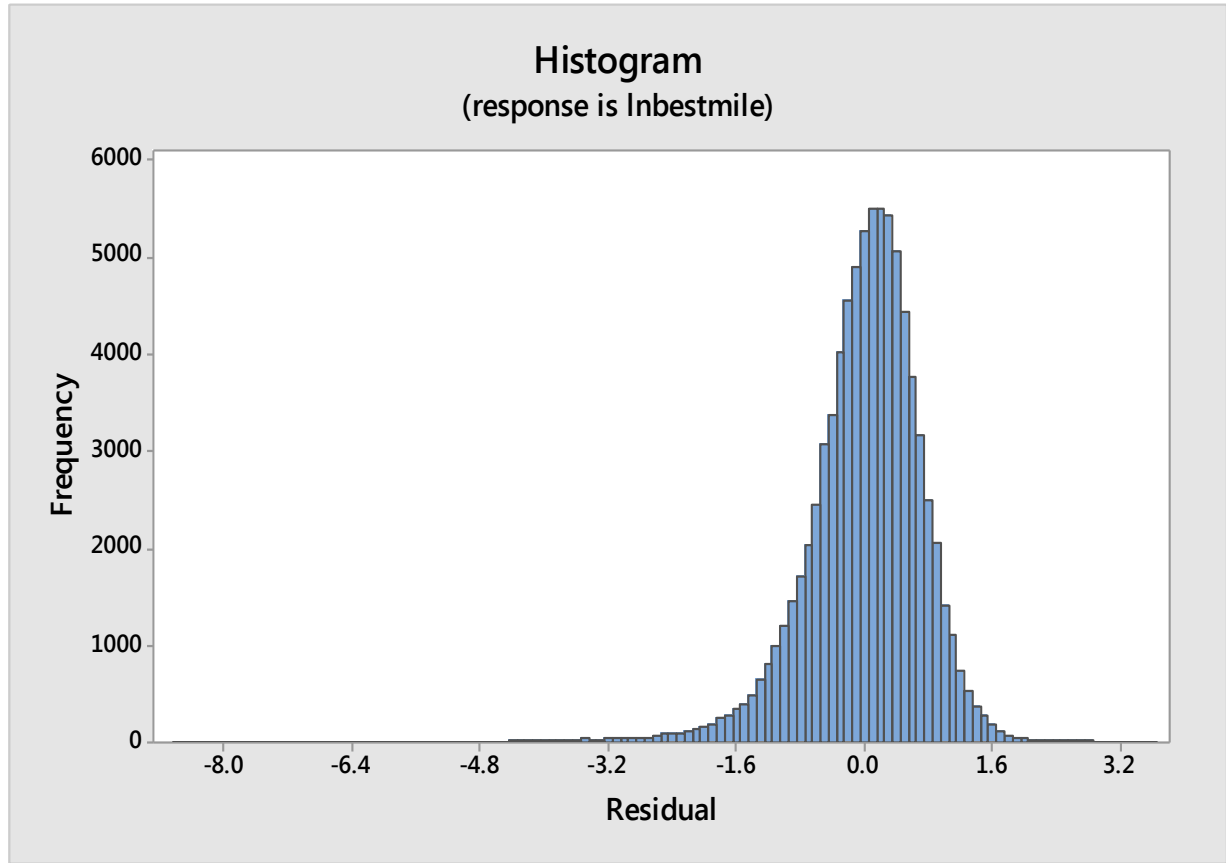

Figure 12: Residual Distribution, Histogram 


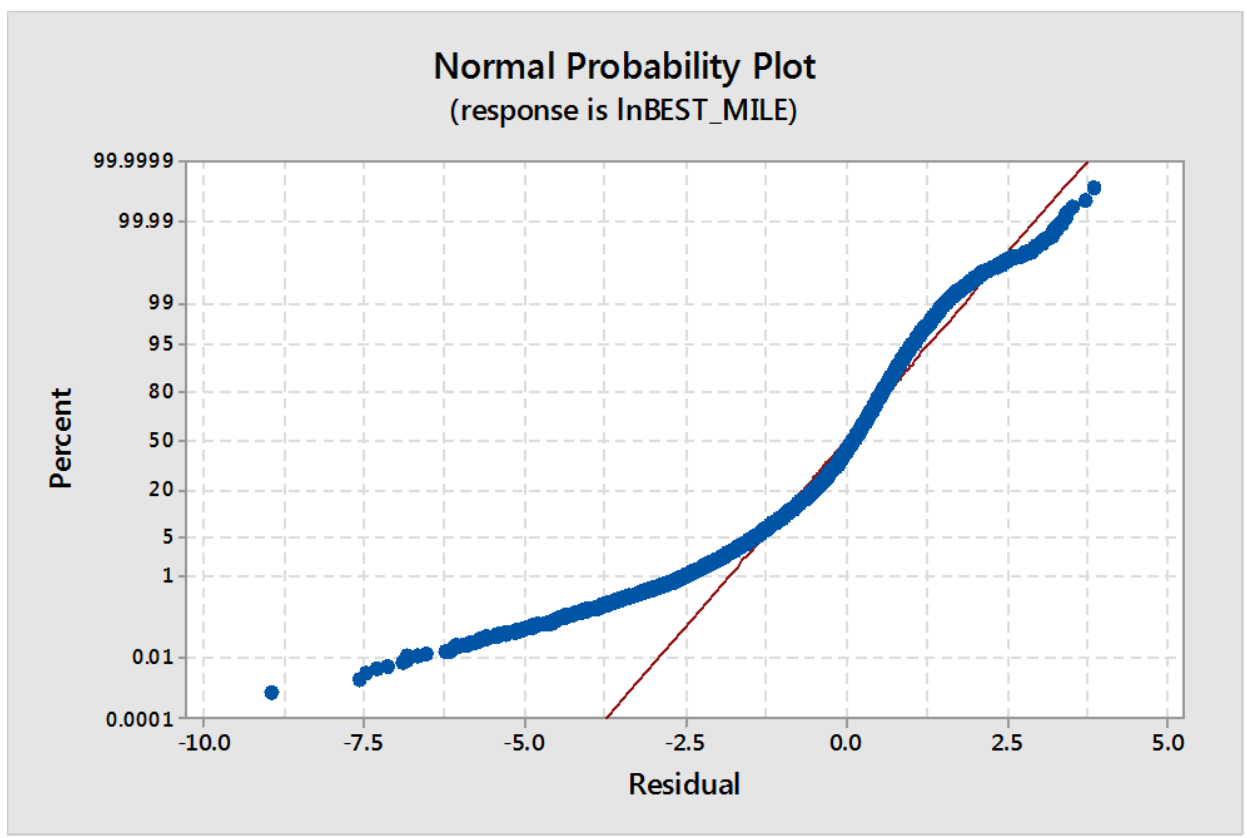

Figure 13: Normal Probability Plot of Residuals 


\section{CHAPTER V}

\section{SUMMARY AND CONCLUSIONS}

\subsection{Introduction}

This final chapter of the dissertation presents a brief summary of the study purpose and thesis, the findings as relating to the foundational literature and observed convergences and divergences therein. The implications of the findings for policy directions, a description of the limitations of the study, and finally, future directions for studies of a similar purpose or bent are also discussed.

\subsection{Summary Of the Study}

A column in the Wall Street Journal (Wall Street Journal, May 27, 2009) responding to the current administration's announcement of initiatives to increase fuelefficiency standards as a means to reduce the demand for gasoline questioned "But what if drivers who find that they can go longer on a tank of gas drive more? Would 
that additional driving cancel out the environmental benefits?"13 ${ }^{13}$ This study hoped to determine if that would, indeed be the case; the question framed was "is the random vehicle $i$ that is more fuel efficient than vehicle $i_{1}$, all else being equal, associated with greater vehicle miles travelled?" Jevons' Paradox (Jevons, 1865) posits that it would; in that a more efficient good/service will be utilized more. Building on the theory underlying Jevons' paradox and applying findings from related studies that have determined person, household and vehicle characteristics that affect vehicle VMT, a multiple regression model of the form

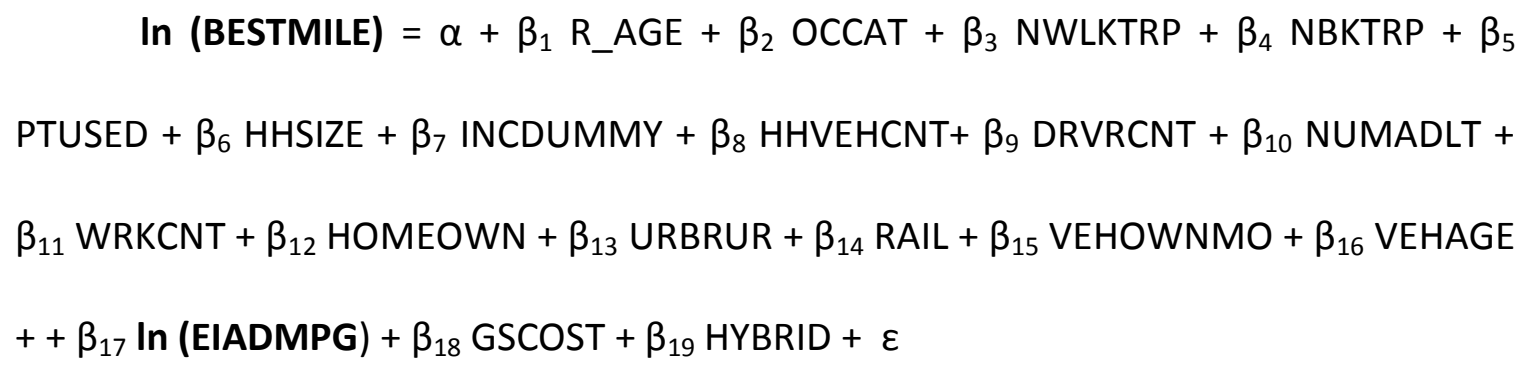

was built. Data from the NHTS 2009 (NHTS, 2010), a cross-sectional microlevel survey data was used in the analysis.

\subsection{Findings in the Context of Existing Literature}

5.3.1 Variables of interest; fuel economy, hybrid and fuel cost

The primary thesis of the study was that a vehicle with greater fuel economy,

\footnotetext{
${ }^{13}$ Available online at http://online.wsj.com/article/SB124338431100556717.html (Last retrieved May 25, 2011)
} 
i.e., efficiency, would, all things being equal, be associated with greater vehicle miles travelled than a less fuel efficient vehicle. The results of the analysis indicated that this was indeed the case. Of all the variables included in the analysis, the EIADMPG (EIA Derived Miles Per Gallon coding for fuel economy) of a random household vehicle had the greatest observed significance in the model for explaining observed variation in VMT (coded as BESTMILE). The direction, as hypothesized, was positive. For every $1 \%$ increase in fuel economy $(\mathrm{mpg}$ ) of a random household vehicle there was an associated $1.2 \%$ increase in vehicle miles travelled, all else being equal. However, the related variable "HYBRID" (whether the random vehicle in question was a hybrid or alternative fuel vehicle) indicated that vehicles with Hybrid capabilities accrued fewer VMT; a $23.57 \%$ decrease in annual miles travelled over vehicles that do not have hybrid capabilities.

Reports indicate that of hybrid owners, the majority $45 \%$, are 45 years and older; a demographic that is typically associated with lower VMT (Experian, 2013). Hybrid owners, as a category, had greater discretionary income, were on average more educated and were willing to use their income to advance their "green" ideals (Experian, 2013). Polls also show the average hybrid owner to be an environmentally conscious consumer and one who is interested in making that be known through choice of vehicle (J.D.Power, 2008). Most hybrid vehicle owners had, prior to the purchase of their hybrid vehicle, owned a smaller vehicle, signaling their propensity to choose to consume less on a continuing basis. 
Consumers who were likely to purchase a more fuel-efficient automobile, rather than a hybrid on the other hand, largely did so to decrease fuel expenditures when faced with either; 1 . significant increases in fuel prices and/or, 2. increased travel prospects. Unlike consumers who chose to buy hybrids, the choice was not based on advancement of an ideal or with the intention to change their consuming behavior (toward being more eco-conscious) but a simple economic response. While these could all be potential reasons for why the hybrid vehicle is associated with fewer VMT than their non-hybrid fuel-efficient counterparts, it raises a very interesting disconnect and a departure from Jevons' Paradox and bears further researching.

In the case of fuel cost, the direction of association was negative and significant; an increase in unit fuel cost was associated with a $17 \%$ decrease in vehicles miles traveled by a random household vehicle, all else being equal. The literature review on this aspect of vehicular travel has produced mixed results; most studies contend that VMT is inelastic and that any increase in fuel cost has implications on travel, if at all, only several months after the fact (the commonly cited number being 12 months) and that it is not a sustained change. While a few have found that consumers do cut back on "discretionary travel" when confronted with high fuel prices. The finding of this study is in keeping with the latter.

Review of studies (Chapter 2) that looked at fuel cost and VMT indicate that a majority of these studies were focused on estimating elasticities and rebound estimates and unlike this study did not involve the controlling for multiple confounding variables 
associated with VMT. This study involved a multivariate regression model that included all available driver, household and vehicle attributes (and fuel cost) that could potentially affect VMT and could therefore explain the divergence from former findings that consumer response to increases in fuel cost are inelastic.

\subsubsection{Other control variables}

The findings associated with the rest of the control variables and whether they converged with or diverged from previous study findings are listed in the table that follows (Table 6). A brief summary of each follows.

Respondent Age; The age of the driver was found to be inversely correlated with VMT; this follows findings from literature (EIA, 2005; Polzin, 2006) that demonstrate that mobility decreases with age and could be a function of no longer being of "working age" and thereby not making daily work trips as well as a function of decreasing number of school trips associated with driving young children to school.

Occupational Category; Studies that examined the association between a respondent's employment and VMT did so in a binary fashion-whether the respondent was employed or not. This study while examining that went a step further and looked at specific occupational categories and their association with VMT. Consistent with previous findings (EIA, 2005, 2013; Polzin, 2006), the study found that those that were employed accrued greater VMT over those that were unemployed. Among the 
employed respondents in the manufacturing, construction or farming industries had the highest vehicle miles traveled per annum estimate. In decreasing order of VMT were those employed in the sales/service industry, in the professional/managerial level category, in the "other" category" and finally those in the clerical or administrative category.

Biking, Walking, Public transit trips, Access to rail; in results that diverged from previous studies reviewed (Arrington \& Cervero, 2008; Ewing \& Cervero 2010), the number of walking trips was determined to not substitute for driving trips. Biking trips were found to be associated with a decrease in VMT, but this result was not statistically significant. The results for Public transit trips and access to rail were consistent with previous findings and significant; trips using public transit and rail do substitute for personal vehicle trips.

Household Size; Consistent with previous findings (NHTS, 2001; Kweon \& Kockleman, 2004), increase in household size was associated with increased VMT, presumably as a function of household structure and an associated increased in household vehicle count. The literature review (Chapter 2 ) indicated that households with young children (those under legal driving age) accrued the most VMT.

Driver Count, Household Vehicle Count; Findings from this study were in keeping with findings from previous studies (EIA, 2001; 2006; 2013) that determined that increase in number of drivers in a household was associated with an increase in VMT. An increase in the number of vehicles in a household was however, associated with a 
decrease in VMT. Note that the unit being measured in previous studies was total household VMT, therefore it would stand to reason that with increase in number of household vehicles the total household VMT would increase. The unit measured in this study was a random vehicle in the household and it appears that addition of a vehicle to the household resulted in no more trips but rather a substitution across vehicles within the household.

Household Income; While studies found that in general, greater disposable income was associated with greater discretionary travel (EIA, 2001; 2006) some studies found that the extremely wealthy accrued fewer VMT possibly on account of less workassociated travel. The findings of this study was in agreement with the former hypothesis; all income categories accrued fewer VMT than the reference categoryannual household income greater than $\$ 100,000$.

Housing Type; Consistent with previous studies, homeowners accrued greater VMT than renters. With home-buying being typically associated with 1) moving from high density areas to low-density areas (suburbs and exurbs), 2) on average, having a bigger household size and income than renters and 3) longer commutes to work it stands to reason that respondents who own the housing unit that they reside in, drive more.

Urban/Rural; In keeping with previous studies, respondents who lived in dense, urban agglomerations drove less than those who resided in rural areas. 
Table 6: Variables, Expected Directions and Actual Directions

\begin{tabular}{|c|c|c|c|}
\hline Category & Variable & $\begin{array}{l}\text { Direction Predicted } \\
\text { by Literature }\end{array}$ & $\begin{array}{l}\text { Direction Observed in } \\
\text { the Study Results }\end{array}$ \\
\hline \multicolumn{4}{|c|}{$\begin{array}{l}\text { Person } \\
\text { Characteristics }\end{array}$} \\
\hline & Respondent Age & $\begin{array}{l}\text { + with age until } 50 \\
\text { decreases after }\end{array}$ & - \\
\hline & Walking trips & - & + \\
\hline & Public transit & - & - \\
\hline & Biking trips & - & - \\
\hline & Occupational Category & & \\
\hline & Employed & + & + \\
\hline & Unemployed & - & - \\
\hline & Distance to Work & + & + \\
\hline \multicolumn{4}{|c|}{$\begin{array}{l}\text { Household } \\
\text { Characteristics }\end{array}$} \\
\hline & Household Size & + & + \\
\hline & Worker Count & + & - \\
\hline & Driver Count & + & + \\
\hline & Household Vehicle Count & + & + \\
\hline & Household Income & & \\
\hline & $<\$ 40,000$ p.a. & - & - \\
\hline & $\$ 40,000-120,000$ & + & - \\
\hline & $>\$ 100,000$ & $-/+$ & - \\
\hline & Housing type & & \\
\hline & Owned & + & + \\
\hline & Rented & + & - \\
\hline & Urban/rural & & \\
\hline & Urban & - & - \\
\hline & Rural & + & + \\
\hline & Rail & - & - \\
\hline \multicolumn{4}{|c|}{$\begin{array}{l}\text { Vehicle } \\
\text { Characteristics }\end{array}$} \\
\hline & Vehicle Owned, months & - & - \\
\hline & Vehicle Age & - & - \\
\hline & Commercial license & + & + \\
\hline & Hybrid & + & - \\
\hline & Vehicle fuel economy & + & + \\
\hline \multicolumn{4}{|l|}{ Fuel cost } \\
\hline & $\begin{array}{l}\text { Cost in nominal US dollars } \\
\text { per gasoline equivalent } \\
\text { Gallon }\end{array}$ & $+/-$ & - \\
\hline
\end{tabular}




\subsection{Limitations of the Study}

\subsubsection{Limitations of the Dataset}

The NHTS 2009 dataset is rich in its micro-level data detail and therefore provides greater nuance than the often used Consumer Expenditure Survey data (Goldberg, 1998; West, 2004) which only provides aggregate data for a household's total vehicle stock and little information on the household/motorist's characteristics. This richness in micro-level data is especially important within the context of studies such as these as literature indicates that vehicle miles traveled is associated with and influenced by a myriad of factors as diverse as respondent age to population density of the MSA the respondent resides in. Being able to factor in data on these confounding variables and controlling for them, confers greater reliability to the empirical results of this study.

The NHTS while providing greater detail on the attributes influencing VMT, is however, cross-sectional and not longitudinal, and since the unit of observation is vehicle "i" in household " $\mathrm{j}$ ", does not permit trend-analysis across the survey years. While this limits us from answering the question, "has VMT changed with time for vehicle i?" it does not limit us from answering the question "is vehicle i that is more fuel efficient than vehicle $i_{1}$ driven more, all else being constant?"

While this question is at the heart of Jevons' paradox, the relationship between fuel economy, VMT and fuel price is one that is a product of short-term and long-term consumer adaptations to efficiency and price signals. As such to get the "bigger picture" 
the ideal dataset would have been a multi-year longitudinal time-series dataset.

However, in the absence of such a dataset, the NHTS cross-sectional dataset was used and in keeping with the tenets of data and model fit, the best model was fit to the best available data.

The observations on the variable WHOMAIN were self-reported. There was no quantifiable measure established within the survey instrument to determine what characterized a member of the household as the main driver of a vehicle within the household. It was recorded, subject to the respondent's view of who among the household drove a particular vehicle the most to qualify being dubbed the main driver of that vehicle. Since this was the variable used to attach driver attributes (driver age, occupational category of driver, number of walking trips driver made, number of biking trips driver made and number of public transit trips made) to a particular random vehicle within the household, it follows that the results on these attributes that are driver-specific are subject to the caveat that the self-reported main driver of the vehicle is, on average, equal to the actual main driver of the vehicle. All other attributes were vehicle-specific and/or household-specific and do not, therefore, hold this limitation.

\subsubsection{The Question of Consumer/Producer Behavior Modification}

Jevons' Paradox is inherently an observation of consumer (and producer) behavior modification in response to an efficiency improvement. Jevons touches upon this aspect of the paradox when he states in his book "If children do as their fathers did 
then multiplication and average consumption both rise; If our parents doubled their income, or doubled the use of iron, or doubled the agricultural produce of the country, then so ought we, unless we are changed either in character or circumstances" (Jevons, 1865). Other scholars (Brookes, 1982a; Khazzoom, 1987) have observed that at the heart of the paradox is the consumer's tendency to substitute for perceived savings, or consume more due to the perceived savings. Given that a regression analysis can only help answer the "if" (if consumption is increasing or decreasing) and the "what" (what attributes have the most association with this observed consumption) but cannot tell us "why" or "how" it happens, the results of this study while helping understand what factors drive increase in miles travelled do not, however, provide answers to the mechanism by which that increase occurs. Qualitative studies that can take a more open-ended approach and can conduct in-depth interviews with subjects would help address this limitation.

\subsubsection{The Vehicle Choice Question}

Related to the aspect of consumer behavior/decision-making is the question of vehicle choice and use; i.e., a household may choose to buy a fuel efficient model because a) they expect to drive more or b) prevailing high fuel prices could make purchasing a fuel efficient model more cost-effective or c) economic incentives could stimulate the purchase of a more fuel-efficient model or d) they have "green" ideas. Fuel prices were high at the start of the summer of 2008 but fell during the winter. Also 
in late 2008-2009, the United States experienced an economic decline. While it stands to reason that households would be influenced by such events in decisions concerning the purchase of a new vehicle, polls show that gasoline price at purchase is unlikely to affect decisions after purchase. Nevertheless, this is a factor that was not addressed in this study and could potentially be a limitation of the study.

\subsubsection{External Validity/Generalizability}

A study's findings are considered "generalizable" when the conclusions that are true of the sample in the study can be extrapolated to another sample from the population, the population itself (sample generalizability) or to an entirely different population (cross-population generalizability) and be expected to hold true. To be generalizable, a study has to; 1 ) have a significantly large sample size, 2) the sample should be randomly collected and 3) the sample should be representative of the population from which it was drawn (Cook et al., 1979; 2006).

The NHTS 2009 sample was a random, representative sample of households within the contiguous United States. The sample used for the purposes of this study, extracted from the NHTS had a significantly large sample size $(n=82,485)$ rendering the results of this study potentially generalizable to another sample from the population from which it was drawn or to the population itself. It should be noted that certain attributes of this sample, albeit randomly collected and intended to be representative of the population, was not entirely representative of the attributes of the population. For instance, the median annual household income of the sample was higher than the 
median annual household income of the population.

With the attributes that affect VMT being specific to the population that was sampled and being of the nature that vary significantly across populations both in their actual measures and in the manner in which they influence VMT, the results of this study are not generalizable across populations.

\subsubsection{Validity of Statistical Conclusions}

The statistical conclusions reached by a study are deemed valid when the relationship established between the variables being studied is statistically correct and reasonable (Cook et al., 1979; 2006) and not subject to a Type I or Type II error. That the findings are "reasonable" are confirmed by cross-validation with reviewed literature and with theory. That the findings are statistically valid is determined by whether any of the following comes into play; 1) low statistical power, 2) violated assumptions of the test statistics, 3) measurement errors, 4) restriction of range, and 5) heterogeneity of the units being studied.

Of the potential threats, the sample being studied had; 1 . restriction of rangethe variable BESTMILE had a set "ceiling" wherein the maximum miles drives per annum were capped at 200,000 miles 2 . Heterogeneity of units-a few variables had a wide range of values and a large number of outliers. However, with this being a large dataset $(\mathrm{n}=82,485)$, such potential threats to statistical validity were more an artifact of the large number of observations and induced a slight skew in the normality plots but no major violations of statistical assumptions. 


\subsection{Policy Implications}

The primary focus of policies and programs aimed at reducing consumption of gasoline (via reduced VMT) has been to promote fuel efficiency. This traditional approach has rested on the assumption that fuel efficiency, all else being held equal, would lead to a decrease in VMT and consequently, a decrease in gasoline consumption. The finding that increases in fuel efficiency do not necessarily equal decrease in VMT, as predicted by Jevons' Paradox and confirmed by this study necessitates a change in this focus and an exploration of other potential means to curb gasoline consumption in conjunction with energy efficiency. A few of the key findings and how they could guide policy direction is discussed below.

\subsubsection{Pricing Policies}

The finding that an increase in fuel cost is associated with a decrease in VMT, all else being equal, lends support for promoting policies that are aimed at increasing the cost of driving. Policies that directly increase the cost of driving as well as those that do so indirectly---increasing the cost of fuel, VMT fees, increase in parking fees--could help curb the rise in VMT.

Gasoline price; one means of increasing the gasoline price would be to increase the federal gasoline tax (which is one of the many components of gasoline price). Likely the least popular of all potential policy options, this might soon become a necessity given that the gasoline tax has been stagnant at the fixed rate of 18.4 cents per gallon for 21 years (ITEP, 2013). With gasoline tax being the primary source of federal 
transportation funding, this lack of change in the tax price has, in recent years, resulted in significant shortfalls between that which is collected and that which is required for transportation projects. It is estimated that in 2015 , given the status quo scenario, the shortfall would be to the tune of $\$ 15$ billion (Cawley, 2013). The increase in gasoline tax would therefore, target both a reduction in gasoline consumption (depending on the level of increase and price elasticity associated with gasoline) and a much-needed increase in the federal transportation funding.

VMT Fee; a fee charged on an annual per mile travelled basis would be another policy option that unlike the gasoline tax (which directly targets gasoline consumption and thereby affects VMT indirectly) would directly target VMT reduction. A study on the impact of levying such a fee (PSRC, 1994) determined that a fee ranging from $\$ 0.01$ to $\$ 0.05$ per mile would result in a $9.3-11 \%$ decrease in VMT and an $8-20 \%$ percent decrease in carbon dioxide emissions. A pilot study conducted in Oregon that looked at impact of a VMT fee (Handy 2010; Rufolo and Kimpel 2009) found it to likewise, be effective at reducing VMT. While potentially effective in reducing VMT, implementation could pose issues with; 1. Equity (its design could make it inherently a regressive fee; Carlson and Howard, 2010) and 2. Pricing for multi-vehicle households.

Parking fees; while some studies (Giuliano and Agarwal, 2010) find that increasing parking fees works as a means to discourage single-occupancy vehicular trips and encourage seeking other modes of transport other studies (UPH, 2009) find this to more useful in reducing congestion. 


\subsubsection{Shifting Modes of Transit}

The finding that bike trips, public transit trips and access to rail were associated with lower VMT suggests that investments/improvements in making these more accessible could directly impact personal vehicle VMT. Ewing and Cervero (2010) found density and multi-use neighborhoods to be significant predictors of choosing alternative means of transport. Their finding that people who resided in denser neighborhoods drove less and took shorter trips is consistent with the finding of this study. Arrington and Cervero (2008) found that access to public transit from place of work and dense working neighborhoods were a more significant predictor of transit ridership (than dense residential neighborhoods). These findings in conjunction with the findings of the current study suggest that investing in mass transit, land-use planning shift toward denser, multi-use neighborhoods and transit-oriented developments could help reduce personal vehicle VMT.

\subsection{Future Directions}

Trends in national VMT have, for the first time since World War II, reached a steady state starting in late 2007 and then declined starting 2009. While the economic downturn, associated unemployment, cost of owning and operating a vehicle etc. have been cited as potential causes, a report by the Frontier Group (Davis et al., 2012) that has subsequently been widely cited in many media outlets, maintains that the millennials and their changing preferences are the driving force behind the end of 
America's storied love affair with the automobile. The report states that between 2001-2009, the average annual VMT traveled by those in the 16 to 34-year-olds demographic decreased by $23 \%$ (Davis et al., 2012) while bike ridership in this demographic for the same period increased by $24 \%$ and public transit ridership increased $40 \%$.

The primary reasons they contend is not the often surmised economic downturn or unemployment as those in this demographic who were employed still accrued only 10,700 miles in 2009 , compared with 12,800 miles in 2001 . Rather, the reasons being, a change in lifestyle and preferences, that they are "consciously choosing" to-- 1. take alternative modes of transport, 2. live and work in dense mixed use neighborhoods with access to public transport, 3. delay becoming licensed drivers and/or own a vehicle. There are very few documented studies exploring this trend. Given how converse to historical trends this is and also given how much effect this could have on the narrative on transportation and transportation planning and policy, future work in this is warranted.

Then there's the question of hybrid vehicles. While the analysis revealed that vehicles with greater fuel economy were associated with greater VMT, all else being equal, hybrid vehicles bucked the trend and accrued significantly less VMT than their non-hybrid counterparts. It bears investigating if this is; 1 . merely due to the nature of the posited eco-conscious consumer who chooses to buy hybrids and drives less regardless of the cost of driving, or 2 . if there is a substitution effect when the hybrid is 
one among more vehicles within a household with the hybrid being used only for certain kinds of travel, or 3.if there is a certain fuel economy threshold at which efficiency does trump consumption, for instance.

American households are still predominantly multi-vehicle households. There are therefore, at play, scale effects and substitution effects. "Scale effects" - the extent to which a multi-vehicle household is predisposed to travel greater VMT, a predisposition evidenced by the owning of more than one vehicle and "Substitution effects" - the propensity to substitute one vehicle for another (a more fuel efficient one for a lesser for example) within the household on the basis of trip purpose and/or fuel cost could both affect the VMT of a random vehicle within a household. This is another aspect that requires further study.

\subsection{Conclusions; The Paradox and Fuel Efficiency Policy}

There is evidence that Jevons' paradox holds; that with increased fuel efficiency there is an associated small increase in VMT. There is also evidence that increase in fuel price drives down fuel consumption and consequently VMT. Also present is growing evidence that continued increases in vehicle fuel efficiency, on the macro-level, has resulted in decreased VMT and gasoline consumption which is contrary to Jevons' predictions. Coupled with the current trend toward less driving, vehicle fuel efficiency may not result in the paradoxical increased macro-level consumption that Jevons' paradox posits, after all. 
Howarth (1998) wrote "The (Jevons') hypothesis is most credibly grounded on the story of the steam engine, coal and the Industrial Revolution. In important respects economic history, evolutionary economics, and institutional economics shed more light on this issue than neoclassical growth theory. One can specify growth models that account for the stylised facts surrounding this development, but in a sense the event marked a type of structural change in technologies, lifestyles, and social institutions that transformed economic relationships rather than fostering smooth change in a continuous model". The change in "lifestyles, technologies and social institutions" that Howarth posits as causing the increase in consumption with increase in efficiency have been, in fact, credited with currently being the agents of change in the opposite direction; the now-observed historical decrease in VMT.

Energy efficiency should, therefore not be completely discredited but rather be continued to be adopted on a micro and macrolevel. Knowing the scale of the potential rebound can enable policy to mandate efficiency improvements that have the expected rebound "built-in" so that the realized energy savings are still greater than would have been possible sans energy efficiency mandates. Then there is the question of quality of life; energy efficiency is linked to both increased productivity and quality of life and could when coupled with the right agents "enable us to fund the transition to 'sustainable development' (Herring, 1998)".

Fuel economy policy is therefore good but not enough, in and of it itself in curbing gasoline consumption. When used in conjunction with other policies that are 
directly aimed at capping consumption, fuel economy policies can in the short-run reduce negative externalities (carbon dioxide emissions), improve welfare and induce technological change and in the long-run induce the sort of macro-level behavioral change predicted by the Environmental Kuznets Curve (Kuznet, 1955) that can result in sustained decreases in consumption. 


\section{REFERENCES}

ACEEE, 2007. The Twin Pillars of Sustainable Energy: Synergies between Energy Efficiency and Renewable Energy Technology and Policy. Aceee.org. Archived from the original on 2008-05-05.

http://web.archive.org/web/20080505041521/http://aceee.org/store/proddetail.cfm?C FID $=2957330 \&$ CFTOKEN $=50269931$ \& ItemID $=432 \&$ CategoryID $=7$.

Binswanger, M., 2001. Technological progress and sustainable development: what about the rebound effect? Ecological Economics, Vol 36 (1): 119-132.

Brookes, L.G., 1990. The greenhouse effect: The fallacies in the energy efficiency solution. Energy Policy, Vol 18 (2):199-201.

Brookes, L.G., 2000. Energy efficiency fallacies revisited. Energy Policy, Vol. 28 (6): 355366.

Brookes, L.G., 1978. The energy price fallacy and the role of nuclear energy in the UK. Energy Policy.

Brookes, L.G.,1979a. A low energy strategy for the U.K. by Gerald Leach et al, a review and a reply. Atom (269).

Brookes, L.G., 1979b. Nuclear energy =more jobs. Energy Manager 12 (6).

Brookes, L.G., 1980. Paper presented at a plenary session of the Annual Conference of the International Association of Energy Economists, Churchill College, Cambridge, June 1980. Reported In: Tempest, P. (Ed.), International Energy Options. Graham and Trotman and O, G and H Inc., 1981, pp. 253--261. 
Brookes, L.G., 1982a. The economics of energy price hikes. Paper presented the Annual Conference of the International Association of Energy Economists, Churchill College, Cambridge, June. (Abstract appears on In: Tempest, P. (Ed.), International Energy Markets. Graham and Trotman and O E and G Inc, 1983, p. 301.

Brookes, L.G., 1982b. Devil's advocate: the results of conserving energy are not all that might be expected. Energy Manager.

Brookes, L.G., 1983. The macroeconomic significance of nuclear power. Nuclear Energy (The Journal of the British Nuclear Energy Society, Vol 22 (4).

Brookes, L.G., 1990b. The fifth fuel and the greenhouse effect. Energy World 18 (2).

Brookes, L.G., 1990c. Energy efficiency and the greenhouse effect. Energy and Environment, Vol 1 (4).

Carlson, D., and Howard, Z., 2010. Impacts of VMT Reduction Strategies on Selected Areas and Groups. Washington State Department of Transportation. Available online at http://www.wsdot.wa.gov/research/reports/fullreports/751.1.pdf (Last Retrieved, June 9, 2014)

Creyts, Jon, Anton Derkach, Scott Nyquist, Ken Ostrowski and Jack Stephenson, 2007. Reducing U.S. Greenhouse Gas Emissions: How Much At What Cost? McKinsey \& Company, Washington, DC.

Dacy, D.C., Kuenne, R.E., and McCoy, P., 1980. Employment impacts of achieving automobile efficiency standards in the United States. Applied Economics 12, 295-312.

Davis, S.J., and Haltiwanger, J.C., 1990. Gross job creation, gross job destruction: microeconomic evidence and macroeconomic implications. NBER Macroeconomics Annual 271, 123-168.

Davis, S.J., and Haltiwanger, J.C., 1999. Gross job flows. In: Ashenfelter, O., Card, D., (Eds.), Handbook of Labor Economics, Vol. 36.Elsevier, Amsterdam

Dernbach, J. C., 2007. Energy efficiency and Conservation as Ethical Responsibilities: Suggestions for IPCC Working Group III Widener University, School of Law. Available at SSRN: http://ssm.com/abstracts 1089423

Ehrlich, P.R., and Holdren, J.P., 1971. Impact of population growth. Science 171:12121217. 
EIA, 1991. Available at; http://www.eia.gov/emeu/rtecs/rtecs1991/rtecs1991.html (Last retrieved, May 25, 2014)

EIA, 1994. Available at; http://www.eia.gov/emeu/rtecs/toc.html (Last retrieved, May $25,2014)$

EIA, 2001. Available at http://www.eia.gov/emeu/rtecs/nhts survey/2001/index.html (Last retrieved, May 25, 2014)

EIA, 2005. Household Vehicles Energy Consumption. Available at http://www.eia.gov/consumption/reports.cfm?t=92 (Last retrieved, June 01, 2014)

Ewing, Reid, and Robert Cervero. 2010. "Travel and the Built Environment." Journal of the American Planning Association 76 (3): 265-94.

FHWA, 2009. National Household Travel Survey: Our Nation's Travel, 2009. Available at http://nhts.ornl.gov/download.shtml (Last Retrieved June 01, 2014)

GEF. Available at http://www.thegef.org/gef/node/4062 (Last retrieved, June 10, 2014) Geller, H., DeCicco, and J., Laitner, S., 1992. Energy efficiency and job creation: the employment and income benefits from investing in energy conservation technologies. Report No. ED922, American Council for an Energy-Efficient Economy; Washington DC. Goldberg, P., 1996. The effects of the corporate average fuel efficiency standards. NBER Working Paper 5673, NBER; Cambridge, MA, July 1996; The effects of the corporate average fuel efficiency standards in the US. The Journal of Industrial Economics, 46 (1), 79-100 (March 1998).

Goldberg, P., 1998. The effects of the corporate average fuel efficiency standards in the US. Journal of Industrial Economics, Vol 46(1): 1-33.

Goodwin, P, Joyce D., and Mark H., 2004. Elasticities of Road Traffic and Fuel Consumption with Respect to Price and Income: A Review. Transport Reviews 24(3): 275-292.

Graus, W. and Worrell E., 2009. Trends in Efficiency and Capacity of Fossil Power Generation in the EU. Energy Policy 37: 2147-2160

Greene, David L., 1992. Vehicle use and fuel economy: how big is the rebound effect? Energy Journal. Vol 13(1): 117-143.

Greene, David L., 2010. How Consumers Value Fuel Economy: A Literature Review. 
United States Environmental Protection Agency, EPA-420-R-10-008, Washington, DC.

Greene, David L., Kahn, James R., Gibson, Robert C. , 1999. Fuel economy rebound effect for U.S. household vehicles. Energy Journal, Vol 20 (3): 1-32.

Greenhalgh, G., 1990. Energy conservation policies. Energy Policy. Vol 18 (4): 293-299.

Greening, Lorna A., Greene, David L., Difiglio, C., 2000. Energy efficiency and consumption -the rebound effect-a survey. Energy Policy. Vol. 28 (6): 389-401.

Grubb, M.J., 1990. Energy efficiency and economic fallacies, Energy Policy 18: 783-785 Giuliano, Genevieve, and Ajay Agarwal. 2010. "Public Transit as a Metropolitan Growth and Development Strategy." In Urban and Regional Policy and Its Effects, vol. 3, ed. N. Pindus, H. Wial, and H. Wolman (Washington, DC: Brookings Institution).

Helfand, G., and Wolverton, A., 2009. "Evaluating the Consumer Response to Fuel Economy: A Review of the Literature." Discussion paper, National Center for Environmental Economics, US Environmental Protection Agency. Hernandez, A.I, and Pifarre, F.S., 2009. Short-run Scenarios and Working Policies Whereby Economy- Wide Rebound Effects Might be Mitigated. Working Paper.

Herring, H., 2000. Is Energy Efficiency Environmentally Friendly? Energy \& Environment, Vol. 11: 313-326.

Herring, H., (ed.), 2000. How Green is Energy Efficiency? Energy \& Environment, Vol.11 (5).

Howarth, R., 1997. Energy efficiency and economic growth. Contemporary Economic Policy. XV.

http://cees.colorado.edu/isea/Browse (Retrieved on January 29, 2011)

Hunter and Schmidt, 2004. Methods of Meta-Analysis: Correcting Error and Bias in Research Findings.

Institute on Taxation and Economic Policy (ITEP), 2013. A Federal Gas Tax for The Future. Available online at http://itep.org/itep reports/2013/09/a-federal-gas-tax-forthe-future.php\#.U3pXrLS8D9s (Last retrieved, June 9, 2014)

Jevons, W.S., 1965. The Coal Question: An Inquiry Concerning the Progress of the Nation, and the Probable Exhaustion of Our Coal-Mines, 3rd ed. Revised by Flux, A.W., Kelley, A.M., New York. 
Khazzoom, J. D., 1980. Economic implications of mandated efficiency in standards or household appliances. Energy Journal, Vol. 1 (4): 21-40.

Khazzoom, J. D., 1987. Energy saving resulting from the adoption of more efficient appliances, Energy Journal, Vol. 8 : 85-89.

Khazzoom, J. D., 1989. Energy saving resulting from the adoption of more efficient appliances: a rejoinder, Energy Journal, Vol 10(1): 157-166.

Kleit, A.N., 2002. Short- and long-range impacts of increase in the corporate average fuel economy (CAFE) standard. Report prepared for General Motors. 2002.

Kuznets, S., 1955. Economic growth and income inequality. American Economic Review, 49: 1-28.

Lax, D. 1987. "Feasibility of Estimating In-Use Vehicle Fuel Efficiency from Household Survey Data." Research performed under contract for ORNL/DOE/EIA. Energy and Environmental Analysis Inc., Arlington, VA.

Lovins, Amory B., J.Henly, H. Ruderman, M.D.Levine, 1988. Energy saving resulting from the adoption of more efficient appliances: another view; a follow up, The Energy Journal, Vol. 9: 155

Lovins, Amory B. 1988. Energy saving from more efficient appliances: another view. The Energy Journal, Vol. 9: 155-162.

Mintz, M., A. Vyas, and L. Conley, 1993. "Differences Between EPA-Test and In-Use Fuel Economy: Are the Correction Factors Correct?" Transportation Research Record 1416, pp. 124-130, Transportation Research Board, National Research Council, Washington, DC.

Morrow, W. Ross, Kelly Sims Gallagher, Gustavo Collantes, and Henry Lee., 2010. Analysis of Policies to Reduce Oil Consumption and Greenhouse-Gas Emissions from the U.S. Transportation Sector, Energy Policy, Vol. 38 (3): 1305-1320.

MVMA, 1990. US employment effect of higher fuel economy standards. 30 January, unpublished paper. (The MVMA is now known as the American Automobile Manufacturers Association, AAMA.)

NHTS, 2009. Available at http://nhts.ornl.gov/download.shtml\#2009 (Last retrieved, June 1, 2014)

Parry, Ian W.H., and Kenneth A. S., 2005. Does Britain or the United States Have the 
Right Gasoline Tax? American Economics Review, Vol 95 (4): 1276-1289.

Parry, Ian W.H., Margaret Walls, and Winston H., 2007. Automobile Externalities and Policies. Journal of Economic Literature, Vol 45(2): 373-399.

Patterson, M.G., 1996. What is energy efficiency: concepts, indicators and methodological issues. Energy Policy, Vol. 24(5):377-390.

Polzin, Steven E. 2006. The Case for Moderate Growth in Vehicle Miles of Travel: A Critical Juncture in U.S. Travel Behavior Trends. Center for Urban Transportation Research: Report Prepared for the U.S. Department of Transportation.

Puller, Steven L., and Lorna A. G., 1999. Household Adjustment to Gasoline Price Change: An Analysis Using 9 Years of US Survey Data, Energy Economics, Vol. 21(1): 3752.

Reichert, J. 2000. "Change in Method for Estimating Fuel Economy for the Residential Transportation Energy Consumption Survey," Energy Information Administration on www.eia.doe.gov/emeu/rtecs/contents.html.

Rosenthal, R., and Rubin, D. B., 1979. Comparing significance levels of independent studies. Psychological Bulletin, 86, 1165-1168.

Rufolo, A. M., and T. J. Kimpel. 2009. "Transit's Effect on Mileage Responses to Oregon's Experiment in Road Pricing." Transportation Research Record 2115: 60-65.

Saunders, H.D., 1992a. Does energy conservation worsen global warming? In: Fesharaki, F., Dorian, J. (Eds.), International Issues in Energy Policy, Development and Economics. Westview, Boulder, CO.

Saunders, H.D., 1992b. The Khazzoom-Brookes postulate and neoclassical growth. The Energy Journal, Vol 13 (4).

Saunders, H.D., 1996. Fuel-conserving production functions. Working paper. Refer to author.

Saunders, H.D., 2000, A view from the macro side: rebound, backfire and KhazzoomBrookes. Energy Policy Vol.28: 6(7), 439-449

Schipper, Lee (ed.), 2000. On the rebound: the interaction of energy efficiency, energy use and economic activity. Energy Policy, Vol. 28 (6). 
Schipper, L., Grubb, M., 2000. On the rebound? Feedbacks between energy intensities and energy uses in IEA countries. Energy Policy, Vol.28: 367-388.

Schipper, L., Unander, F., Murthishaw, S., Ting, M., 2001. Indicators of energy use and carbon emissions: understanding the energy-economy link. Annual Review of Energy and Environment, Vol. 26: 49-81.

Schurr, Sam H., 1990. Electricity in the American Economy: Agent of Technological Change. Greenwood Press, USA.

Sterner, T., 2007. Fuel taxes: An important instrument for climate policy. Energy Policy, Vol.35 (6): 3194-202.

Sutherland, R., 1996. The Economics of Energy Conservation Policy, Energy Policy, Vol.24, (4): 361-370.

Taylor and Russell, 1939. The relationship of validity coefficients to the practical effectiveness of tests in selection - discussion and tables.

Taylor, P., Lavagne d'Ortigue O., N. Trudeau and M. Francoeur, 2008. Energy Efficiency Indicators for Public Electricity Production from Fossil Fuels. IEA Information paper.

Teotia, A., et al., 1999. CAFE compliance by light trucks: economic impacts of clean diesel engines. Energy Policy 27, 889-900.

Union of Concerned Scientists, 2002. Fuel Economy as an Engine for Job Growth. UCSPublications, Cambridge, MA, February 2002.

Union of concerned scientists, 2011. Translating New Auto Standards into On-Road Fuel Efficiency. Available at This fact sheet is available online at www.ucsusa.org. (Last retrieved, June 10, 2014).

WCED, 1987. Our Common Future. The World Commission on Environment and Development. Oxford: Oxford University Press.

West, S. E., and Williams, R. C., 2005. The cost of reducing gasoline consumption. American Economic Review, Vol. 95 (2): 294-299.

WSSD Report, 2002. Johannesburg Plan of Action. http://daccessdds.un.org/doc/UNDOC/GEN/N02/636/93/PDF/N0263693.pdf?OpenElem ent 